Tabela 15 Valores de Volume do Fármaco Disperso e Classificação das Suspensões Oftálmicas de Dexametasona e Polimixina B, quanto ao Tipo de Sedimento e Características de Ressuspensão, Determinados Logo Após a Preparação $\left(T_{0}\right)$ e Decorridos 7 dias $\left(T_{7}\right)$

\begin{tabular}{|c|c|c|c|c|}
\hline \multirow[t]{2}{*}{ Fórmulas } & \multicolumn{2}{|c|}{ Volume do támaco disperso } & \multirow{2}{*}{$\begin{array}{c}\text { Ressuspensão } \\
\end{array}$} & \multirow{2}{*}{ Sedimento } \\
\hline & T. $T_{0}$ & $T_{7}$ & & \\
\hline 1. & 100,0 & 95,0 & $\operatorname{Re}$ & $\mathrm{F}$ \\
\hline 2. & 100,0 & 95,0 & $\mathrm{Di}$ & C \\
\hline 3. & 100,0 & 95,0 & $\mathrm{Re}$ & $\mathrm{F}$ \\
\hline 4. & 100,0 & 95,0 & $\mathrm{Re}$ & $\mathrm{F}$ \\
\hline 5 & 100,0 & 95,0 & $\mathrm{Re}$ & $\mathrm{F}$ \\
\hline 6 & 100,0 & 95,0 & $\mathrm{Fa}$ & $\mathrm{F}$ \\
\hline ? & 100,0 & 95,0 & $\mathrm{Di}$ & C \\
\hline 8 & 100,0 & 95,0 & $\mathrm{Di}$ & C \\
\hline 9 & 100,0 & 95,0 & $\mathrm{Fa}$ & $\mathrm{F}$ \\
\hline 10 & 100,0 & 95,0 & $\mathrm{Fa}$ & $\mathrm{F}$ \\
\hline 11 & 100,0 & 95,0 & $\mathrm{Fa}$ & $\mathrm{F}$ \\
\hline 12 & 100,0 & 95,0 & $\mathrm{Fa}$ & $\mathrm{F}$ \\
\hline 13 & 100,0 & 95,0 & $\mathrm{Fa}$ & $\mathrm{F}$ \\
\hline 14 & 100,0 & 95,0 & $\mathrm{Fa}$ & $\mathrm{F}$ \\
\hline 15 & 100,0 & 95,0 & $\mathrm{Di}$ & C \\
\hline 16 & 100,0 & 95,0 & $\mathrm{Re}$ & $\mathrm{F}$ \\
\hline 17 & 100,0 & 95,0 & $\mathrm{Fa}$ & $\mathrm{F}$ \\
\hline 18 & 100,0 & 95,0 & $\mathrm{Fa}$ & $\mathrm{F}$ \\
\hline
\end{tabular}

Fa-Fácil Re-Regular Di-Difícil F-Floculado C - Compactado 
TABELA 16 Valores em UFC/placa Obtidos no Teste para Comprovar a Inativação do Sistema Conservante.

\begin{tabular}{|c|c|c|c|c|c|c|c|c|c|c|c|c|c|c|c|c|c|c|c|}
\hline \multirow[b]{2}{*}{ OHzaninges } & \multicolumn{19}{|c|}{ 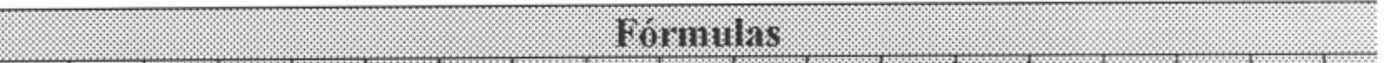 } \\
\hline & (6. & tix & 2. & 3 & 4 & 5 & 6 & 3 & 8 & 9 & 10 & $1 /$ & 12 & 8 & 1,4 & 15 & 16 & $1 / 1$ & 18 \\
\hline \multirow{5}{*}{$\begin{array}{l}\text { Candida } \\
\text { albicans }\end{array}$} & 107 & 103 & 101 & 103 & 102 & 100 & 106 & 103 & 101 & 106 & 100 & 101 & 101 & 106 & 102 & 100 & 102 & 106 & $10=$ \\
\hline & 103 & 100 & 104 & 106 & 106 & 104 & 105 & 100 & 101 & 102 & 102 & 100 & 102 & 105 & 105 & 101 & 99 & 105 & 105 \\
\hline & 105 & 98 & 100 & 100 & 104 & 102 & 104 & 103 & 100 & 104 & 103 & 102 & 105 & 104 & 104 & 103 & 98 & 107 & 101 \\
\hline & 105 & 97 & 102 & 99 & 105 & 102 & 103 & 102 & 102 & 105 & 99 & 98 & 103 & 103 & 103 & 104 & 100 & 105 & $\overline{101}$ \\
\hline & 104 & 102 & 103 & 106 & 108 & 101 & 108 & 104 & 100 & 103 & 101 & 99 & 104 & 106 & 105 & 102 & 101 & 106 & $\overline{10 \epsilon}$ \\
\hline & & & & & & & & & & & & & & & & & & & \\
\hline \multirow{5}{*}{$\begin{array}{c}\text { Aspergillus } \\
\text { niger }\end{array}$} & 99 & 98 & 97 & 99 & 90 & 98 & 98 & 99 & 99 & 93 & 92 & 98 & 97 & 96 & 99 & 95 & 92 & 95 & 93 \\
\hline & 97 & 95 & 98 & 101 & 92 & 96 & 97 & 101 & 98 & 96 & 95 & 100 & 95 & 99 & 98 & 94 & 92 & 98 & 93 \\
\hline & 95 & 96 & 97 & 98 & 93 & 99 & 99 & 102 & 100 & 95 & 94 & 97 & 93 & 98 & 97 & 96 & 93 & 97 & 94 \\
\hline & 94 & 97 & 99 & 97 & 90 & 95 & 96 & 98 & 101 & 94 & 96 & 98 & 94 & 95 & 99 & 98 & 94 & 94 & 92 \\
\hline & 95 & 99 & 102 & 99 & 89 & 99 & 99 & 100 & 98 & 96 & 95 & 101 & 95 & 98 & 98 & 97 & 93 & 97 & 93 \\
\hline & & & & & & & & & & & & & & & & & & & \\
\hline \multirow{5}{*}{ P. cepacia } & 102 & 102 & 104 & 107 & 105 & 102 & 104 & 102 & 100 & 105 & 103 & 103 & 103 & 104 & 103 & 101 & 103 & 107 & 102 \\
\hline & 101 & 102 & 103 & 106 & 103 & 103 & 103 & 103 & 103 & 103 & 105 & 105 & 104 & 106 & 102 & 104 & 102 & 104 & $10<$ \\
\hline & 104 & 105 & 105 & 102 & 104 & 105 & 105 & 104 & 104 & 104 & 102 & 104 & 106 & 107 & 105 & 103 & 101 & 106 & $10 z$ \\
\hline & 105 & 103 & 102 & 104 & 104 & 104 & 102 & 105 & 102 & 104 & 103 & 103 & 103 & 102 & 106 & 106 & 105 & 106 & $\overline{10 \epsilon}$ \\
\hline & 103 & 104 & 106 & 106 & 106 & 105 & 106 & 106 & 101 & 102 & 104 & 102 & 105 & 105 & 104 & 102 & 106 & 105 & $11 \mathrm{C}$ \\
\hline & & & & & & & & & & & & & & & & & & & \\
\hline \multirow{5}{*}{ S. aureus } & 101 & 105 & 106 & 102 & 103 & 101 & 102 & 103 & 105 & 103 & 102 & 105 & 102 & 102 & 104 & 104 & 105 & 102 & 101 \\
\hline & 103 & 104 & 103 & 104 & 105 & 103 & 105 & 104 & 103 & 102 & 102 & 103 & 103 & 105 & 103 & 105 & 102 & 103 & 103 \\
\hline & 104 & 103 & 104 & 103 & 103 & 105 & 107 & 102 & 106 & 106 & 103 & 105 & 102 & 106 & 105 & 102 & 105 & 104 & 105 \\
\hline & 103 & 102 & 105 & 102 & 105 & 102 & 102 & 105 & 101 & 106 & 102 & 106 & 101 & 103 & 104 & 107 & 103 & 105 & $10 \epsilon$ \\
\hline & 105 & 104 & 104 & 107 & 102 & 101 & 104 & 103 & 103 & 103 & 105 & 101 & 104 & 102 & 102 & 101 & 105 & 102 & 101 \\
\hline & & & & & & & & & & & & & & & & & & & \\
\hline \multirow{5}{*}{$\begin{array}{c}P . \\
\text { aeruginosa }\end{array}$} & 103 & ND & ND & ND & ND & ND & ND & ND & ND & ND & ND & ND & ND & ND & ND & ND & ND & ND & $\mathrm{ND}$ \\
\hline & 102 & ND & ND & ND & ND & ND & ND & ND & ND & ND & ND & ND & ND & ND & ND & ND & ND & ND & $\mathrm{ND}$ \\
\hline & 105 & ND & ND & ND & $\mathrm{ND}$ & ND & ND & ND & ND & ND & ND & ND & ND & ND & ND & ND & ND & ND & $\overline{N D}$ \\
\hline & 104 & ND & ND & ND & ND & ND & ND & ND & ND & ND & ND & ND & ND & ND & ND & ND & ND & ND & $\overline{N D}$ \\
\hline & 104 & ND & ND & ND & $\mathrm{ND}$ & ND & ND & ND & ND & ND & ND & ND & ND & ND & ND & ND & ND & ND & $\overline{N D}$ \\
\hline
\end{tabular}

0 = Solução Fisiológica estéril (controle)

As fórmulas de 1 a 18 foram avaliadas nas diluições 1:10

UFC = Unidade Formadora de Colônia

$\mathrm{ND}=$ Não detectado nas condições experimentais 
TABELA 17 Médias e Desvios Padrões do Número de UFC/placa no Estudo para Comprovar a Inativação do Sistema Conservante

\begin{tabular}{|c|c|c|c|c|c|c|c|c|}
\hline \multirow[t]{2}{*}{ Formula } & \multicolumn{2}{|c|}{$\begin{array}{l}\text { Candioda } \\
\text { albicans }\end{array}$} & \multicolumn{2}{|c|}{ Asperginus } & \multicolumn{2}{|c|}{$\begin{array}{l}\text { Pseudomonas } \\
\text { cepacia }\end{array}$} & \multicolumn{2}{|c|}{$\begin{array}{l}\text { Staphylococcus } \\
\text { aureus }\end{array}$} \\
\hline & Média & $\begin{array}{l}\text { Desvio } \\
\text { padrão }\end{array}$ & Média & $\begin{array}{l}\text { Desvio } \\
\text { padráo }\end{array}$ & Media & $\begin{array}{l}\text { Desvio } \\
\text { padráo }\end{array}$ & Medial & $\begin{array}{l}\text { Desvio } \\
\text { padrá。 }\end{array}$ \\
\hline 0 & 104.8 & 1,48 & 96,0 & 2,00 & 103,0 & 1,58 & 103,2 & 1,48 \\
\hline 1 & 100.0 & 2,55 & 97,0 & 1,58 & 103,2 & 1,30 & 103,6 & 1,14 \\
\hline 2 & 102.0 & 1,58 & 98,6 & 2,07 & 104,0 & 1,58 & 104,4 & 1,14 \\
\hline 3 & 102.8 & 3,27 & 98,8 & 1,48 & 105,0 & 2,00 & 103,6 & 2,07 \\
\hline 4 & 105.0 & 2,24 & 90,8 & 1,64 & 104,4 & 1,14 & 103,6 & 1,34 \\
\hline 5 & 101.8 & 1,48 & 97,4 & 1,82 & 103,8 & 1,30 & 102,4 & 1,67 \\
\hline 6 & 105.2 & 1,92 & 97,8 & 1,30 & 104,0 & 1,58 & 104,0 & 2,12 \\
\hline 7 & 102.4 & 1,52 & 100,0 & 1,58 & 104,0 & 1,58 & 103,4 & 1,14 \\
\hline 8 & 100.8 & 0,84 & 99,2 & 1,30 & 102,0 & 1,58 & 103,6 & 1,95 \\
\hline 9 & 104.0 & 1,58 & 94,8 & 1,30 & 103,6 & 1,14 & 104,0 & 1,87 \\
\hline 10 & 101.0 & 1,58 & 94,4 & 1,52 & 103,4 & 1,14 & 102,8 & 1,30 \\
\hline 11 & 100.0 & 1,58 & 98,8 & 1,64 & 103,4 & 1,14 & 104,0 & 2,00 \\
\hline 12 & 103.0 & 1,58 & 94,8 & 1,48 & 104,2 & 1,30 & 102,4 & 1,14 \\
\hline 13 & 104.8 & 1,30 & 97,2 & 1,64 & 104,8 & 1,92 & 103,6 & 1,82 \\
\hline 14 & 103.8 & 1,30 & 98,2 & 0,84 & 104,0 & 1,58 & 103,6 & 1,14 \\
\hline 15 & 102.0 & 1,58 & 96,0 & 1,58 & 103,2 & 1,92 & 103,8 & 2,39 \\
\hline 16 & 100.0 & 1,58 & 92,8 & 0,84 & 103,4 & 2,07 & 104,0 & 1,41 \\
\hline 17 & 105.8 & 0,84 & 96,2 & 1,64 & 105,6 & 1,14 & 103,2 & 1,30 \\
\hline 18 & 103.0 & 2,35 & 93,0 & 0,71 & 105,0 & 3,16 & 103.2 & 228 \\
\hline
\end{tabular}


TABELA 18 Resultados da Análise de Variância para Comparação das Médias de UFC/placa no Estudo de Comprovação de Inativação do Sistema conservante.

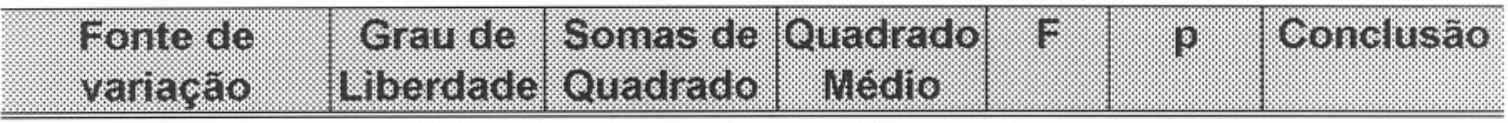

\section{Candida albicans}

\begin{tabular}{l|c|c|c|c|c|c}
\hline fórmula & 18 & 316,34 & 17,57 & 5,53 & 0,0001 & $\mathrm{~S}$ \\
erro & 76 & 241,60 & 3,18 & & & \\
\hline \hline total & 94 & 557,94 & & & & \\
\hline
\end{tabular}

Aspergillus niger

\begin{tabular}{l|c|c|c|c|c|c}
\hline fórmula & 18 & 548,59 & 30,48 & 13,28 & 0,0001 & $\mathrm{~S}$ \\
erro & 76 & 174,40 & 2,29 & & & \\
\hline \hline total & 94 & 722,99 & & & & \\
\hline
\end{tabular}

\section{Pseudomonas cepacia}

\begin{tabular}{l|c|c|c|c|c|c}
\hline fórmula & 18 & 63,75 & 3,54 & 1,29 & 0,2209 & NS \\
erro & 76 & 209,20 & 2,75 & & & \\
\hline \hline total & 94 & 272,95 & & & & \\
\hline
\end{tabular}

\section{Staphylococcus aureus}

\begin{tabular}{l|c|c|c|c|c|c}
\hline fórmula & 18 & 25,75 & 1,43 & 0,51 & 0,9441 & NS \\
erro & 76 & 212,00 & 2,79 & & & \\
\hline \hline total & 94 & 237,75 & & & & \\
\hline
\end{tabular}

p: nível de significância

S: significante $(p<0,01)$
F: parâmetro estatístico

NS: não significante

TABELA 19 Diferenças Significativas Obtidas na Análise de Variância dos Valores de UFC/placa Comparativamente à Fórmula Controle.

\begin{tabular}{|c|c|}
\hline formula & Diferenca média \\
\hline \multicolumn{2}{|c|}{ Candida albicans } \\
\hline 10 & $-3,8$ \\
\hline 8 & $-4,0$ \\
\hline 11 & $-4,8$ \\
\hline 1 & $-4,8$ \\
\hline 16 & $-4,8$ \\
\hline \multicolumn{2}{|c|}{ Aspergillus niger } \\
\hline 7 & 4,0 \\
\hline 8 & 3,2 \\
\hline 18 & $-3,0$ \\
\hline 16 & $-3,2$ \\
\hline 4 & $-5,2$ \\
\hline
\end{tabular}



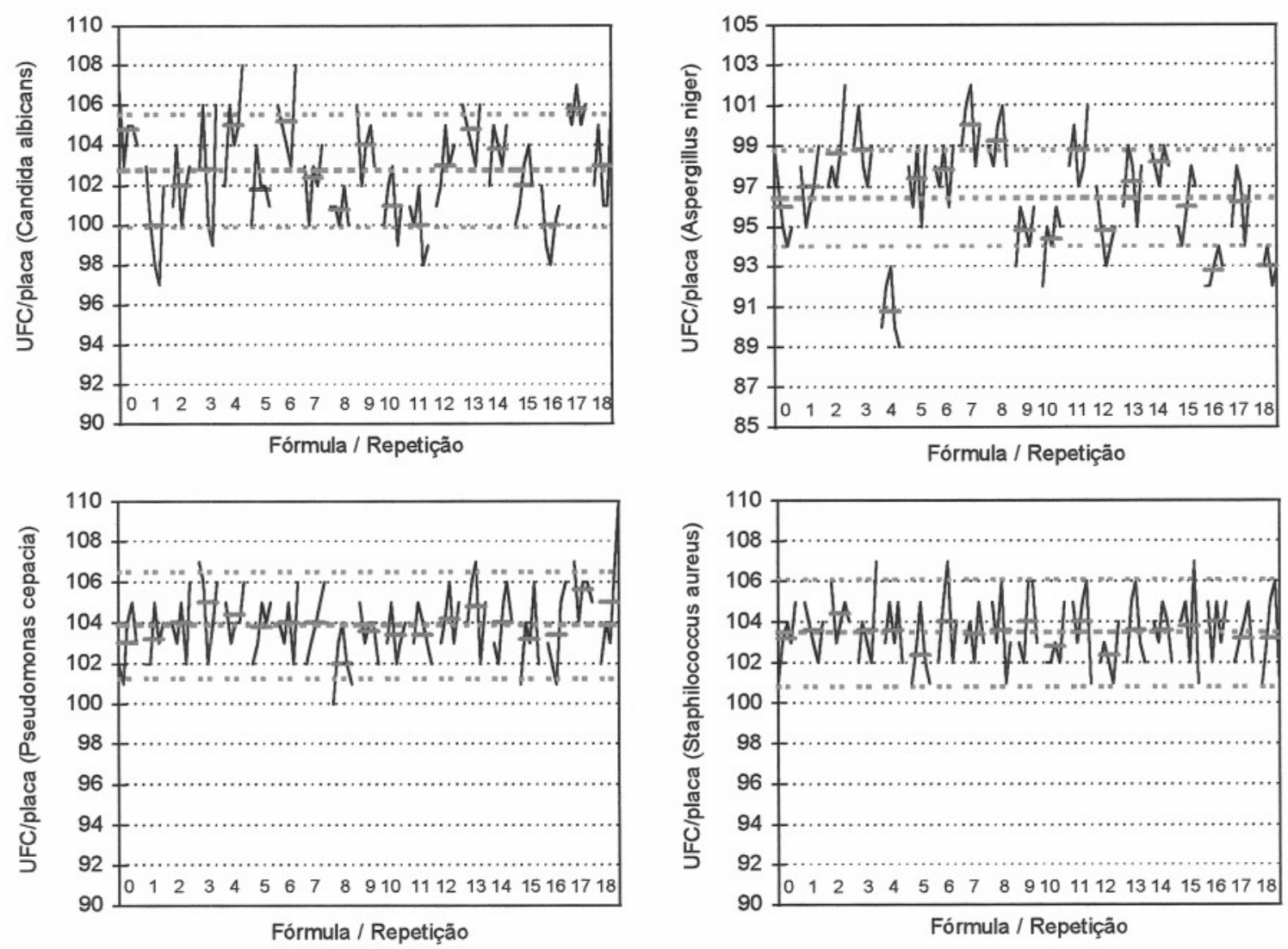

FIGURA 2 Análise das Médias de Valores de UFC/placa para os Microrganismos em Estudo. 
TABELA 20 Valores de Contagem Microbiana (UFC/placa) Obtidos no Estudo quanto a Interferência dos Agentes Inativantes no Crescimento dos Microrganismos.

\begin{tabular}{|c|c|c|}
\hline Microrganismoros & $\begin{array}{l}\text { Meio de cultirace } \\
\text { agentes mativantes }\end{array}$ & 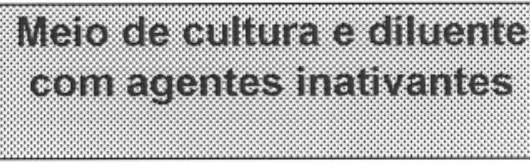 \\
\hline \multirow{5}{*}{$\begin{array}{l}\text { Candida } \\
\text { albicans }\end{array}$} & 107 & 108 \\
\hline & 103 & 101 \\
\hline & 105 & 102 \\
\hline & 105 & 109 \\
\hline & 104 & 102 \\
\hline \multirow{5}{*}{$\begin{array}{l}\text { Aspergillus } \\
\text { niger }\end{array}$} & 99 & 95 \\
\hline & 97 & 93 \\
\hline & 95 & 96 \\
\hline & 94 & 94 \\
\hline & 95 & 98 \\
\hline \multirow{5}{*}{$\begin{array}{l}\text { Pseudomonas } \\
\text { cepacia }\end{array}$} & 102 & 103 \\
\hline & 101 & 102 \\
\hline & 104 & 104 \\
\hline & 105 & 103 \\
\hline & 103 & 106 \\
\hline \multirow{5}{*}{$\begin{array}{c}\text { Staphylococcus } \\
\text { aureus }\end{array}$} & 101 & 109 \\
\hline & 103 & 106 \\
\hline & 104 & 104 \\
\hline & 103 & 104 \\
\hline & 105 & 102 \\
\hline \multirow{5}{*}{$\begin{array}{l}\text { Pseudomonas } \\
\text { aeruginosa }\end{array}$} & 103 & 102 \\
\hline & 102 & 101 \\
\hline & 105 & 102 \\
\hline & 104 & 109 \\
\hline & 104 & 103 \\
\hline
\end{tabular}


TABELA 21 Médias e Desvios Padrões do Número de UFC/placa no Estudo para a Comprovação da Não Interferência dos Agentes Inativantes no Crescimento Microbiano.

\begin{tabular}{|c|c|c|c|c|}
\hline Microrganismos & lnativante. & n & Media & Desvio pratrâ. \\
\hline C. albicans & presente & 5 & 104,4 & 3,78 \\
\hline C. albicans & isento & 5 & 104,8 & 1,48 \\
\hline A. niger & presente & 5 & 95,2 & 1,92 \\
\hline A. niger & isento & 5 & 96,0 & 2,00 \\
\hline P. cepacia & presente & 5 & 103,6 & 1,52 \\
\hline P. cepacia & isento & 5 & 103,0 & 1,58 \\
\hline S. aureus & presente & 5 & 105,0 & 2,65 \\
\hline S. aureus & isento & 5 & 103,2 & 1,48 \\
\hline$P$. aeruginosa & presente & 5 & 103,4 & 3,21 \\
\hline$P$. aeruginosa & isento & 5 & 103,6 & 1,14 \\
\hline
\end{tabular}

$\mathrm{n}$ : número de réplicas do ensaio

TABELA 22 Resultados da Análise de Variância para Comparação das Médias de UFC/placa no Estudo para Comprovar a Não Interferência dos Agentes Inativantes no Crescimento Microbiano.

\begin{tabular}{|c|c|c|c|c|c|c|}
\hline Fonte de variacia & Grau de & Sorialias de & Quadrado & F & p & Conciusa \\
\hline $\begin{array}{l}\text { microrganismo } \\
\text { inativante } \\
\text { microrg. } x \text { Inativante } \\
\text { erro } \\
\text { total }\end{array}$ & \begin{tabular}{|c|}
4 \\
1 \\
4 \\
40 \\
49 \\
\end{tabular} & \begin{tabular}{|c|}
558,28 \\
0,50 \\
10,60 \\
199,20 \\
768,58 \\
\end{tabular} & $\begin{array}{c}139,57 \\
0,50 \\
2,65 \\
4,98\end{array}$ & $\begin{array}{c}28,03 \\
0,10 \\
0,53\end{array}$ & $\begin{array}{l}0,0001 \\
0,7530 \\
0,7128\end{array}$ & $\begin{array}{l}\text { NS } \\
\text { NS }\end{array}$ \\
\hline
\end{tabular}

F: parâmetro estatístico p: nível de significância NS: não significante 


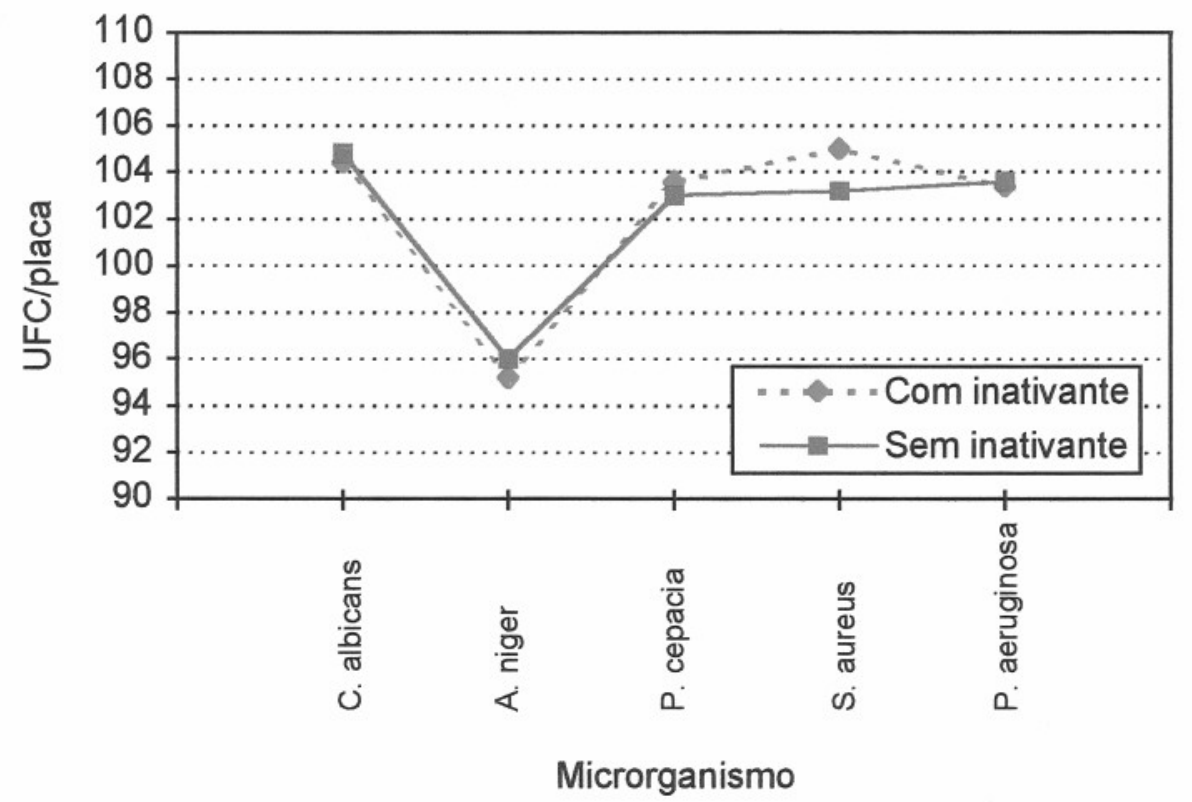

FIGURA 3 Médias do Número de UFC/placa no Estudo para a Comprovação da Não Interferência dos Agentes Inativantes no Crescimento Microbiano. 
TABELA 23 Valores de Contagem Microbiana (UFC/placa) Obtidos no Teste para a Comprovação da Ausência do Efeito Residual dos Agentes Antimicrobianos na Técnica de Contagem por Filtração em Membrana.

\begin{tabular}{|c|c|c|}
\hline Wicrorganismos & IESTE & SONKROLE \\
\hline \multirow{3}{*}{ Candida albicans } & 105 & 102 \\
\hline & 108 & 101 \\
\hline & 103 & 105 \\
\hline \multirow{3}{*}{ Aspergillus niger } & 94 & 93 \\
\hline & 94 & 93 \\
\hline & 91 & 92 \\
\hline \multirow{3}{*}{$\begin{array}{c}\text { Pseudomonas } \\
\text { cepacia }\end{array}$} & 108 & 102 \\
\hline & 106 & 106 \\
\hline & 104 & 103 \\
\hline \multirow{3}{*}{$\begin{array}{c}\text { Staphylococcus } \\
\text { aureus }\end{array}$} & 105 & 108 \\
\hline & 102 & 104 \\
\hline & 105 & 102 \\
\hline \multirow{3}{*}{$\begin{array}{c}\text { Pseudomonas } \\
\text { aeruginosa }\end{array}$} & 103 & 102 \\
\hline & 104 & 104 \\
\hline & 103 & 103 \\
\hline
\end{tabular}

TABELA 24 Médias e Desvios Padrões do Número de UFC/placa para a Comprovação da Ausência do Efeito Residual dos Agentes Antimicrobianos na Técnica de Contagem por Fiiltração em Membrana.

\begin{tabular}{l|c|c|c|c}
\hline Microrganismos & Grupo & ( & Media & Desvio Padrao \\
\hline C. albicans & Controle & 3 & 102,7 & 2,08 \\
C. albicans & Teste & 3 & 105,3 & 2,52 \\
A. niger & Controle & 3 & 92,7 & 0,58 \\
A. niger & Teste & 3 & 93,0 & 1,73 \\
P. cepacia & Controle & 3 & 103,7 & 2,08 \\
P. cepacia & Teste & 3 & 106,0 & 2,00 \\
S. aureus & Controle & 3 & 104,7 & 3,06 \\
S. aureus & Teste & 3 & 104,0 & 1,73 \\
P. aeruginosa & Controle & 3 & 103,0 & 1,00 \\
P. aeruginosa & Teste & 3 & 103,3 & 0,58 \\
\hline
\end{tabular}

$\mathrm{n}$ : número de réplicas 
TABELA 25 Resultados Obtidos na Análise de Variância para Comparação das Médias de UFC/placa no Estudo para Comprovar a Ausência de Efeito Residual dos Agentes Antimicrobianos na Técnica de Contagem por Filtração em Membrana.

\begin{tabular}{l|c|c|c|c|c|c}
\hline $\begin{array}{c}\text { Fonte de } \\
\text { variação }\end{array}$ & $\begin{array}{c}\text { Grau de } \\
\text { Liberdade }\end{array}$ & $\begin{array}{c}\text { Somas de } \\
\text { Quadrado }\end{array}$ & $\begin{array}{c}\text { Quadrado } \\
\text { Médio }\end{array}$ & $\mathbf{F}$ & $\mathbf{p}$ & Conclusão \\
\hline \hline microrganismo & 4 & 616,33 & 154,08 & 42,80 & 0,0001 & \\
tratamento & 1 & 7,50 & 7,50 & 2,08 & 0,1644 & NS \\
microxTratamento & 4 & 12,33 & 3,08 & 0,86 & 0,5066 & NS \\
erro & 20 & 72,00 & 3,60 & & & \\
total & 29 & 708,17 & & & & \\
\hline
\end{tabular}

F: parâmetro estatístico

p: nível de significância

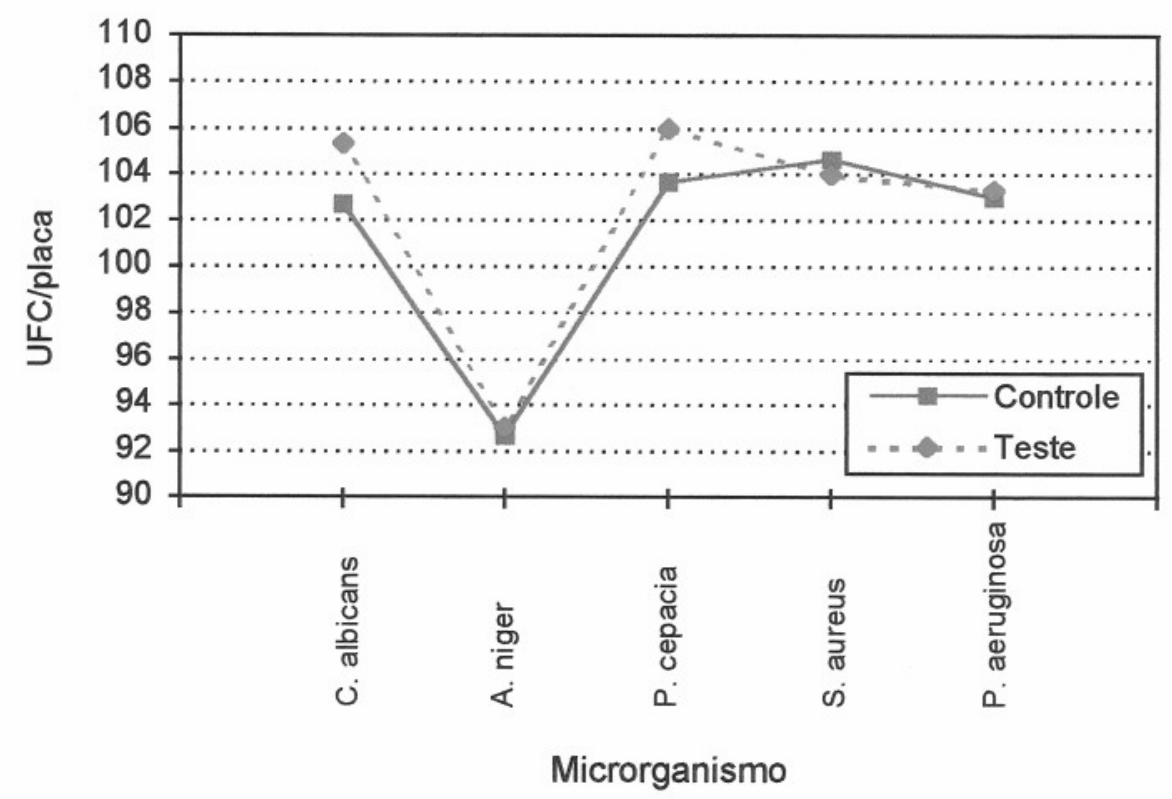

FIGURA 4 Média do Número de UFC/placa no Estudo para a Comprovação da Ausência de Efeito Residual dos Agentes Antimicrobianos na Técnica de Contagem por Filtração em Membrana. 
TABELA 26 Número de Sobreviventes de Pseudomonas cepacia (UFC/mL) no Teste de Eficácia de Conservantes.

\begin{tabular}{|c|c|c|c|c|c|}
\hline forrmulas & T. & T. I, & 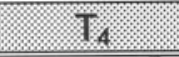 & 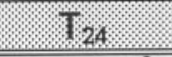 & $T_{48}$ \\
\hline $1:(1)$ & $1,3 \times 10^{7}$ & $1,2 \times 10^{7}$ & $1,1 \times 10^{7}$ & $2,9 \times 10^{6}$ & $2,9 \times 10^{5}$ \\
\hline 2 & $1,97 \times 10^{7}$ & $2,0 \times 10^{7}$ & $1,98 \times 10^{7}$ & $7,5 \times 10^{6}$ & $6,8 \times 10^{6}$ \\
\hline 3 & $1,4 \times 10^{7}$ & $1,4 \times 10^{7}$ & $1,25 \times 10^{7}$ & $5,4 \times 10^{6}$ & $4,0 \times 10^{6}$ \\
\hline 4 & $1,5 \times 10^{7}$ & $7,9 \times 10^{6}$ & $5,6 \times 10^{6}$ & $2,0 \times 10^{6}$ & $4,6 \times 10^{5}$ \\
\hline 5 & $1,2 \times 10^{7}$ & $1,2 \times 10^{7}$ & $1,2 \times 10^{7}$ & $2,7 \times 10^{6}$ & $3,0 \times 10^{5}$ \\
\hline 6 & $1,2 \times 10^{7}$ & zero & zero & zero & zero \\
\hline 7 & $1,3 \times 10^{7}$ & $1,4 \times 10^{7}$ & $1,1 \times 10^{7}$ & $8,2 \times 10^{6}$ & $5,2 \times 10^{6}$ \\
\hline 8 & $1,8 \times 10^{7}$ & $1,8 \times 10^{7}$ & $1,8 \times 10^{7}$ & $6,7 \times 10^{6}$ & $6,3 \times 10^{6}$ \\
\hline 9 & $6,8 \times 10^{6}$ & zero & zero & zero & zero \\
\hline 10 & $7,0 \times 10^{6}$ & zero & zero & zero & zero \\
\hline 1.1 & $8,7 \times 10^{6}$ & zero & zero & zero & zero \\
\hline 12. & $6,9 \times 10^{6}$ & zero & zero & zero & zero \\
\hline 13 & $7,0 \times 10^{6}$ & zero & zero & zero & zero \\
\hline 1.4 & $6,6 \times 10^{6}$ & zero & zero & zero & zero \\
\hline 15 & $1,2 \times 10^{7}$ & $1,5 \times 10^{7}$ & $1,1 \times 10^{7}$ & $8,9 \times 10^{6}$ & $5,0 \times 10^{6}$ \\
\hline 16 & $1,3 \times 10^{7}$ & $7,9 \times 10^{6}$ & $6,5 \times 10^{6}$ & $1,5 \times 10^{6}$ & $8,0 \times 10^{4}$ \\
\hline $1 \%$ & $1,2 \times 10^{7}$ & $4,1 \times 10^{5}$ & $1,5 \times 10^{5}$ & zero & zero \\
\hline 18 & $1,2 \times 10^{7}$ & $1,2 \times 10^{7}$ & $1,3 \times 10^{7}$ & $1,2 \times 10^{7}$ & $1,4 \times 10^{7}$ \\
\hline
\end{tabular}

$\mathrm{T}_{0}=$ contagem imediatamente após a inoculação da amostra

$T_{2}, T_{4}, T_{24}$ e $T_{48}=$ contagem $2,4,24$ e 48 horas após a inoculação

TABELA 27 Logarítmo (base 10) do Número de Sobreviventes de Pseudomonas cepacia (LogUFC/mL) no Teste de Eficácia de Conservantes.

\begin{tabular}{|c|c|c|c|c|c|}
\hline \%ormulas. & 18 & $T_{2}$ & T. & 1.24 & 1.8 \\
\hline : & 7,11 & 7,08 & 7,04 & 6,46 & 5,46 \\
\hline 2. & 7,29 & 7,30 & 7,30 & 6,88 & 6,83 \\
\hline 3. & 7,15 & 7,15 & 7,10 & 6,73 & 6,60 \\
\hline 4 & 7,18 & 6,90 & 6,75 & 6,30 & 5,66 \\
\hline 5 & 7,08 & 7,08 & 7,08 & 6,43 & 5,48 \\
\hline 6 & 7,08 & - & - & - & - \\
\hline 7 . & 7,11 & 7,15 & 7,04 & 6,91 & 6,72 \\
\hline 8 & 7,26 & 7,26 & 7,26 & 6,83 & 6,80 \\
\hline 9 & 6,83 & - & - & - & - \\
\hline 10 & 6,85 & - & - & - & - \\
\hline 11 & 6,94 & - & - & - & - \\
\hline 12 & 6,84 & - & - & - & - \\
\hline 13 & 6,85 & - & - & - & - \\
\hline 14 & 6,82 & - & - & - & - \\
\hline 15. & 7,08 & 7,18 & 7,04 & 6,95 & 6,70 \\
\hline 16 & 7,11 & 6,90 & 6,81 & 6,18 & 4,90 \\
\hline 17 . & 7,08 & 5,61 & 5,18 & - & - \\
\hline 18 & 7,08 & 7,08 & 7,11 & 7,08 & 7,15 \\
\hline
\end{tabular}


TABELA 28 Valor D, Equação da Reta e Coeficiente de Correlação Referentes a Pseudomonas cepacia.

\begin{tabular}{|c|c|c|c|}
\hline formula & $\begin{array}{l}\text { Valor } \text { D } \\
\text { (Horas) }\end{array}$ & Equagao & $\begin{array}{l}\text { Coeficiente de } \\
\text { correlacáo }\end{array}$ \\
\hline 1 & 29,17 & $Y=-0,0343 X+7,1648$ & $-0,99$ \\
\hline 2 & 90,50 & $Y=-0,0111 X+7,2924$ & $-0,93$ \\
\hline 3 & 81,05 & $Y=-0,0123 X+7,1385$ & $-0,97$ \\
\hline 4 & 35,18 & $Y=-0,0284 X+7,0014$ & $-0,98$ \\
\hline 5 & 29,38 & $Y=-0,0340 X+7,1611$ & $-0,99$ \\
\hline 6 & 0,28 & $Y=-3,5400 X+7,0800$ & $-1,00$ \\
\hline 7 & 119,82 & $Y=-0,0083 X+7,1162$ & $-0,98$ \\
\hline 8 & 90,91 & $Y=-0,0110 X+7,2536$ & $-0,92$ \\
\hline 9 & 0,29 & $Y=-3,4150 X+6,8300$ & $-1,00$ \\
\hline 10 & 0,29 & $Y=-3,4250 X+6,8500$ & $-1,00$ \\
\hline 11. & 0,28 & $Y=-3,4700 X+6,9400$ & $-1,00$ \\
\hline 12 & 0,29 & $Y=-3,4200 X+6,8400$ & $-1,00$ \\
\hline 13 & 0,29 & $Y=-3,4250 X+6,8500$ & $-1,00$ \\
\hline 14 & 0,29 & $Y=-3,4100 X+6,8200$ & $-1,00$ \\
\hline 15. & 117,70 & $Y=-0,0085 X+7,1225$ & $-0,96$ \\
\hline 16 & 23,03 & $Y=-0,0434 X+7,0573$ & $-0,99$ \\
\hline 17 & 3,63 & $Y=-0,2752 X+6,5312$ & $-0,99$ \\
\hline 18 & - & $Y=0,0011 X+7,0822$ & $+0,76$ \\
\hline
\end{tabular}

( - ) não callculado

TABELA 29 Número de Sobreviventes de Staphylococcus aureus (UFC/mL) no Teste de Eficácia de Conservantes.

\begin{tabular}{|c|c|c|c|c|c|}
\hline formulas & $T_{0}$ & 12 & $1 / 4$ & 124 & I. \\
\hline (1) & $6,8 \times 10^{6}$ & zero & zero & zero & zero \\
\hline 2. & $2,58 \times 10^{7}$ & $4,4 \times 10^{6}$ & $2,07 \times 10^{5}$ & $4,0 \times 10^{3}$ & $6,7 \times 10^{2}$ \\
\hline 3 & $1,73 \times 10^{7}$ & zero & zero & zero & zero \\
\hline 4 & $1,60 \times 10^{7}$ & $7,1 \times 10^{2}$ & zero & zero & zero \\
\hline 5 & $1,08 \times 10^{\prime}$ & zero & zero & zero & zero \\
\hline 6 & $1,27 \times 10^{\prime}$ & $4,0 \times 10^{1}$ & zero & zero & zero \\
\hline 7 . & $1,95 \times 10^{\prime}$ & $1,20 \times 10^{3}$ & $3,5 \times 10^{2}$ & $2,0 \times 10^{1}$ & zero \\
\hline 8 & $2,01 \times 10^{\prime}$ & $3,5 \times 10^{6}$ & $1,28 \times 10^{5}$ & $1,60 \times 10^{3}$ & $3,5 \times 10^{2}$ \\
\hline 9 & $1,13 \times 10^{\prime}$ & zero & zero & zero & zero \\
\hline 10 & $1,01 \times 10^{\prime}$ & zero & zero & zero & zero \\
\hline 1.1 & $5,8 \times 10^{6}$ & $7,0 \times 10^{1}$ & zero & zero & zero \\
\hline 12 & $3,1 \times 10^{6}$ & $5,6 \times 10^{5}$ & $4,0 \times 10^{3}$ & zero & zero \\
\hline 13 & $6,8 \times 10^{6}$ & zero & zero & zero & zero \\
\hline 14 & $1,28 \times 10^{7}$ & $3,0 \times 10^{1}$ & zero & zero & zero \\
\hline 15 & $1,16 \times 10^{\prime}$ & $1,30 \times 10^{3}$ & $4,6 \times 10^{2}$ & $2,0 \times 10^{1}$ & zero \\
\hline 16 & $9,2 \times 10^{6}$ & zero & zero & zero & zero \\
\hline 17 & $1,09 \times 10^{7}$ & $9,8 \times 10^{2}$ & zero & zero & zero \\
\hline 18 & $3,0 \times 10^{\prime}$ & $4,2 \times 10^{6}$ & $1,07 \times 10^{6}$ & $1,18 \times 10^{5}$ & $9,2 \times 10^{4}$ \\
\hline
\end{tabular}

$\mathrm{T}_{0}=$ contagem imediatamente após a inoculação da amostra

$T_{2}, T_{4}, T_{24}$ e $T_{48}=$ contagem após 2, 4, 24 e 48 horas após a inoculação 
TABELA 30 Logarítmo (base 10) do Número de Sobreviventes de Staphylococcus aureus (LogUFC/mL) no Teste de Eficácia de Conservantes.

\begin{tabular}{|c|c|c|c|c|c|}
\hline Formulas & 10 & 12 & 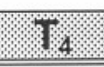 & 124 & I. 4.8 \\
\hline (1) & 6,83 & - & - & - & - \\
\hline 2 & 7,41 & 6,64 & 5,32 & 3,60 & 2,83 \\
\hline 3 & 7,24 & - & - & - & - \\
\hline 4. & 7,20 & 2,85 & - & - & - \\
\hline 5 & 7,03 & - & - & - & - \\
\hline 6. & 7,10 & 1,60 & - & - & - \\
\hline ?. & 7,29 & 3,08 & 2,54 & 1,30 & - \\
\hline 8 & 7,30 & 6,54 & 5,11 & 3,20 & 2,54 \\
\hline 9 & 7,05 & - & - & - & - \\
\hline 10 & 7,00 & - & - & - & - \\
\hline (1: & 6,76 & 1,85 & - & - & - \\
\hline 12 & 6,49 & 5,75 & 3,60 & - & - \\
\hline 13 & 6,83 & - & - & - & - \\
\hline 14 & 7,11 & 1,48 & - & - & - \\
\hline 15 & 7,06 & 3,11 & 2,66 & 1,30 & - \\
\hline 16 & 6,96 & - & - & - & - \\
\hline 17 & 7,04 & 2,99 & - & - & - \\
\hline 18 & 7,48 & 6,62 & 6,03 & 5,07 & 4,96 \\
\hline
\end{tabular}

( - ) não calculado

TABELA 31 Valor D, Equação da Reta e Coeficiente de Correlação Referentes a Staphylococcus aureus.

\begin{tabular}{|c|c|c|c|}
\hline Formula & $\begin{array}{l}\text { Yaior } 0 \\
\text { (Horas) }\end{array}$ & efuacaro & $\begin{array}{l}\text { Coeticlente } \\
\text { correlacal }\end{array}$ \\
\hline 簤 & 0,29 & $Y=-3,4150 X+6,8300$ & $-1,00$ \\
\hline 2 & 11,55 & $Y=-0,0866 X+6,5100$ & $-0,91$ \\
\hline 3 & 0,28 & $Y=-3,6200 X+7,2400$ & $-1,00$ \\
\hline 4. & 0,56 & $Y=-1,8000 X+6,9500$ & $-0,99$ \\
\hline 5 & 0,28 & $Y=-3,5150 X+7,0300$ & $-1,00$ \\
\hline 6 & 0,56 & $Y=-1,7750 X+6,4500$ & $-0,95$ \\
\hline 1. & - & $Y=-0,1035 X+4,4561$ & $-0,77$ \\
\hline 8 & 11,01 & $Y=-0,0909 X+6,3553$ & $-0,91$ \\
\hline 9 & 0,28 & $Y=-3,5250 X+7,0500$ & $-1,00$ \\
\hline 10 & 0,28 & $Y=-3,5000 X+7,0000$ & $-1,00$ \\
\hline 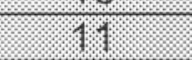 & 0,59 & $Y=-1,6900 X+6,2500$ & $-0,97$ \\
\hline 12 & 3,99 & $Y=-0,2504 X+5,8380$ & $-0,96$ \\
\hline 13 & 0,28 & $Y=-3,4150 X+6,8300$ & $-1,00$ \\
\hline $1,4$. & 0,56 & $Y=-1,7775 X+6,4183$ & $-0,95$ \\
\hline 15 & - & $Y=-0,1024 X+4,4235$ & $-0,79$ \\
\hline 16 & 0,28 & $Y=-3,4800 X+6,9600$ & $-1,00$ \\
\hline (1) & 0,59 & $Y=-1,7600 X+6,8633$ & -1.00 \\
\hline 18 & 22,94 & $Y=-0,0436 X+6,7121$ & $-0,84$ \\
\hline
\end{tabular}


TABELA 32 Número de Sobreviventes de Candida albicans (UFC/mL) no Teste de Eficácia de Conservantes.

\begin{tabular}{|c|c|c|c|c|c|}
\hline Formulias & , & (: & 18 & 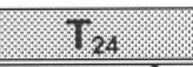 & 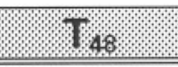 \\
\hline 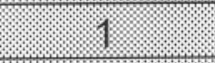 & $2,0 \times 10^{6}$ & $1,90 \times 10^{5}$ & $7,2 \times 10^{4}$ & $6,0 \times 10^{2}$ & zero \\
\hline 2. & $1,62 \times 10^{6}$ & $1,00 \times 10^{6}$ & $6,8 \times 10^{5}$ & $1,3 \times 10^{5}$ & $7,4 \times 10^{4}$ \\
\hline 3. & $2,5 \times 10^{6}$ & $4,4 \times 10^{5}$ & $1,7 \times 10^{4}$ & $7,9 \times 10^{2}$ & zero \\
\hline 4. & $5,0 \times 10^{6}$ & $3,1 \times 10^{6}$ & $1,0 \times 10^{6}$ & $1,02 \times 10^{5}$ & $9,1 \times 10^{3}$ \\
\hline 5. & $1,0 \times 10^{6}$ & $1,5 \times 10^{5}$ & $5,8 \times 10^{4}$ & $4,6 \times 10^{2}$ & zero \\
\hline 6. & $1,5 \times 10^{6}$ & $3,6 \times 10^{5}$ & $1,55 \times 10^{5}$ & $1,65 \times 10^{3}$ & zero \\
\hline ?ר. & $4,8 \times 10^{6}$ & $2,2 \times 10^{6}$ & $1,05 \times 10^{6}$ & $3,5 \times 10^{4}$ & $1,48 \times 10^{3}$ \\
\hline 8 & $2,0 \times 10^{6}$ & $1,55 \times 10^{6}$ & $6,3 \times 10^{5}$ & $1,10 \times 10^{5}$ & $4,6 \times 10^{4}$ \\
\hline 9 & $3,5 \times 10^{6}$ & $1,20 \times 10^{6}$ & $8,5 \times 10^{5}$ & $3,7 \times 10^{5}$ & $5,6 \times 10^{4}$ \\
\hline 10 & $3,7 \times 10^{6}$ & $2,3 \times 10^{6}$ & $1,48 \times 10^{6}$ & $5,4 \times 10^{5}$ & $9,3 \times 10^{4}$ \\
\hline (1) : & $1,05 \times 10^{6}$ & $2,4 \times 10^{5}$ & $5,9 \times 10^{4}$ & $1,46 \times 10^{4}$ & $2,13 \times 10^{2}$ \\
\hline 12. & $1,12 \times 10^{6}$ & $1,9 \times 10^{5}$ & $4,4 \times 10^{4}$ & $6,7 \times 10^{3}$ & $5,0 \times 10^{1}$ \\
\hline 13 & $1,19 \times 10^{6}$ & $1,4 \times 10^{5}$ & $5,5 \times 10^{4}$ & $7,1 \times 10^{3}$ & $5,0 \times 10^{1}$ \\
\hline 14. & $1,21 \times 10^{6}$ & $5,9 \times 10^{5}$ & $3,3 \times 10^{4}$ & $3,0 \times 10^{2}$ & $2,0 \times 10^{1}$ \\
\hline 15 & $5,2 \times 10^{6}$ & $2,4 \times 10^{6}$ & $9,5 \times 10^{5}$ & $3,4 \times 10^{4}$ & $1,23 \times 10^{3}$ \\
\hline 16 & $1,32 \times 10^{6}$ & $3,0 \times 10^{4}$ & $8,0 \times 10^{3}$ & $8,0 \times 10^{1}$ & zero \\
\hline $1 \%$ & $1,75 \times 10^{6}$ & $4,9 \times 10^{5}$ & $1,31 \times 10^{5}$ & $8,5 \times 10^{3}$ & $4,0 \times 10^{1}$ \\
\hline 18 & $1,41 \times 10^{6}$ & $2,3 \times 10^{5}$ & $5,2 \times 10^{4}$ & $4,4 \times 10^{4}$ & $2,1 \times 10^{4}$ \\
\hline
\end{tabular}

$\mathrm{T}_{0}=$ contagem imediatamente após a inoculação da amostra

$T_{4}, T_{8}, T_{24}$ e $T_{48}=$ contagem após 4, 8, 24 e 48 horas após a inoculação

TABELA 33 Logarítmo (base 10) do Número de Sobreviventes de Candida albicans (Log UFC/mL) no Teste de Eficácia de Conservantes.

\begin{tabular}{|c|c|c|c|c|c|}
\hline formulas & 18 & \% & I. & 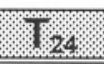 & $T_{48}$ \\
\hline (:) & 6,30 & 5,28 & 4,86 & 2,78 & - \\
\hline 2 & 6,21 & 6,00 & 5,83 & 5,11 & 4,87 \\
\hline 3 & 6,40 & 5,64 & 4,23 & 2,90 & - \\
\hline 4 & 6,70 & 6,49 & 6,00 & 5,01 & 3,96 \\
\hline S. & 6,00 & 5,18 & 4,76 & 2,66 & - \\
\hline 6 & 6,18 & 5,56 & 5,19 & 3,22 & - \\
\hline 11. & 6,68 & 6,34 & 6,02 & 4,54 & 3,17 \\
\hline 8. & 6,30 & 6,19 & 5,80 & 5,04 & 4,66 \\
\hline 9 & 6,54 & 6,08 & 5,93 & 5,57 & 4,75 \\
\hline II & 6,57 & 6,36 & 6,17 & 5,73 & 4,97 \\
\hline $1 / 1$ & 6,02 & 5,38 & 4,77 & 4,16 & 2,33 \\
\hline 12 & 6,05 & 5,28 & 4,64 & 3,83 & 1,70 \\
\hline 13.3 & 6,08 & 5,15 & 4,74 & 3,85 & 1,70 \\
\hline $1 / 4$ & 6,08 & 5,77 & 4,52 & 2,48 & 1,30 \\
\hline 15 & 6,72 & 6,38 & 5,98 & 4,53 & 3,09 \\
\hline 16 & 6,12 & 4,48 & 3,90 & 1,90 & - \\
\hline $17 \%$ & 6,24 & 5,69 & 5,12 & 3,93 & 1,60 \\
\hline 18 & 6,06 & 5,36 & 4,72 & 4,64 & 4,32 \\
\hline
\end{tabular}


TABELA 34 Valor D, Equação da Reta e Coeficiente de Correlação Referentes a Candida albicans.

\begin{tabular}{|c|c|c|c|}
\hline Pormula & $\begin{array}{l}\text { Valor: D } \\
\text { (Horas) }\end{array}$ & equacaso. & $\begin{array}{l}\text { Coeficiente de } \\
\text { correlacáo }\end{array}$ \\
\hline ! & 7,89 & $Y=-0,1267 X+5,9719$ & $-1,00$ \\
\hline 2 & 35,46 & $Y=-0,0282 X+6,0780$ & $-0,95$ \\
\hline 3 & 7,90 & $Y=-0,1266 X+5,9606$ & $-0,99$ \\
\hline 4. & 17,45 & $Y=-0,0573 X+6,5953$ & $-0,99$ \\
\hline 5. & 8,16 & $Y=-0,1226 X+5,7792$ & $-1,00$ \\
\hline 6. & 7,84 & $Y=-0,1275 X+6,1721$ & $-1,00$ \\
\hline ? & 13,48 & $Y=-0,0742 X+6,5982$ & $-0,99$ \\
\hline 8 & 28,49 & $Y=-0,0351 X+6,1884$ & $-0,96$ \\
\hline 9 & 30,03 & $Y=-0,0333 X+6,3335$ & $-0,98$ \\
\hline 10 & 31,15 & $Y=-0,0321 X+6,4998$ & $-1,00$ \\
\hline 1.1 & 14,16 & $Y=-0,0706 X+5,7165$ & $-0,98$ \\
\hline 12 & 11,96 & $Y=-0,0836 X+5,7040$ & $-0,99$ \\
\hline 1.3. & 12,00 & $Y=-0,0833 X+5,7035$ & $-0,99$ \\
\hline 1.4 & 9,84 & $Y=-0,1016 X+5,7369$ & $-0,96$ \\
\hline 15 & 13,11 & $Y=-0,0763 X+6,6217$ & $-0,99$ \\
\hline 16 & 8,57 & $Y=-0,1167 X+5,2412$ & $-0,97$ \\
\hline $1 \%$ & 10,72 & $Y=-0,0933 X+6,0835$ & $-1,00$ \\
\hline 18 & - & $Y=-0,0283 X+5,4947$ & $-0,80$ \\
\hline
\end{tabular}

TABELA 35 Número de Sobreviventes de Aspergillus niger (UFC/mL) no Teste de Eficácia de Conservantes.

\begin{tabular}{|c|c|c|c|c|c|c|}
\hline Pómulas & $=T_{0}:=$ & $\mid T_{4}:=$ & T: & $T_{24}$ & $T_{48}$ & dias. \\
\hline 1. & $1,5 \times 10^{5}$ & $1,3 \times 10^{5}$ & $1,2 \times 10^{5}$ & $9,0 \times 10^{4}$ & $8,0 \times 10^{4}$ & $4,4 \times 10^{4}$ \\
\hline 2 & $1,0 \times 10^{5}$ & $1,2 \times 10^{5}$ & $1,1 \times 10^{5}$ & $1,0 \times 10^{5}$ & $1,3 \times 10^{5}$ & $1,2 \times 10^{5}$ \\
\hline 3 & $1,7 \times 10^{5}$ & $8,0 \times 10^{4}$ & $7,2 \times 10^{4}$ & $6,8 \times 10^{4}$ & $6,5 \times 10^{4}$ & $6,0 \times 10^{4}$ \\
\hline 4 & $1,0 \times 10^{5}$ & $8,9 \times 10^{4}$ & $7,0 \times 10^{4}$ & $6,5 \times 10^{4}$ & $6,0 \times 10^{4}$ & $5,0 \times 10^{4}$ \\
\hline 5 & $1,5 \times 10^{5}$ & $1,3 \times 10^{5}$ & $1,1 \times 10^{5}$ & $8,7 \times 10^{4}$ & $7,5 \times 10^{4}$ & $4,4 \times 10^{4}$ \\
\hline 6 & $1,5 \times 10^{5}$ & $8,5 \times 10^{4}$ & $5,5 \times 10^{4}$ & $4,2 \times 10^{4}$ & $3,0 \times 10^{4}$ & $9,0 \times 10^{3}$ \\
\hline 7. & $1,2 \times 10^{5}$ & $1,1 \times 10^{5}$ & $1,5 \times 10^{5}$ & $1,3 \times 10^{5}$ & $1,1 \times 10^{5}$ & $1,0 \times 10^{5}$ \\
\hline (6) & $1,0 \times 10^{5}$ & $1,0 \times 10^{5}$ & $1,1 \times 10^{5}$ & $1,2 \times 10^{5}$ & $1,4 \times 10^{5}$ & $1,2 \times 10^{5}$ \\
\hline 9 & $1,0 \times 10^{5}$ & $6,9 \times 10^{4}$ & $4,5 \times 10^{4}$ & $2,2 \times 10^{4}$ & $2,8 \times 10^{3}$ & zero \\
\hline 18 & $1,1 \times 10^{5}$ & $6,6 \times 10^{4}$ & $4,3 \times 10^{4}$ & $1,8 \times 10^{4}$ & $2,5 \times 10^{3}$ & zero \\
\hline 1.1 & $1,0 \times 10^{5}$ & $3,9 \times 10^{4}$ & $3,5 \times 10^{4}$ & $3,0 \times 10^{4}$ & $2,0 \times 10^{4}$ & $2,5 \times 10^{3}$ \\
\hline 12 & $1,3 \times 10^{5}$ & $4,5 \times 10^{4}$ & $4,0 \times 10^{4}$ & $3,0 \times 10^{4}$ & $2,5 \times 10^{4}$ & $3,0 \times 10^{3}$ \\
\hline 13 & $1,6 \times 10^{5}$ & $7,9 \times 10^{4}$ & $7,3 \times 10^{4}$ & $6,0 \times 10^{4}$ & $4,4 \times 10^{4}$ & $4,0 \times 10^{4}$ \\
\hline 14 & $1,0 \times 10^{5}$ & $8,9 \times 10^{4}$ & $6,5 \times 10^{4}$ & $4,2 \times 10^{4}$ & $2,0 \times 10^{4}$ & $4,0 \times 10^{3}$ \\
\hline 15 & $1,4 \times 10^{5}$ & $1,1 \times 10^{5}$ & $1,5 \times 10^{5}$ & $1,2 \times 10^{5}$ & $1,2 \times 10^{5}$ & $1.0 \times 10^{5}$ \\
\hline 16 & $1,7 \times 10^{5}$ & $8,4 \times 10^{4}$ & $7,9 \times 10^{4}$ & $6,1 \times 10^{4}$ & $4,0 \times 10^{4}$ & $3,0 \times 10^{4}$ \\
\hline 17. & $1,0 \times 10^{5}$ & $1,0 \times 10^{5}$ & $1,1 \times 10^{5}$ & $1,2 \times 10^{5}$ & $1,0 \times 10^{5}$ & $1,2 \times 10^{5}$ \\
\hline 18 & $1,6 \times 10^{5}$ & $1,2 \times 10^{5}$ & $1,6 \times 10^{5}$ & $1,1 \times 10^{5}$ & $1,3 \times 10^{5}$ & $1,0 \times 10^{5}$ \\
\hline
\end{tabular}

$\mathrm{T}_{0}=$ contagem imediatamente após a inoculação da amostra

$\mathrm{T}_{4}, \mathrm{~T}_{8}, \mathrm{~T}_{24}, \mathrm{~T}_{48}$ e $\mathrm{T}_{7}=$ contagem após $2,4,24$ e 48 horas e 7 dias após a inoculação. 
TABELA 36 Logarítmo (base 10) do Número de Sobreviventes de Aspergillus niger no Teste de Eficácia de Conservantes.

\begin{tabular}{|c|c|c|c|c|c|c|}
\hline fromulias & 18 & 14. & 18 & 182, & 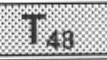 & tras \\
\hline : & 5,18 & 5,11 & 5,08 & 4,95 & 4,90 & 4,64 \\
\hline 2 & 5,00 & 5,08 & 5,04 & 5,00 & 5,11 & 5,08 \\
\hline 3 & 5,23 & 4,90 & 4,86 & 4,83 & 4,81 & 4,78 \\
\hline 4. & 5,00 & 4,95 & 4,85 & 4,81 & 4,78 & 4,70 \\
\hline 6. & 5,18 & 5,11 & 5,04 & 4,94 & 4,88 & 4,64 \\
\hline 6 & 5,18 & 4,93 & 4,74 & 4,62 & 4,48 & 3,95 \\
\hline 7 & 5,08 & 5,04 & 5,18 & 5,11 & 5,04 & 5,00 \\
\hline 8 & 5,00 & 5,00 & 5,04 & 5,08 & 5,15 & 5,08 \\
\hline 9 & 5,00 & 4,84 & 4,65 & 4,34 & 3,45 & - \\
\hline 10 & 5,04 & 4,82 & 4,63 & 4,26 & 3,40 & - \\
\hline 1 1: & 5,00 & 4,59 & 4,54 & 4,48 & 4,30 & 3,40 \\
\hline 12 & 5,11 & 4,65 & 4,60 & 4,48 & 4,40 & 3,48 \\
\hline 13 & 5,20 & 4,90 & 4,86 & 4,78 & 4,64 & 4,60 \\
\hline $1: 4.4$ & 5,00 & 4,95 & 4,81 & 4,62 & 4,30 & 3,60 \\
\hline 15 & 5,15 & 5,04 & 5,18 & 5,08 & 5,08 & 5,00 \\
\hline 16 & 5,23 & 4,92 & 4,90 & 4,79 & 4,60 & 4,48 \\
\hline $1 \%$ & 5,00 & 5,00 & 5,04 & 5,08 & 5,00 & 5,08 \\
\hline 18 & 5,20 & 5,08 & 5,20 & 5,04 & 5,11 & 5,00 \\
\hline
\end{tabular}

TABELA 37 Valor D, Equação da Reta e Coeficiente de Correlação Referentes a Aspergillus niger (LogUFC/mL).

\begin{tabular}{|c|c|c|c|}
\hline Pormila & $\begin{array}{l}\text { Yalor: } \mathrm{D} \\
\text { Mroras) }\end{array}$ & Eqgara a & $\begin{array}{l}\text { Coeflciente ie } \\
\text { correlacáo }\end{array}$ \\
\hline 签 & 346,14 & $Y=-0,0029 X+5,0980$ & $-0,95$ \\
\hline 2. & - & $Y=+0,0003 X+5,0384$ & $+0,42$ \\
\hline 3. & - & $Y=-0,0013 X+4,9565$ & $-0,51$ \\
\hline 4 & - & $Y=-0,0014 X+4,9068$ & $-0,81$ \\
\hline 5 & 353,86 & $Y=-0,0028 X+5,0835$ & $-0,94$ \\
\hline 6 & 165,29 & $Y=-0,0060 X+4,9041$ & $-0,92$ \\
\hline t. & - & $Y=-0,0006 X+5,1010$ & $-0,63$ \\
\hline 8. & - & $\mathrm{Y}=+0,0004 \mathrm{X}+5,0417$ & $+0,45$ \\
\hline 9 & 33,78 & $Y=-0,0296 X+4,9559$ & $-1,00$ \\
\hline 10 & 33,90 & $Y=-0,0295 X+4,9324$ & $-1,00$ \\
\hline XI & 124,39 & $Y=-0,0080 X+4,7219$ & $-0,96$ \\
\hline 12 & 126,01 & $Y=-0,0079 X+4,7866$ & $-0,95$ \\
\hline 13 & - & $Y=-0,0024 X+4,9288$ & $-0,69$ \\
\hline 14. & 124,55 & $Y=-0,0080 X+4,8839$ & $-0,97$ \\
\hline 15 & - & $Y=-0,0007 X+5,1187$ & $-0,70$ \\
\hline 16 & - & $Y=-0,0033 X+4,9573$ & $-0,80$ \\
\hline 17 & - & $Y=+0,0004 X+5,0185$ & $+0,57$ \\
\hline 18 & - & $Y=+0,0009 X+5,1423$ & $+0,69$ \\
\hline
\end{tabular}


Fórmula 1

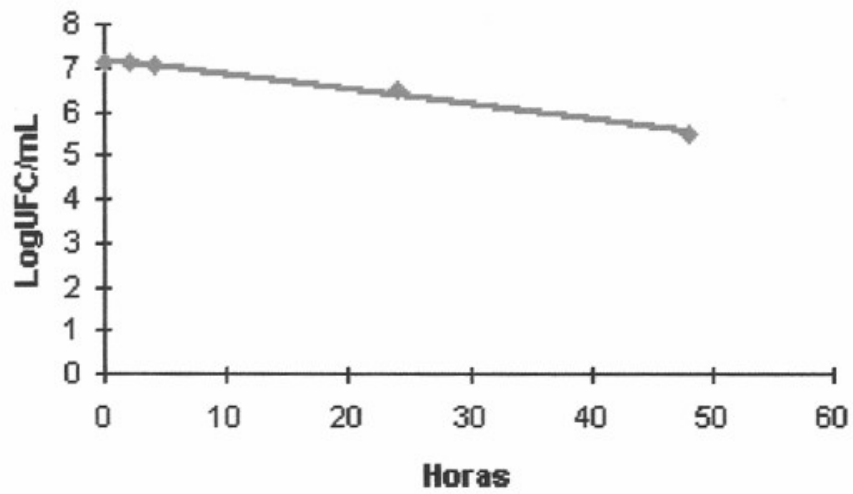

Fórmula 3

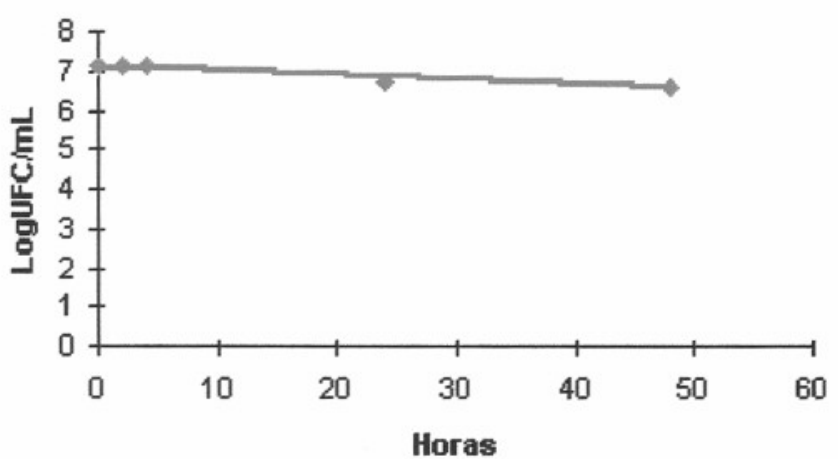

Fórmula 5

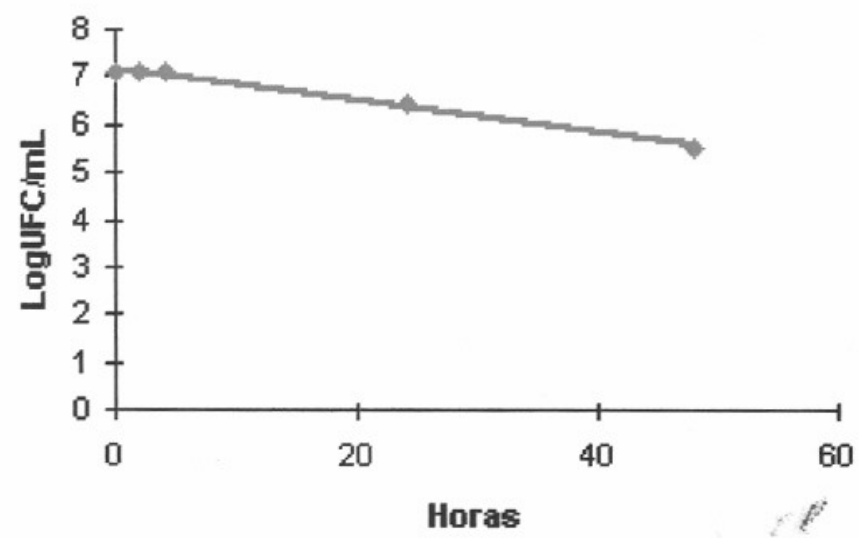

Fórmula 2

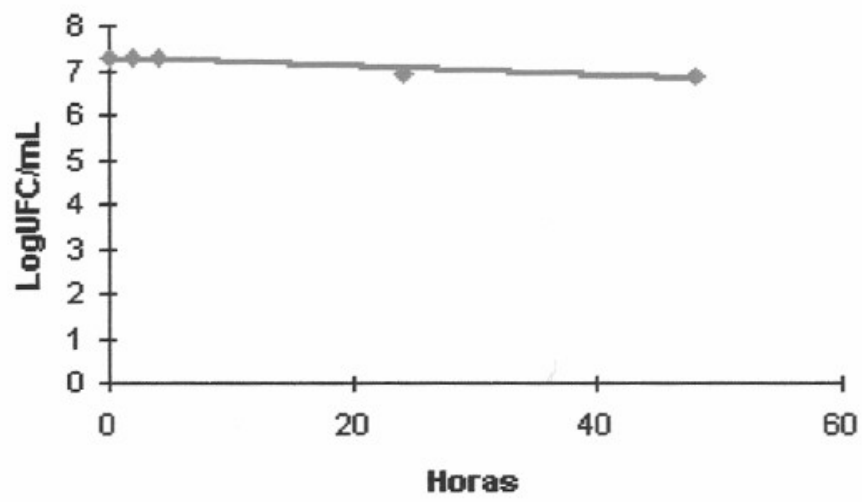

Fórmula 4

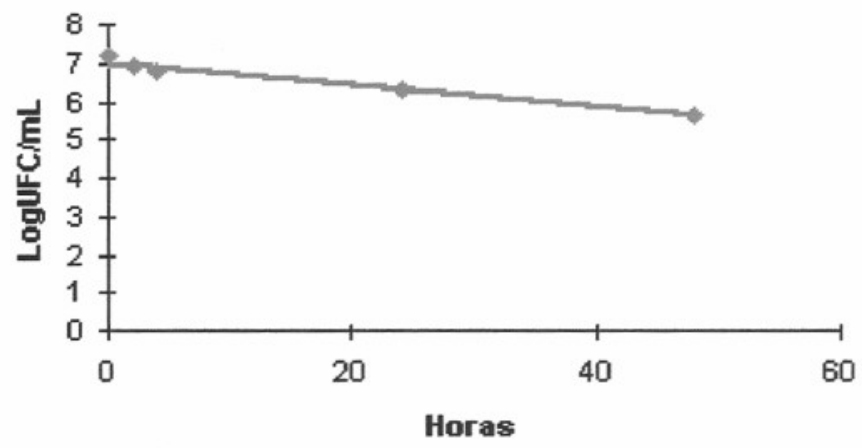

Fórmula 6

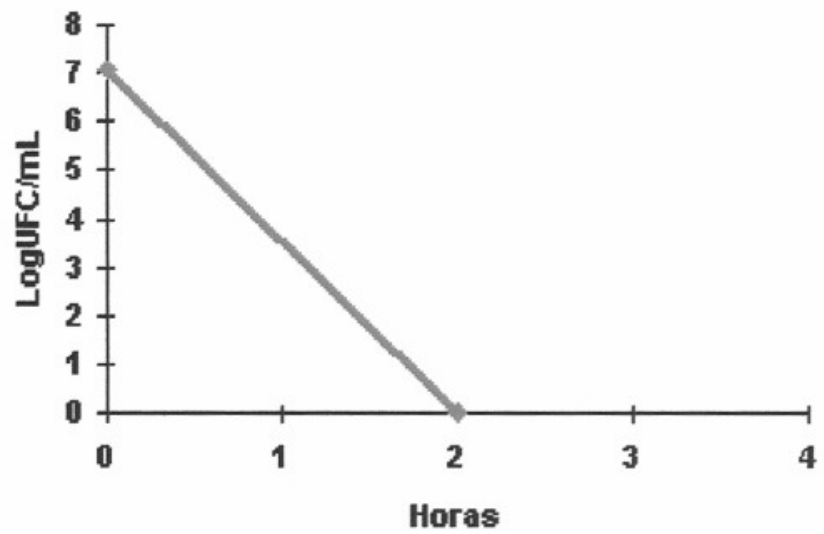

FIGURA 5 Comparativo do Perfil das Curvas de Letalidade (Log UFC/mL x Hora) de Pseudomonas cepacia para Fórmulas de 1 a 6. 
Fórmula 7

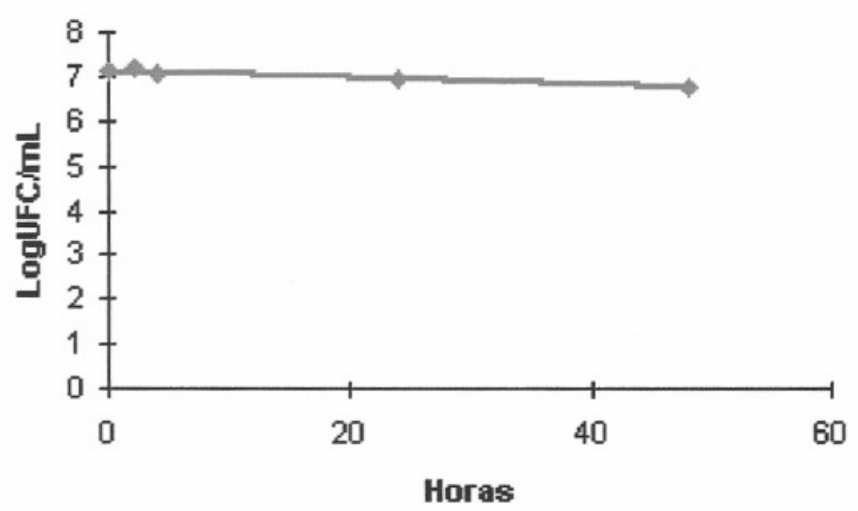

Fórmula 9

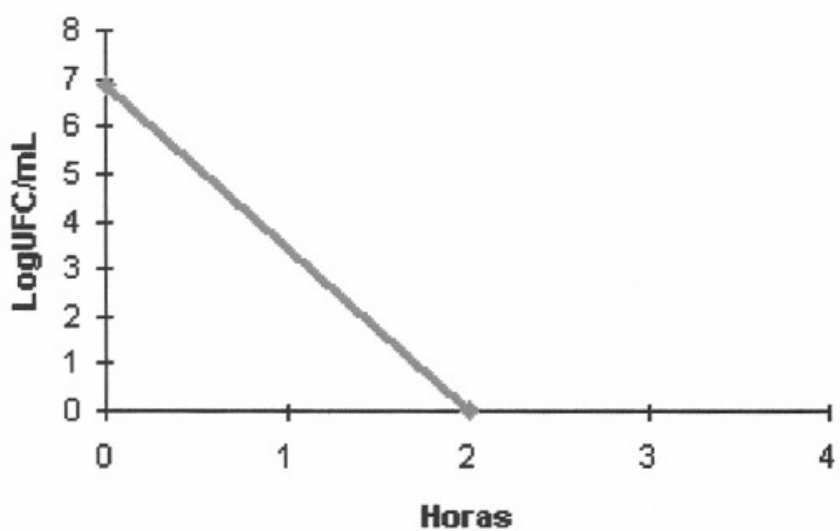

Fórmula 11

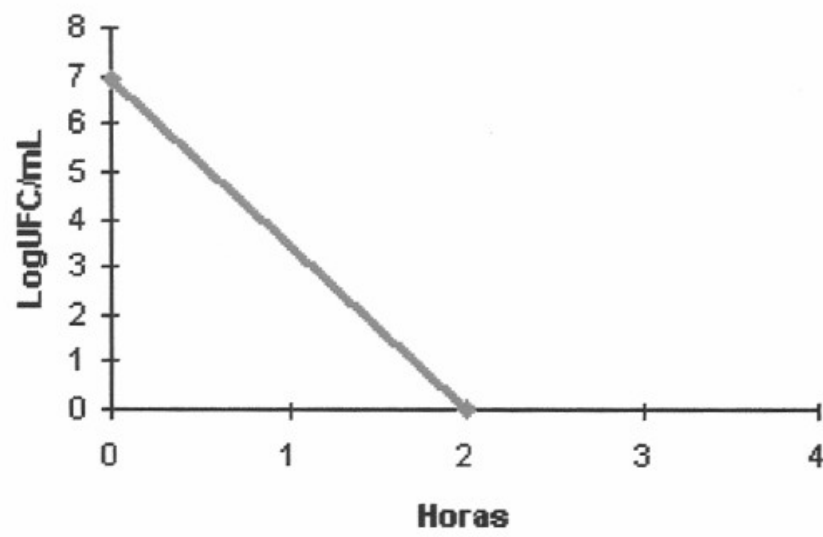

Fórmula 8

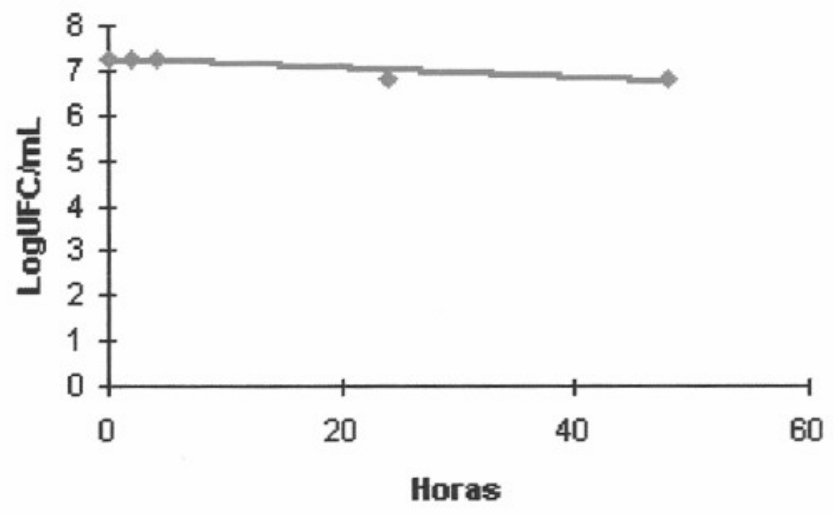

Fórmula 10

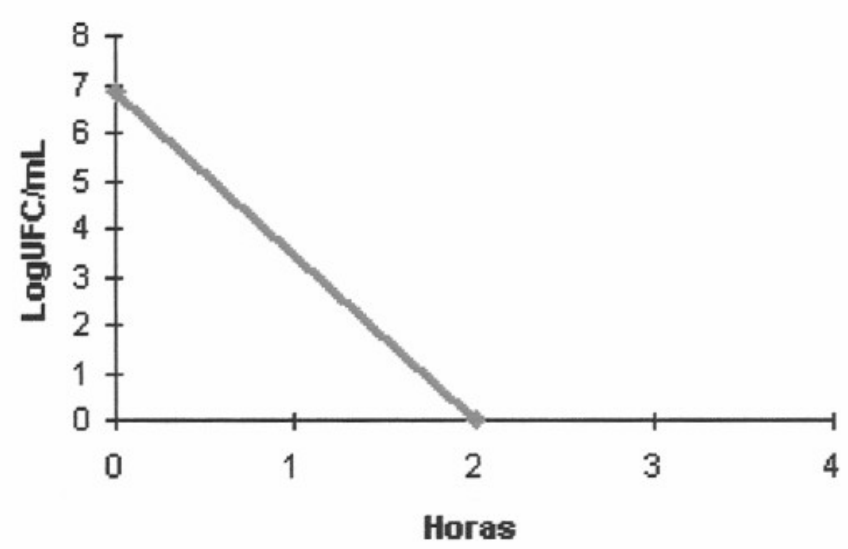

Fórmula 12

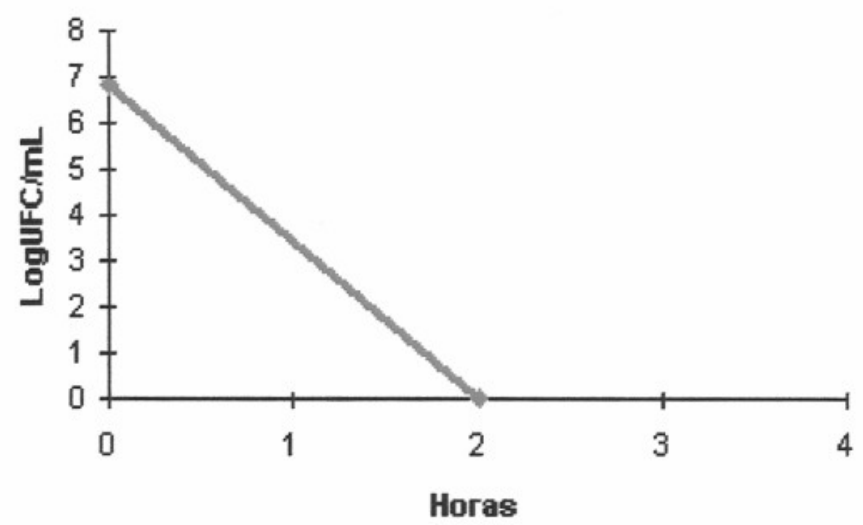

FIGURA 6 Comparativo do Perfil das Curvas de Letalidade (Log UFC/mL x Hora) de Pseudomonas cepacia para Fórmulas de 7 a 12. 
Fórmula 13

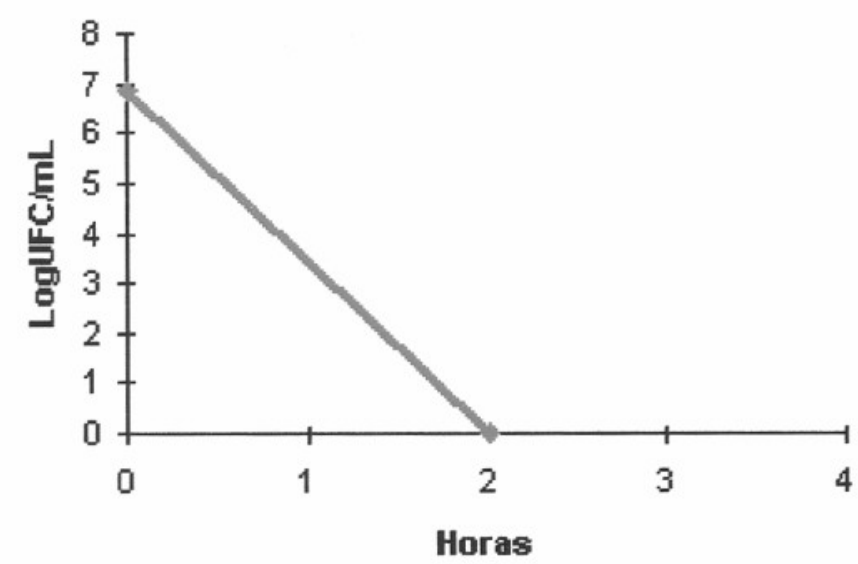

Fórmula 15

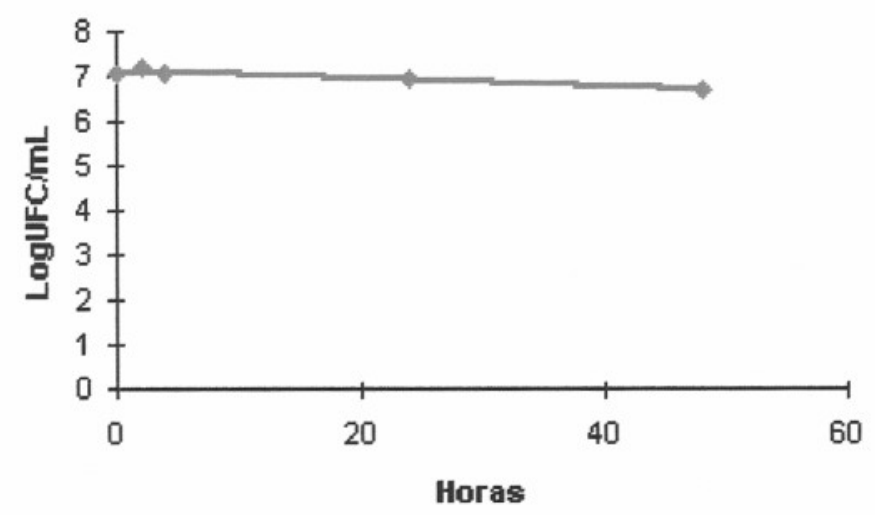

Fórmula 17

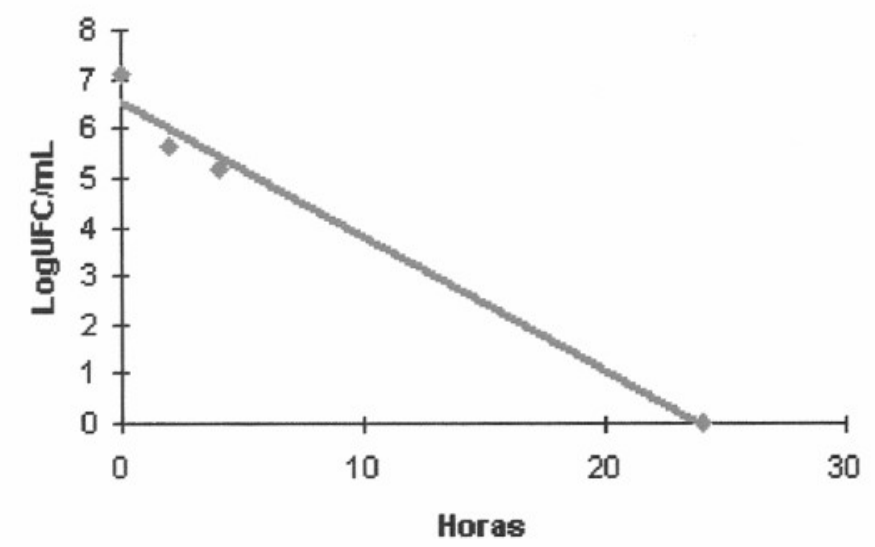

Fórmula 14

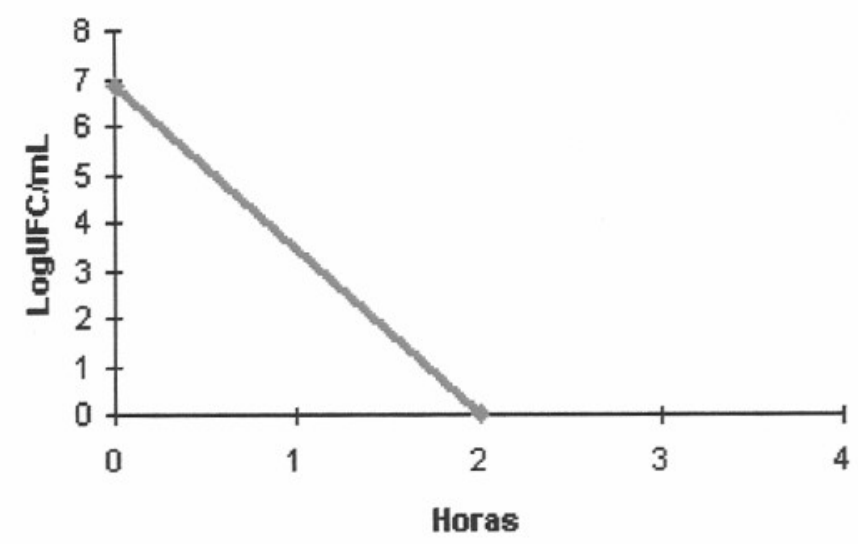

Fórmula 16

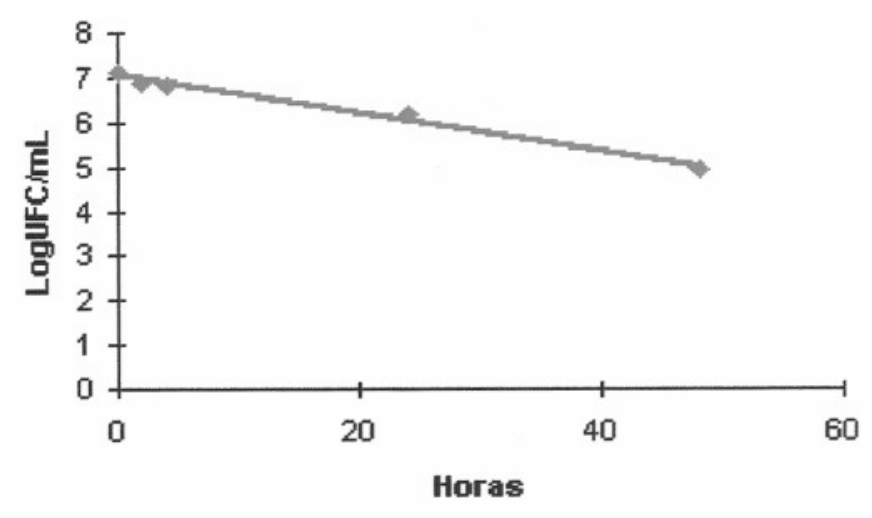

Fórmula 18

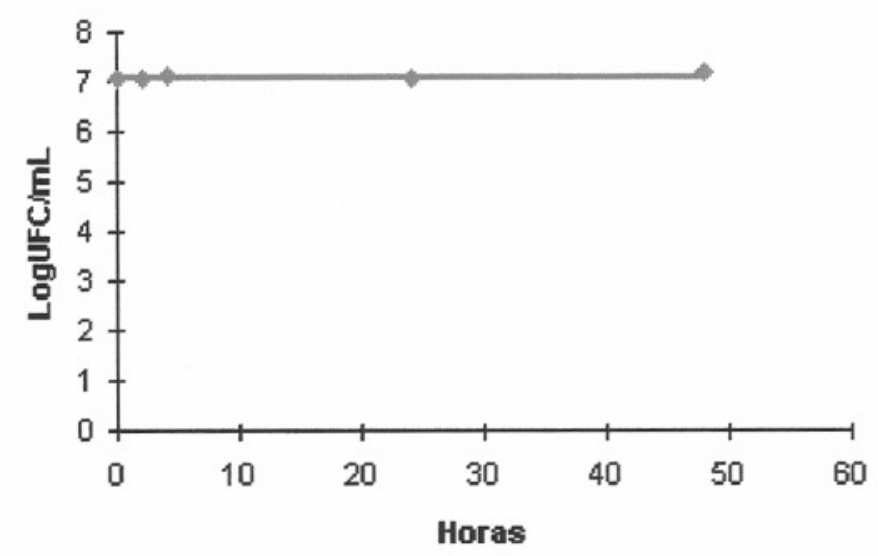

FIGURA 7 Comparativo do Perfil das Curvas de Letalidade (Log UFC/mL x Hora) de Pseudomonas cepacia para Fórmulas de 13 a 18. 
Fórmula 1

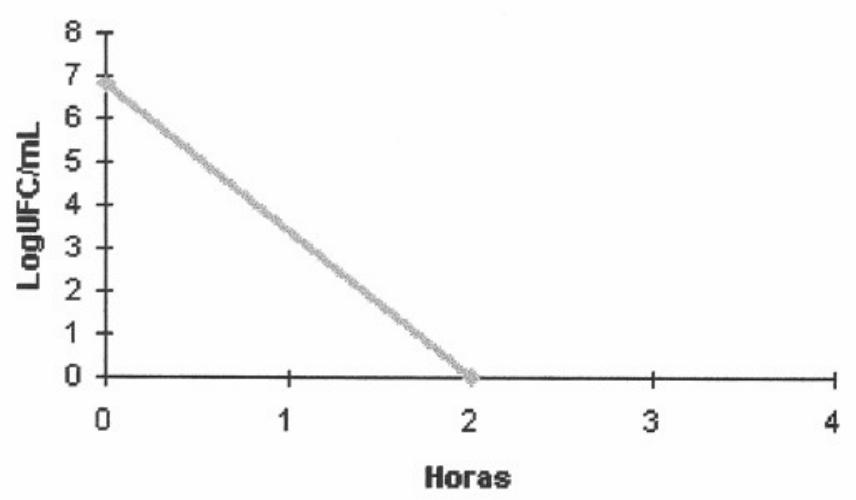

Fórmula 3

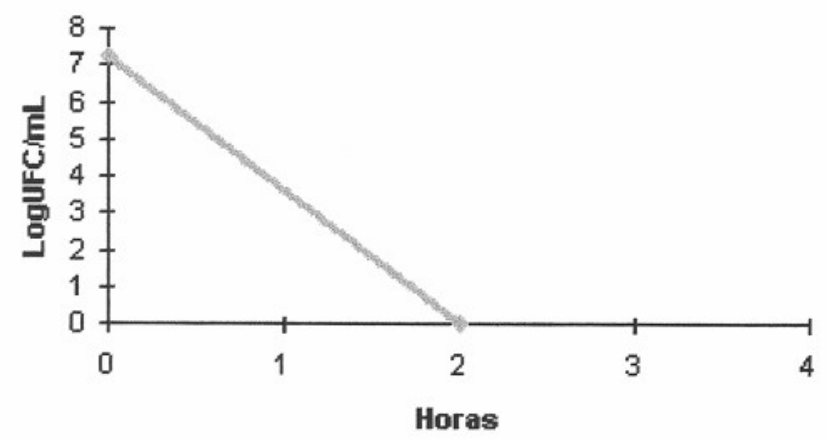

Fórmula 5

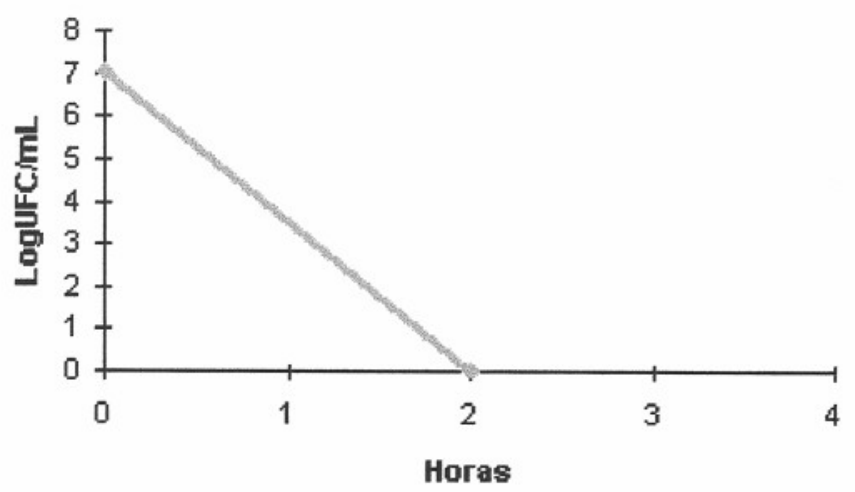

Fórmula 2

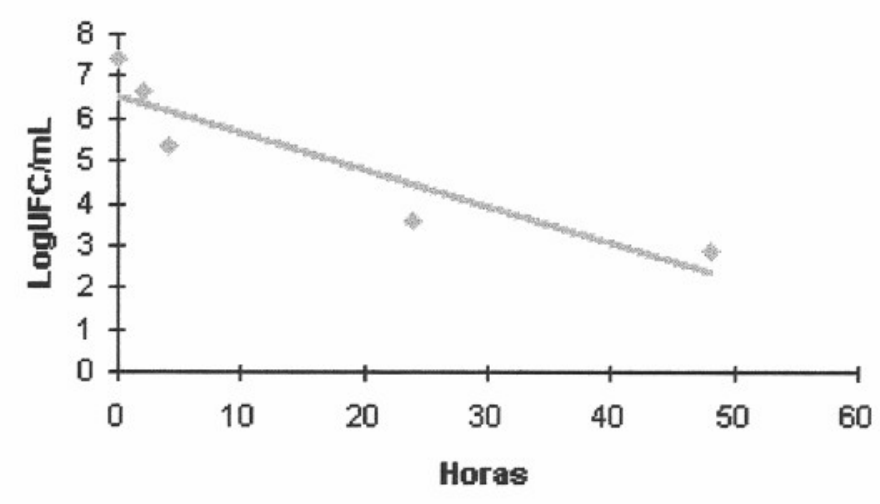

Fórmula 4

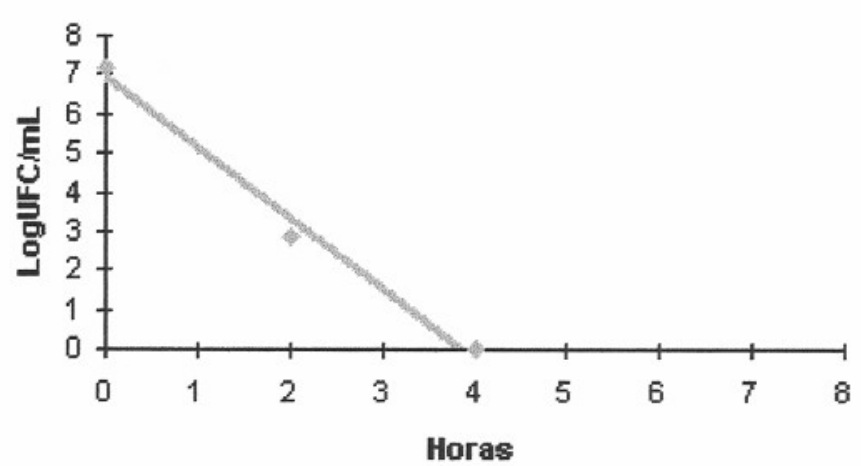

Fórmula 6

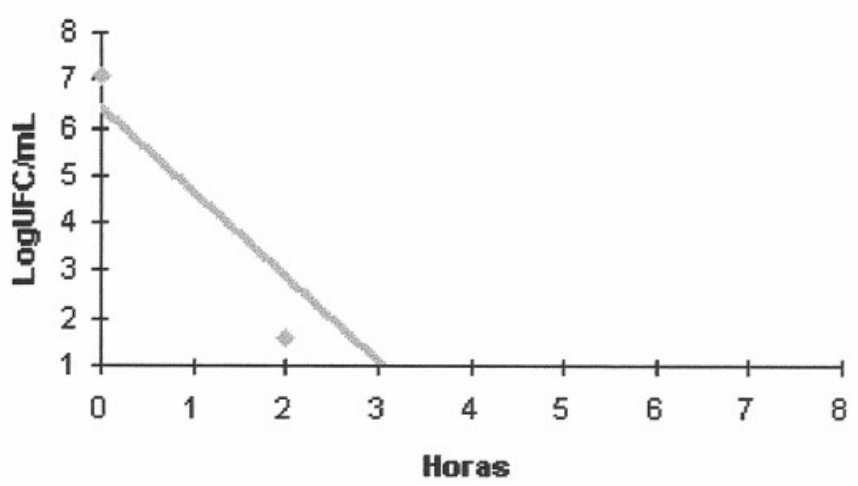

FIGURA 8 Comparativo do Perfil das Curvas de Letalidade (Log UFC/mL x Hora) de Staphylococcus aureus para Fórmulas de 1 a 6. 
Fórmula 7

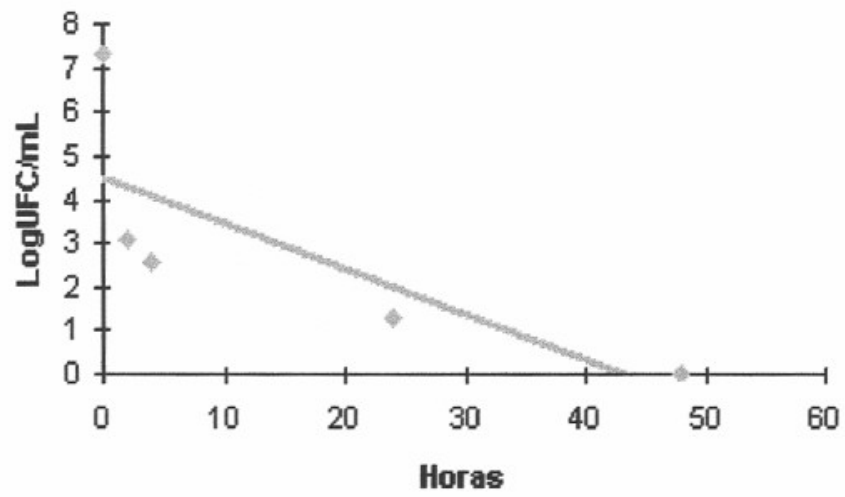

Fórmula 9

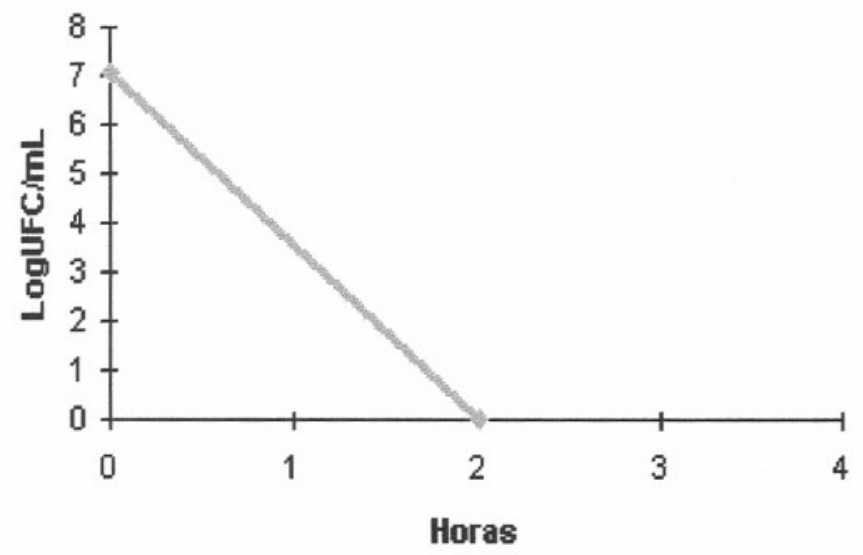

Fórmula 11

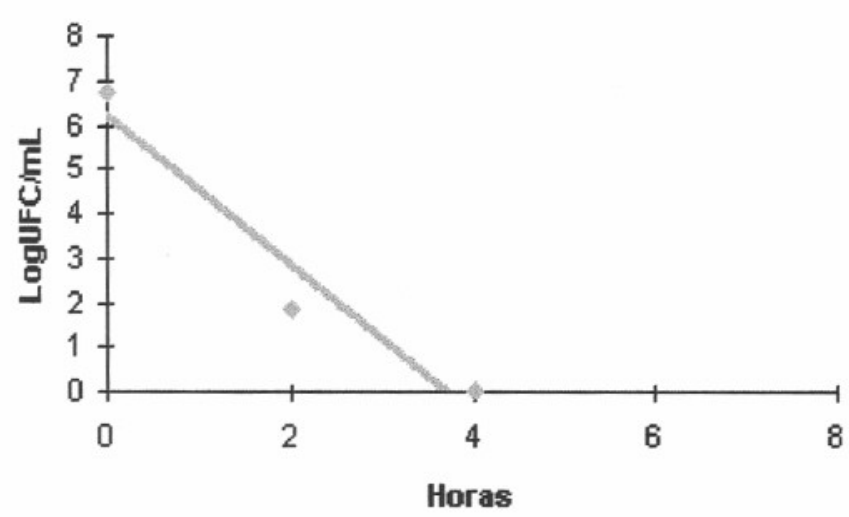

Fórmula 8

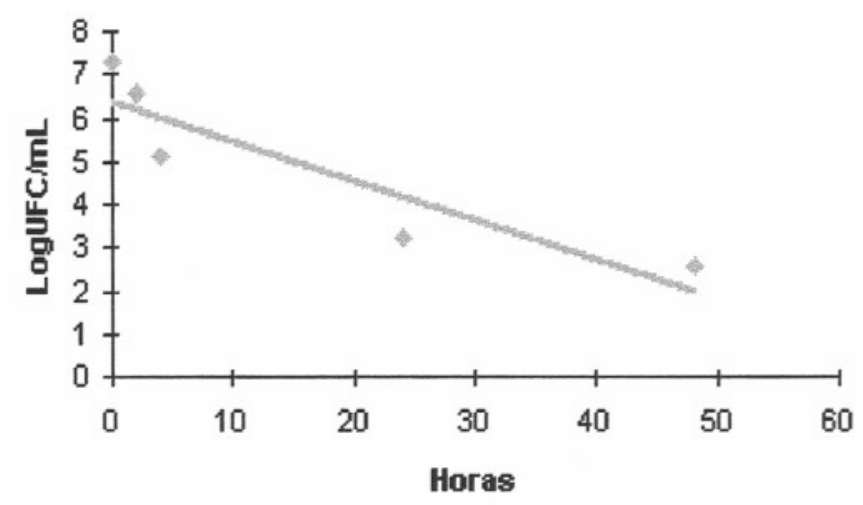

Fórmula 10

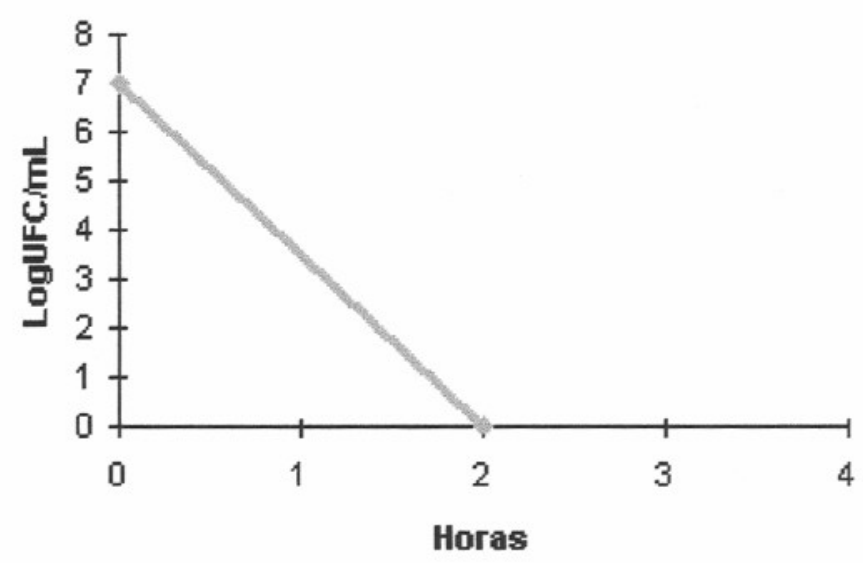

Fórmula 12

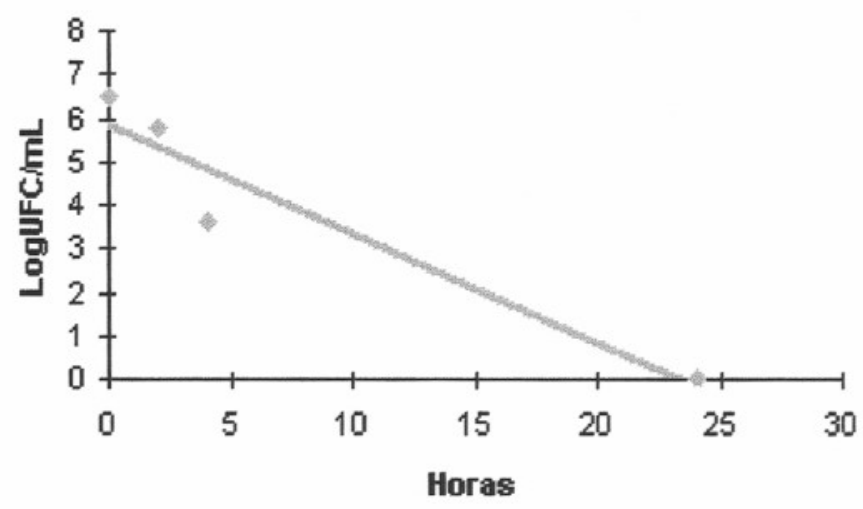

FIGURA 9 Comparativo do Perfil das Curvas de Letalidade (Log UFC/mL x Hora) de Staphylococcus aureus para Fórmulas de 7 a 12. 
Fórmula 13

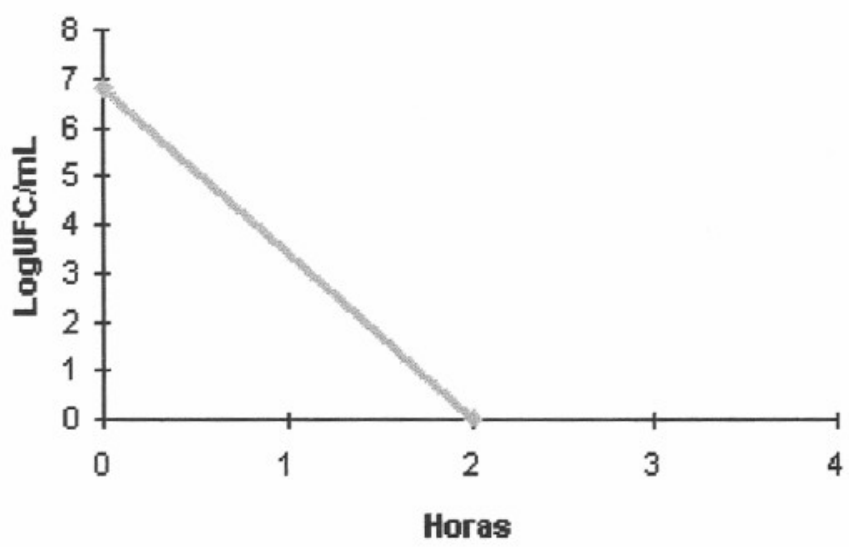

Fórmula 15

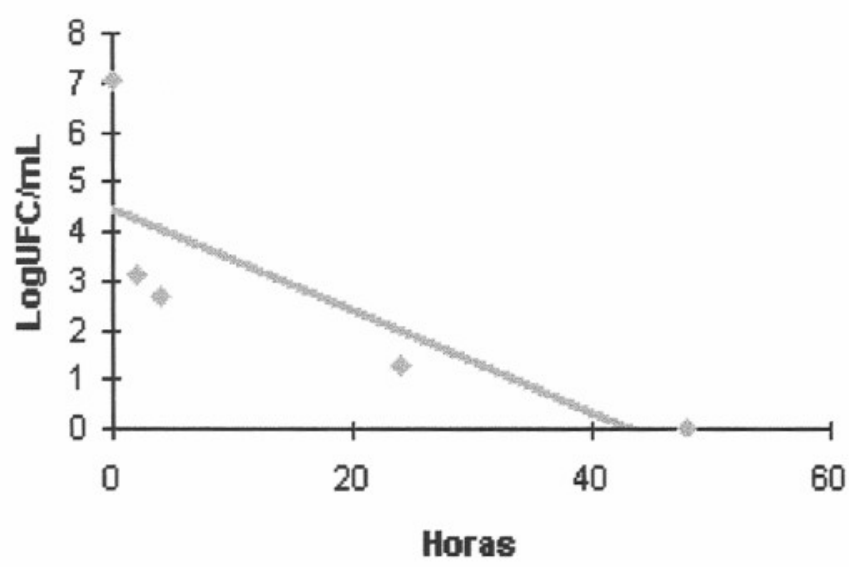

Fórmula 17

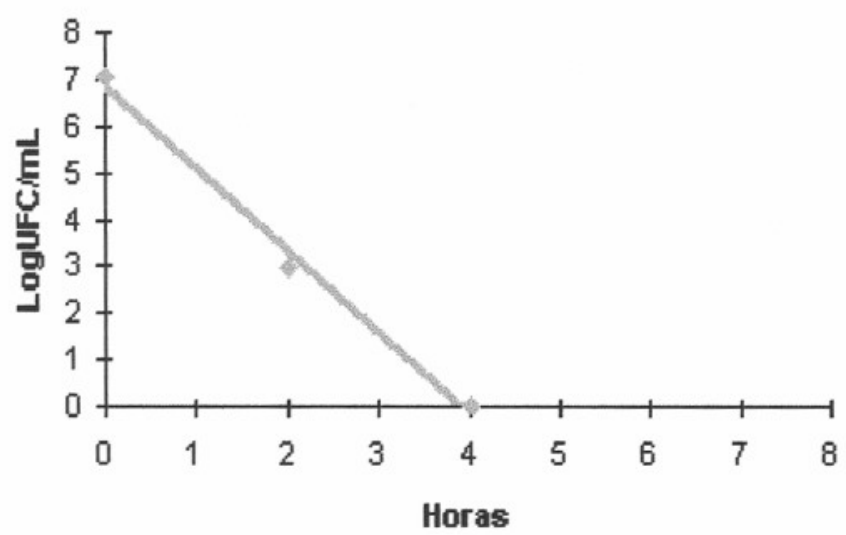

Fórmula 14

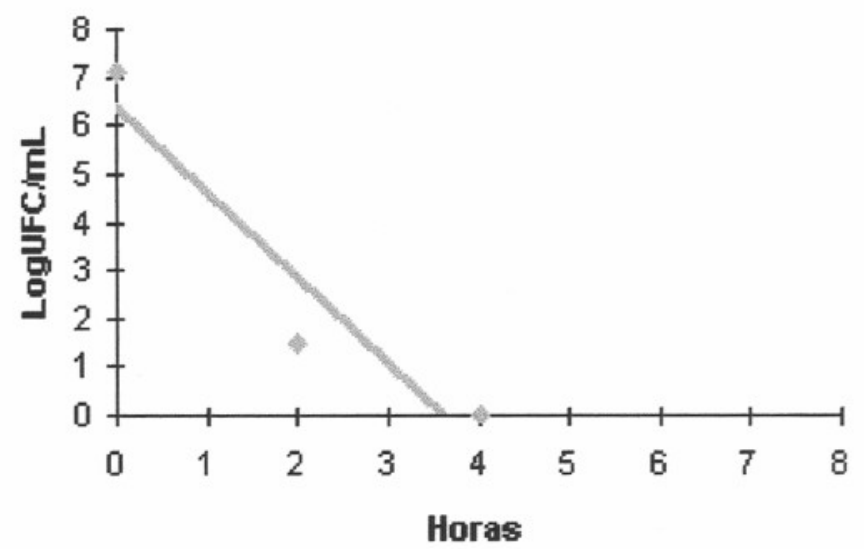

Fórmula 16

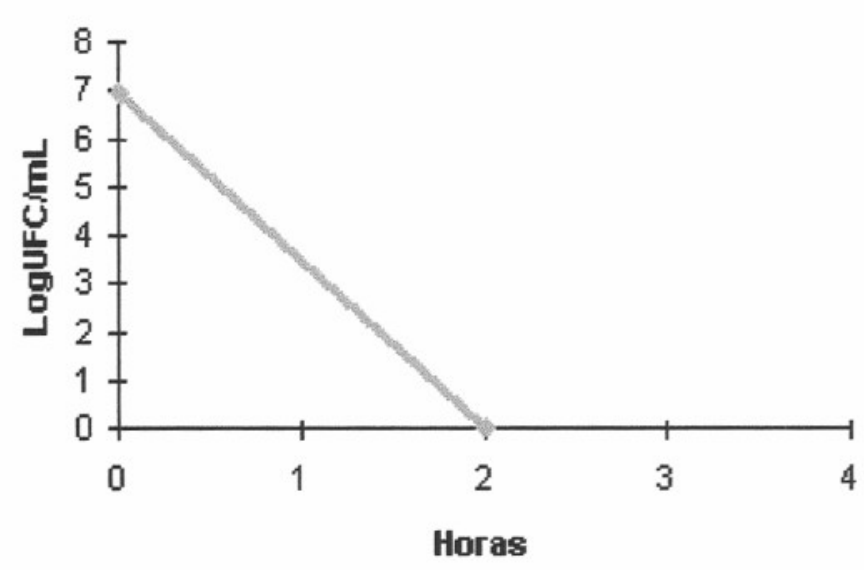

Fórmula 18

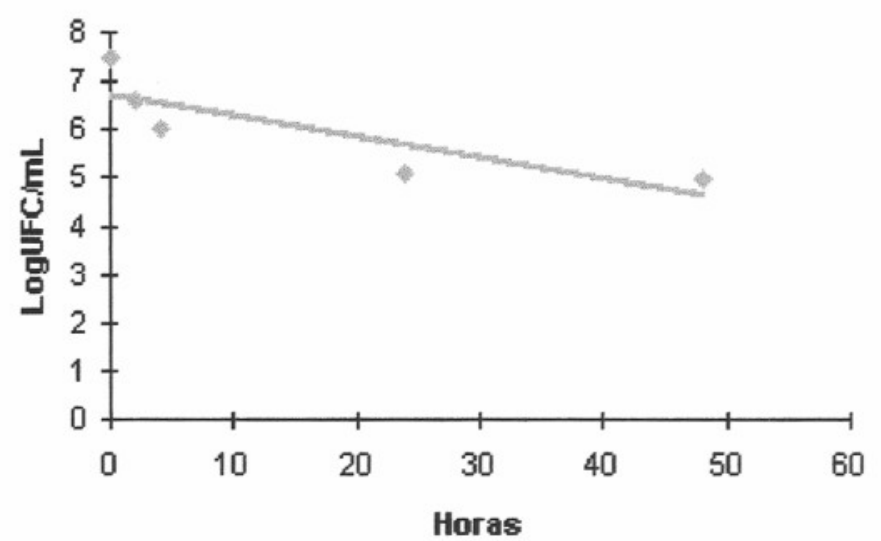

FIGURA 10 Comparativo do Perfil das Curvas de Letalidade (Log UFC/mL x Hora) de Staphylococcus aureus para Fórmulas de 13 a 18. 
Fórmula 1

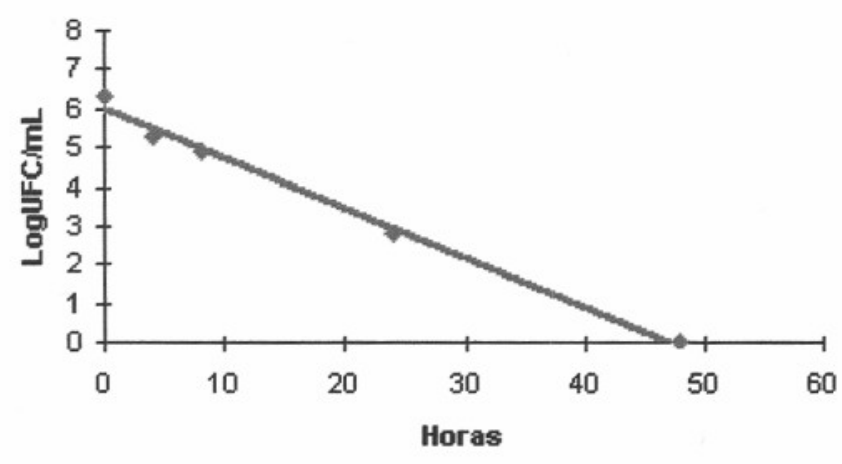

Fórmula 3

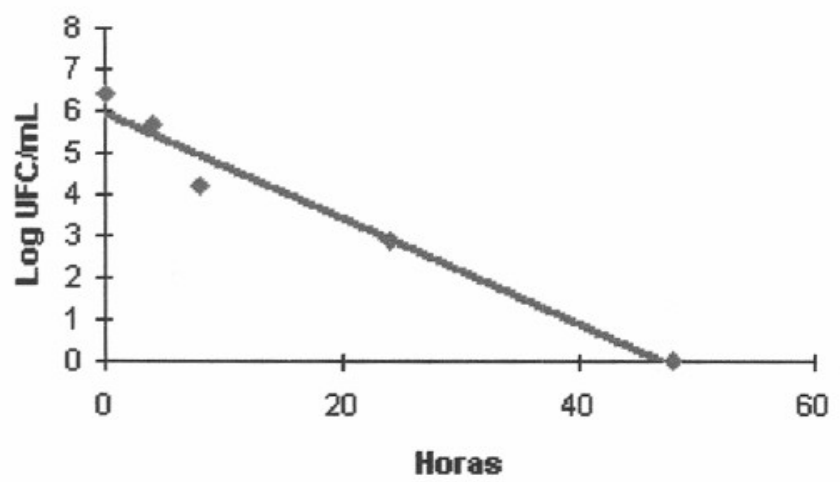

Fórmula 5

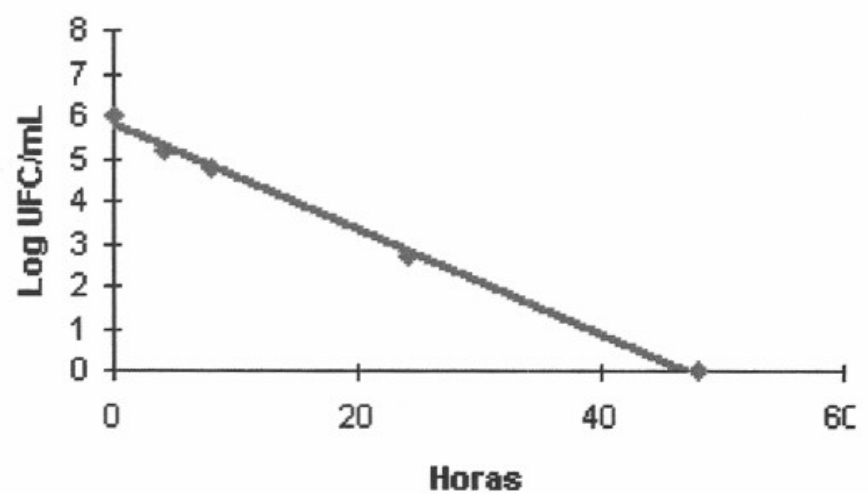

Fórmula 2

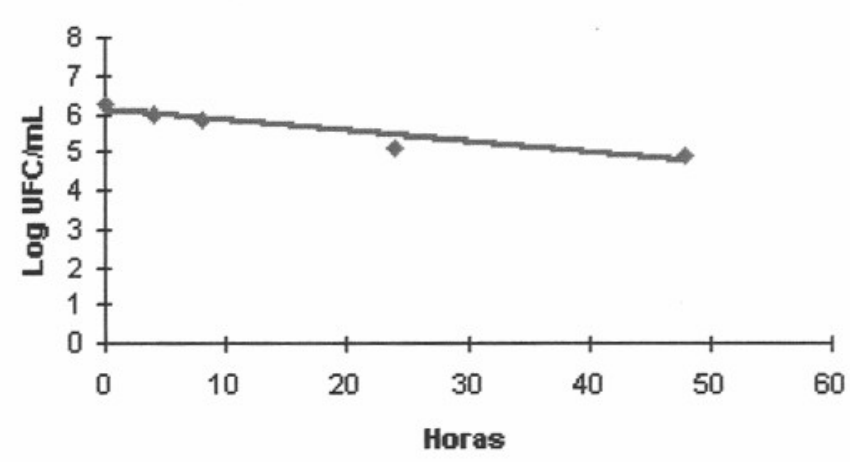

Fórmula 4

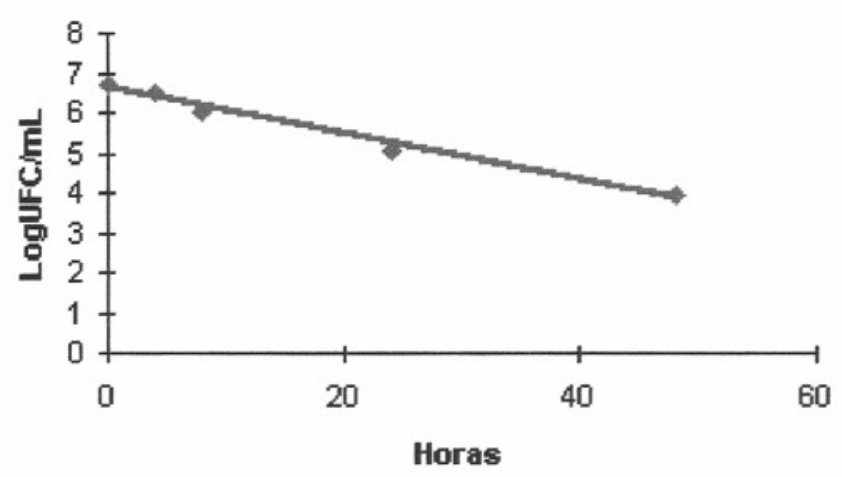

Fórmula 6

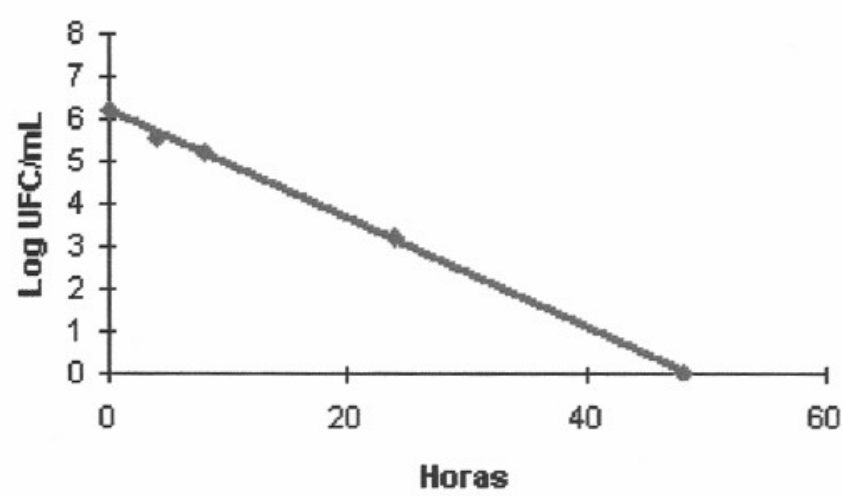

FIGURA 11 Comparativo do Perfil das Curvas de Letalidade (Log UFC/mL x Hora) de Candida albicans para Fórmulas de 1 a 6. 
Fórmula 7

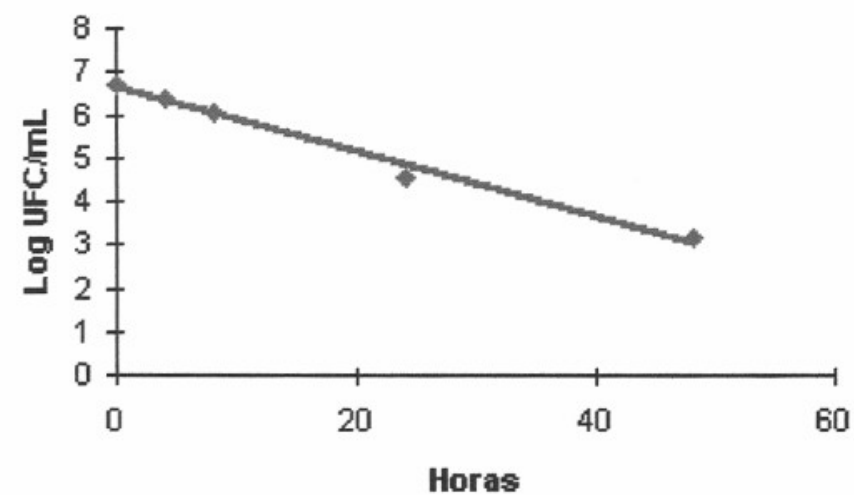

Fórmula 9

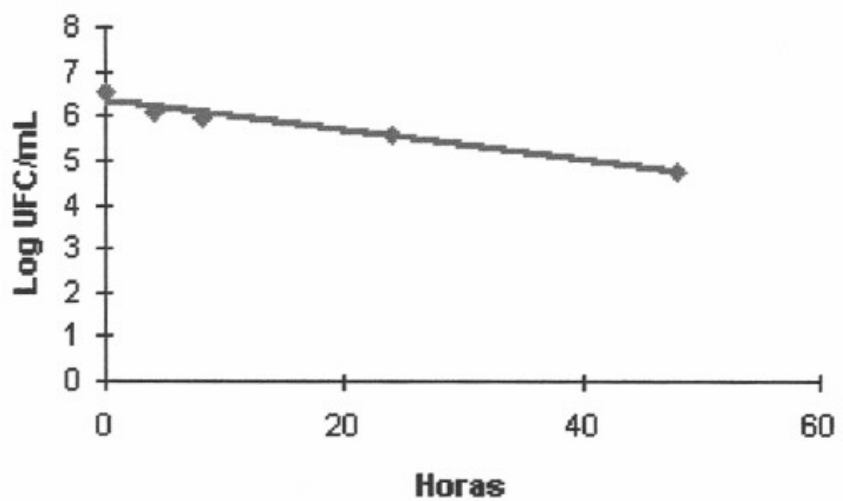

Fórmula 11

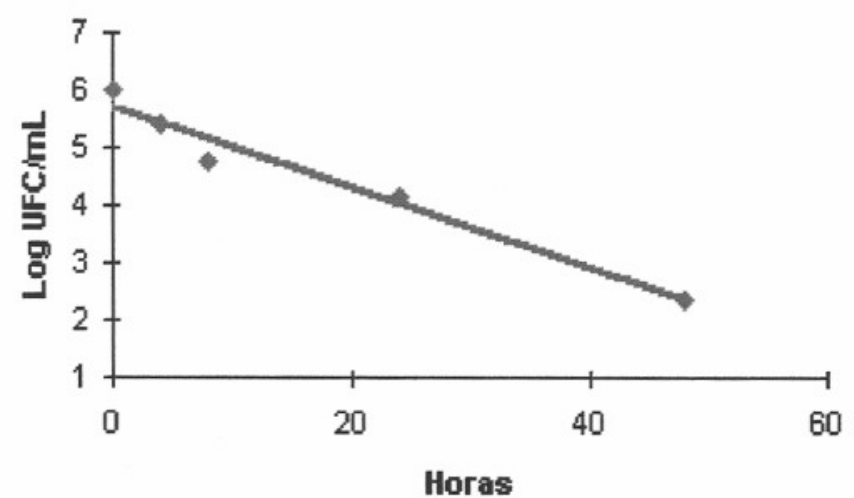

Fórmula 8

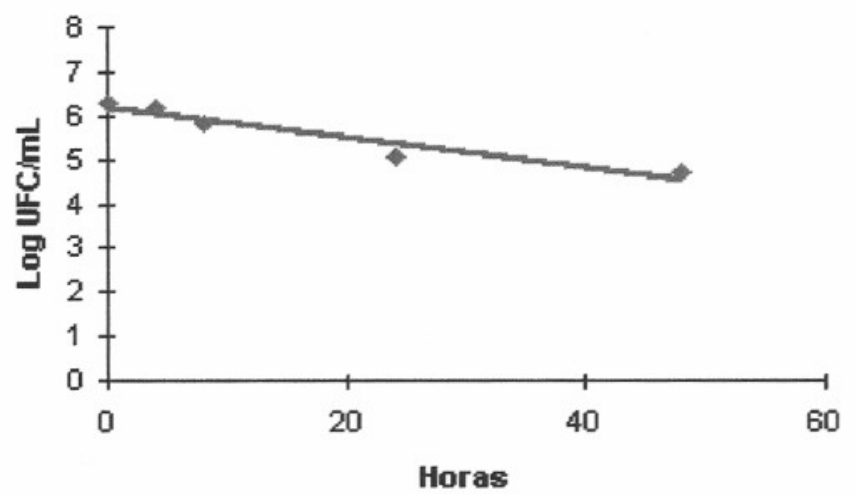

Fórmula 10

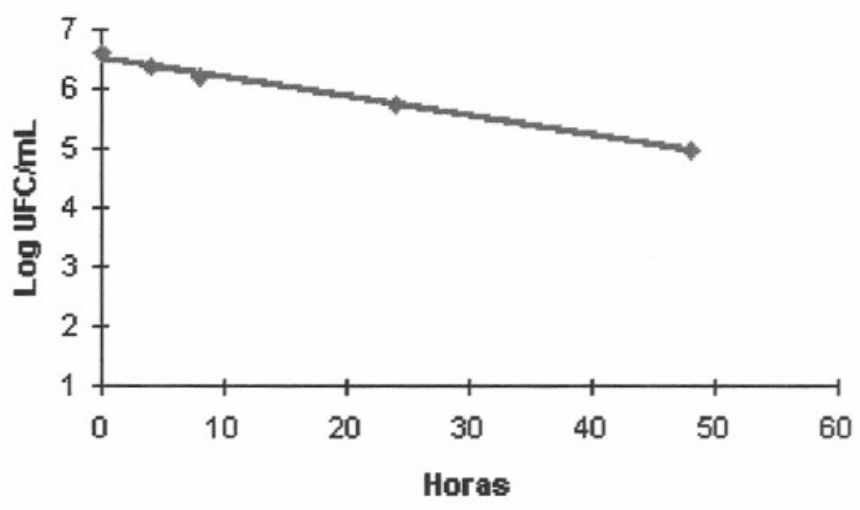

Fórmula 12

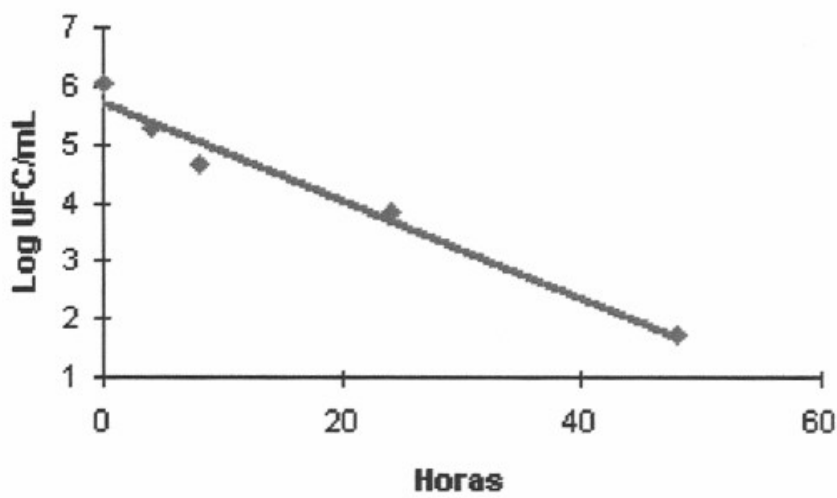

FIGURA 12 Comparativo do Perfil das Curvas de Letalidade (Log UFC/mL x Hora) de Candida albicans para Fórmulas de 7 a 12. 
Fórmula 13

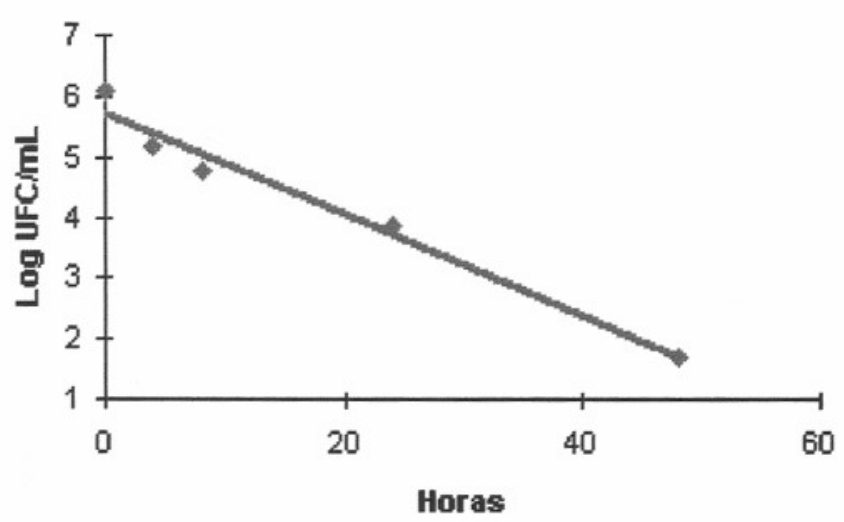

Fórmula 15

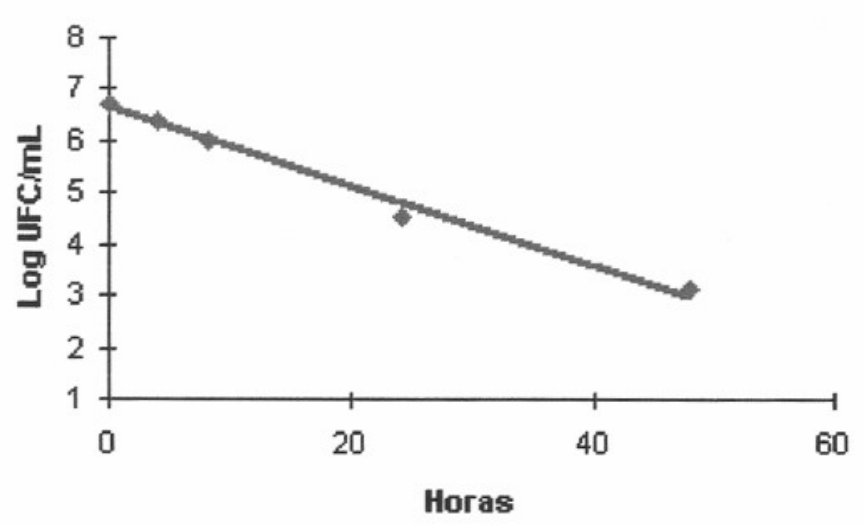

Fórmula 17

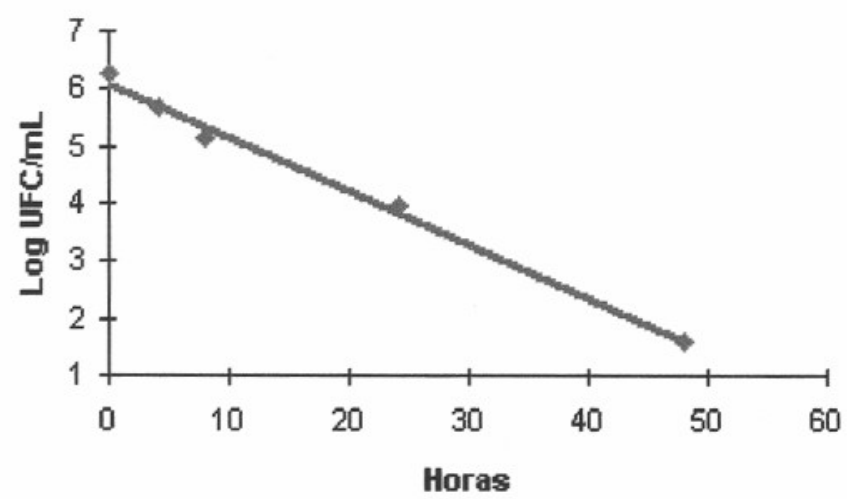

Fórmula 14

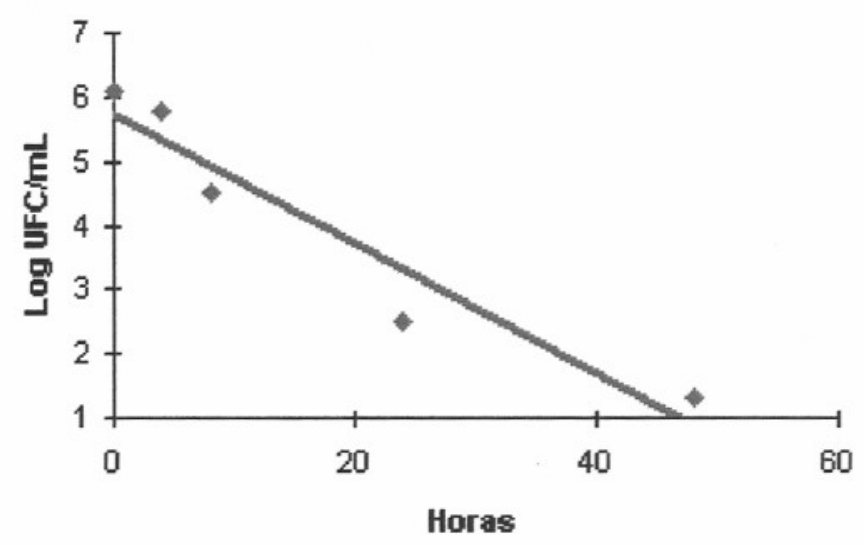

Fórmula 16

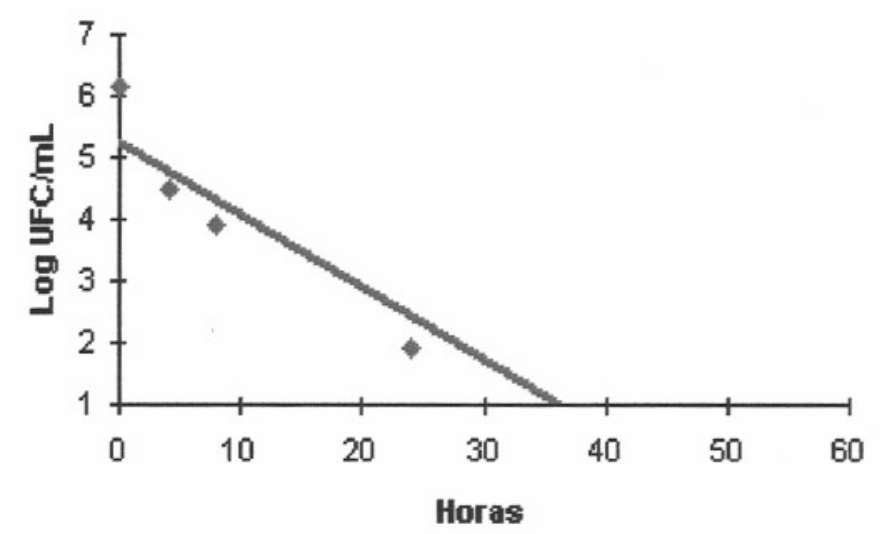

Fórmula 18

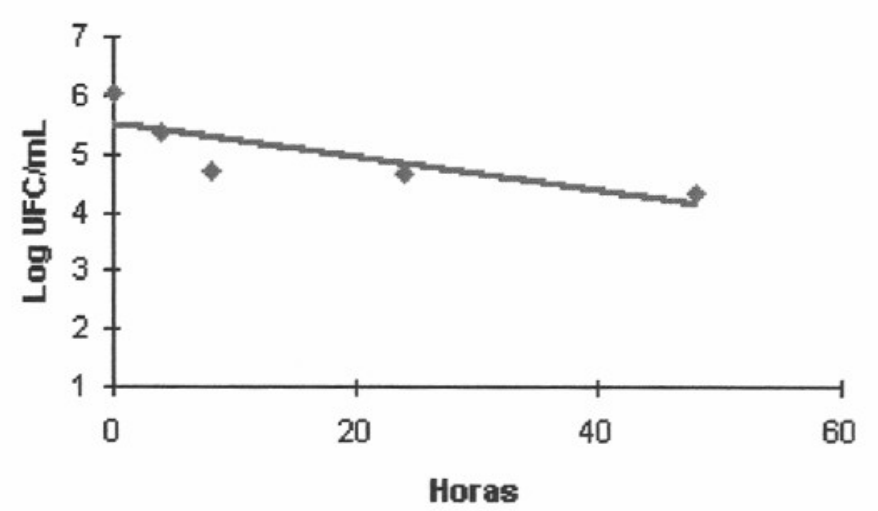

FIGURA 13 Comparativo do Perfil das Curvas de Letalidade (Log UFC/mL x Hora) de Candida albicans para Fórmulas de 13 a 18. 
Fórmula 1

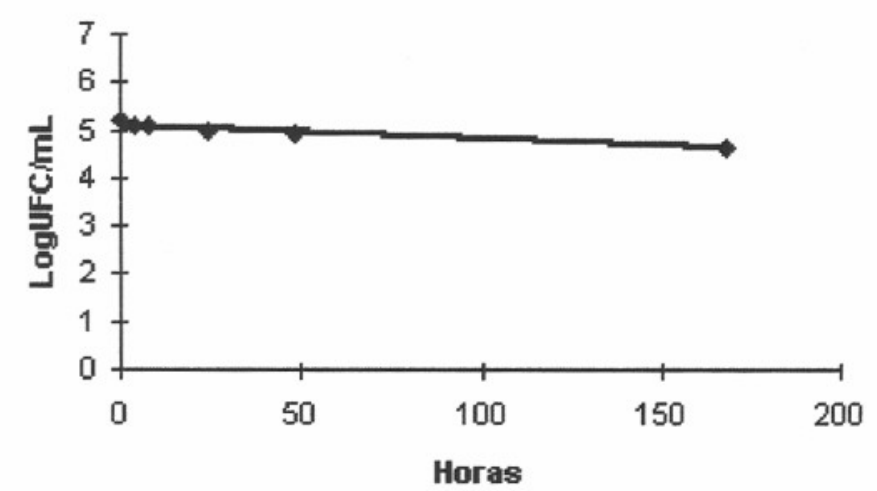

Fórmula 3

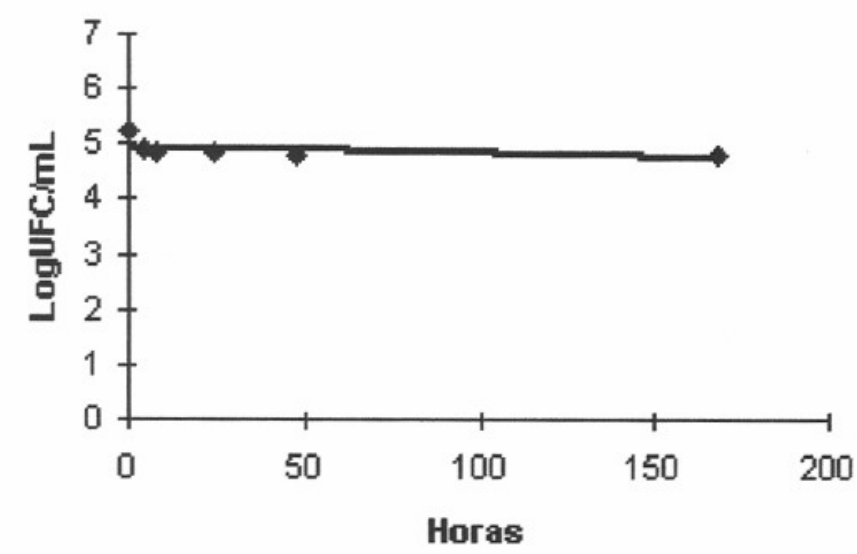

Fórmula 5

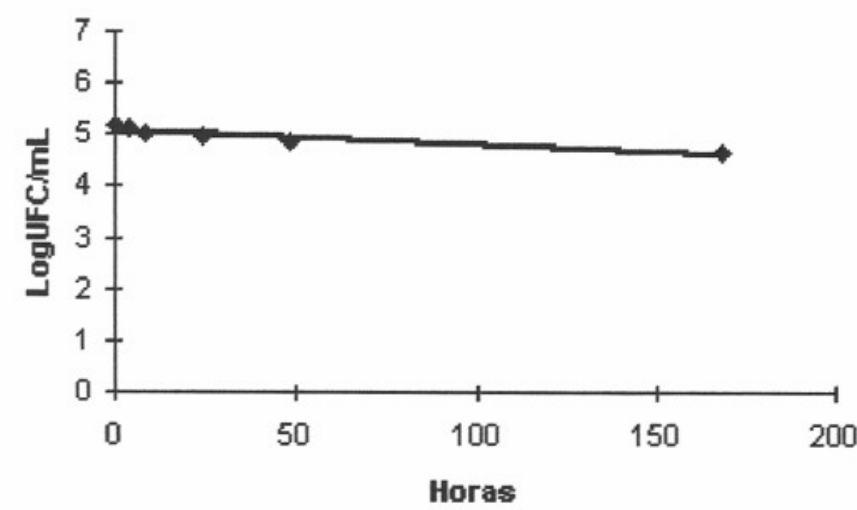

Fórmula 2

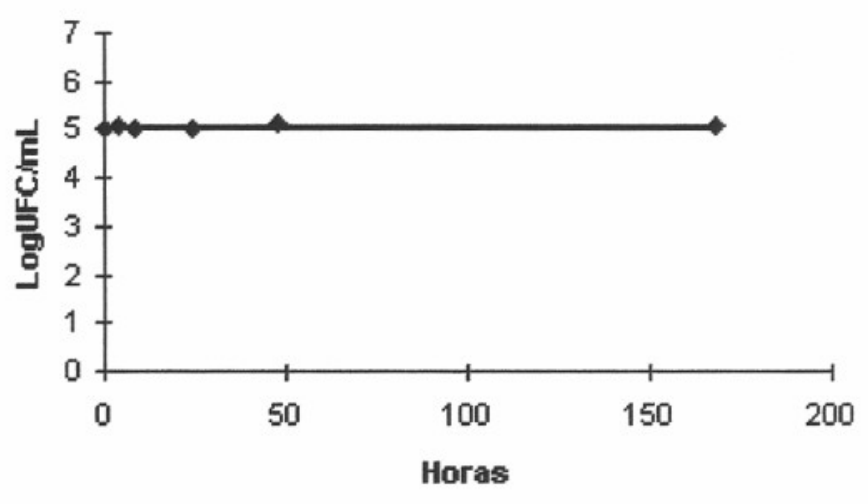

Fórmula 4

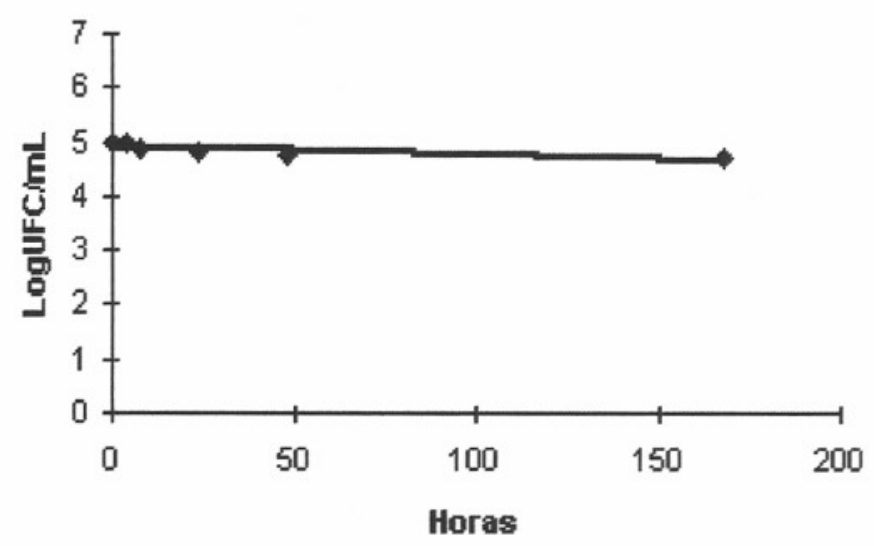

Fórmula 6

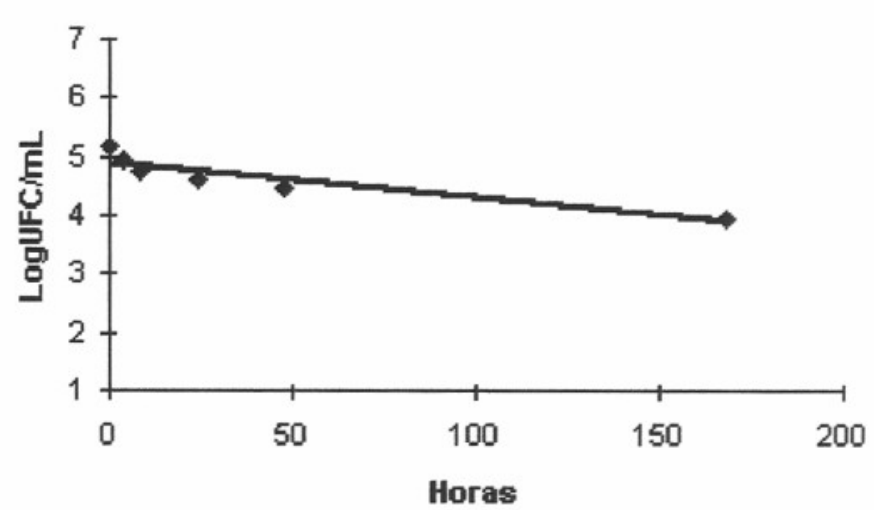

FIGURA 14 Comparativo do Perfil das Curvas de Letalidade (Log UFC/mL x Hora) de Aspergillus niger para Fórmulas de 1 a 6. 
Fórmula 7

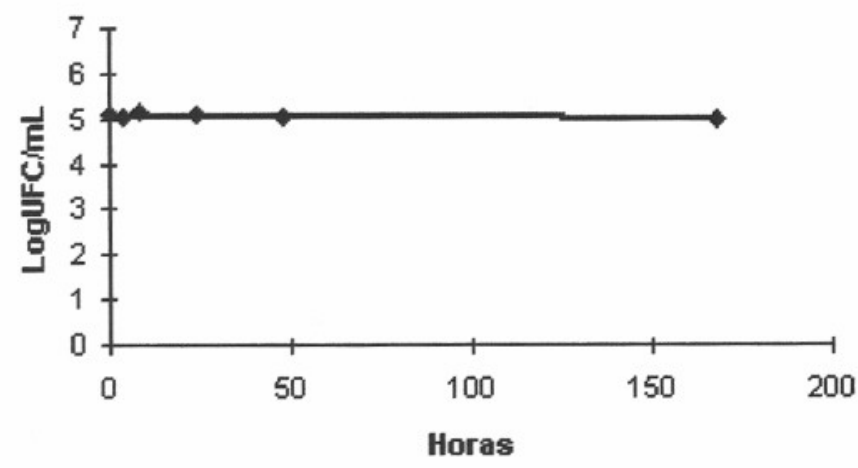

Fórmula 9

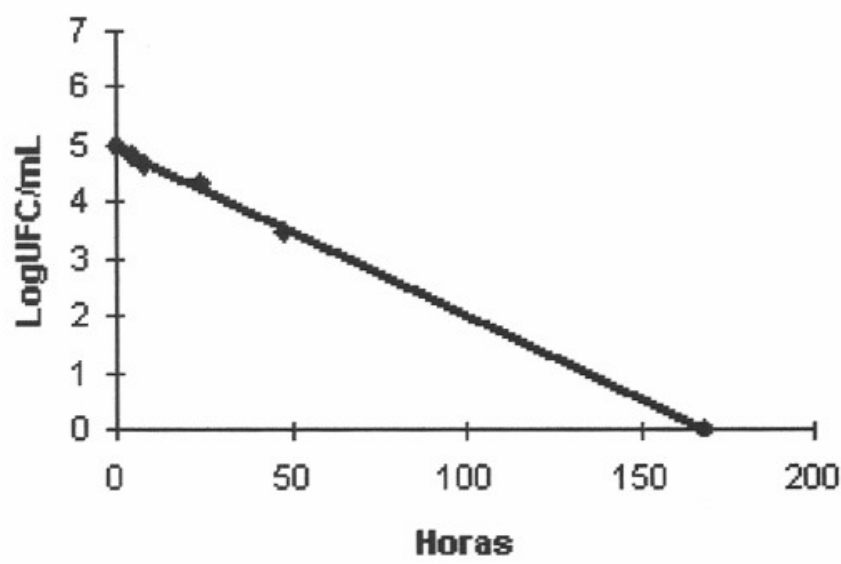

Fórmula 11

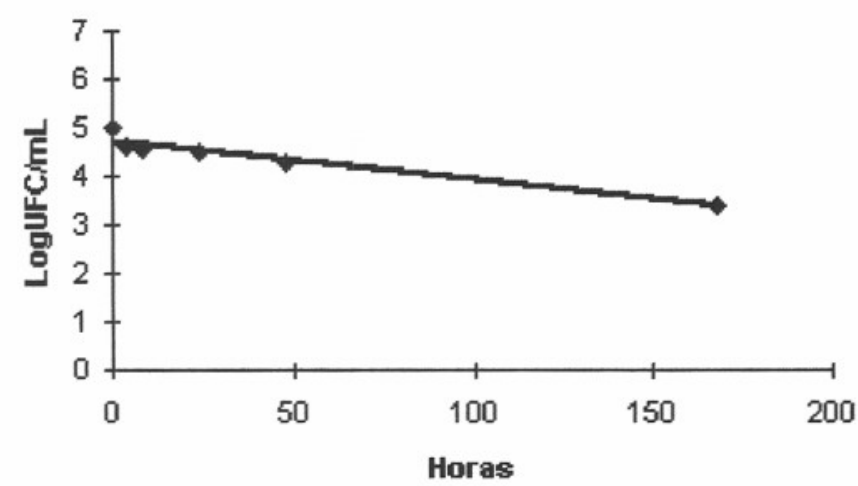

Fórmula 8

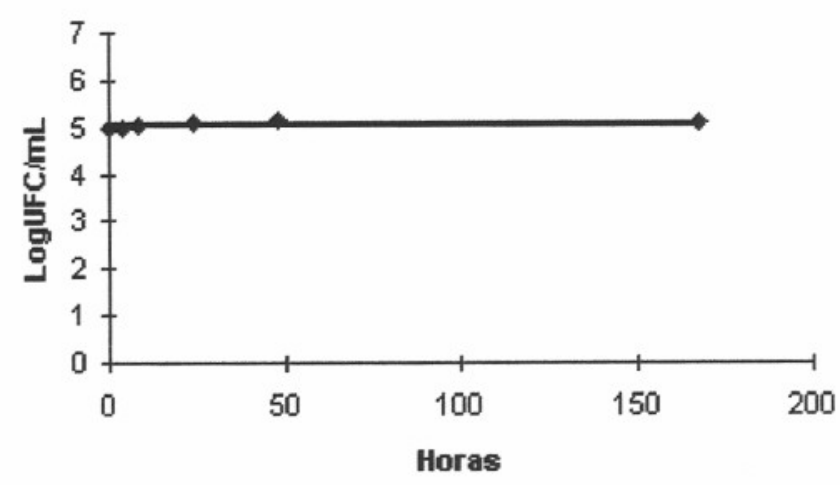

Fórmula 10

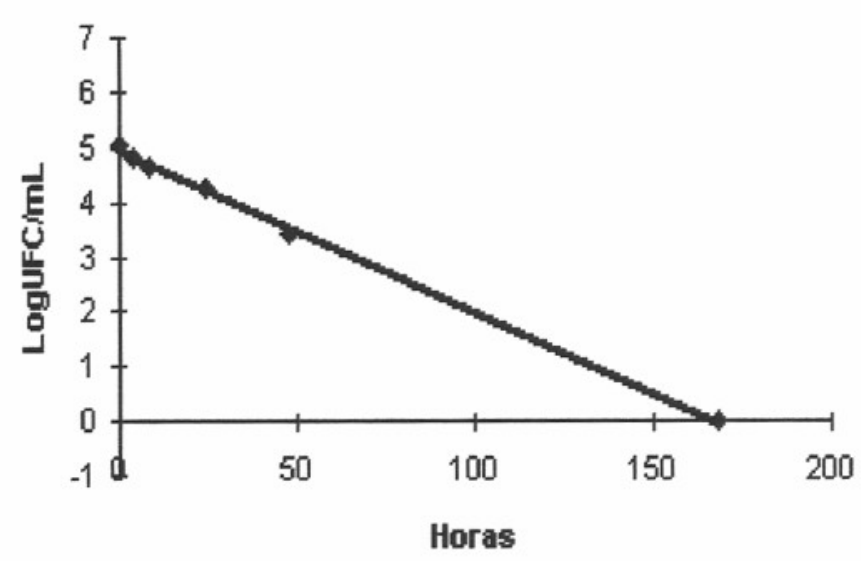

Fórmula 12

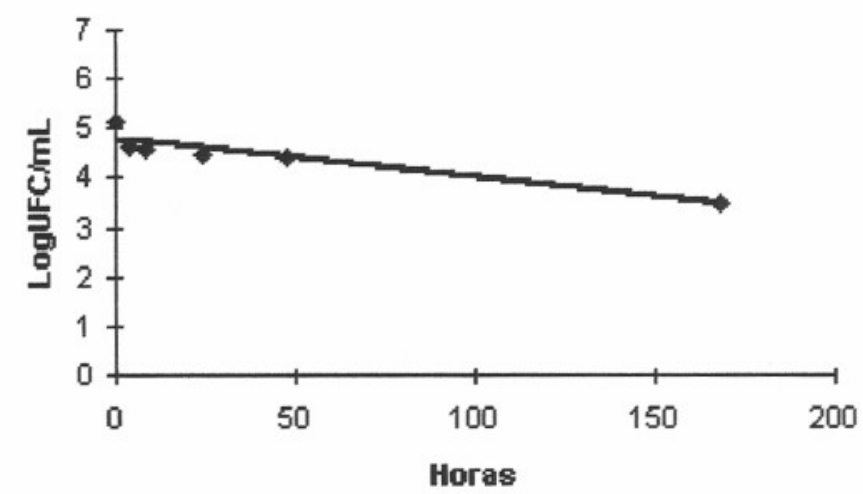

FIGURA 15 Comparativo do Perfil das Curvas de Letalidade (Log UFC/mL x Hora) de Aspergillus niger para Fórmulas de 7 a 12. 
Fórmula 13

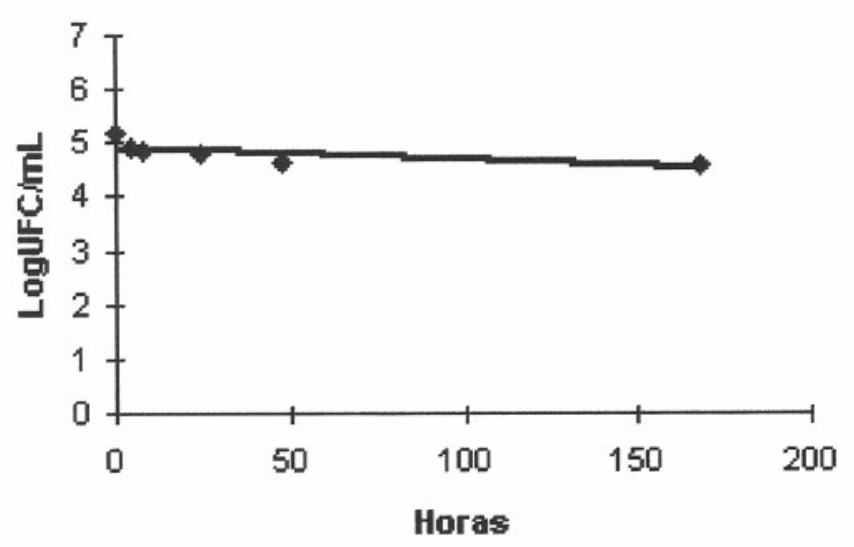

Fórmula 15

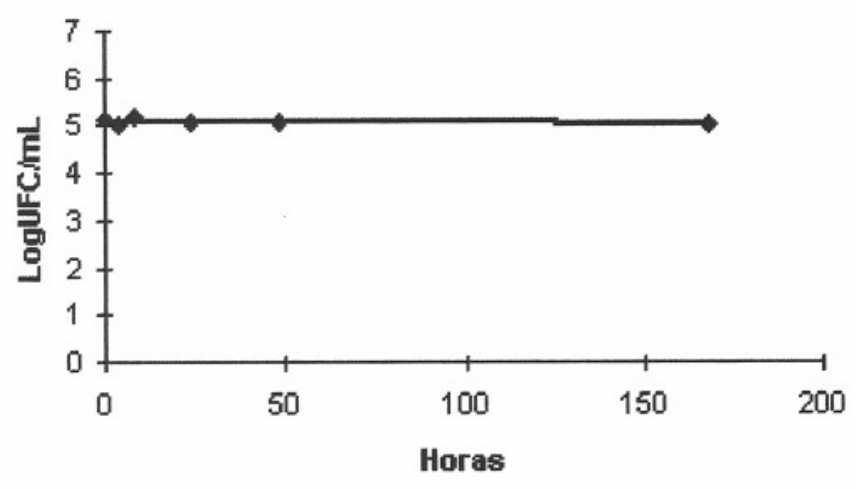

Fórmula 17

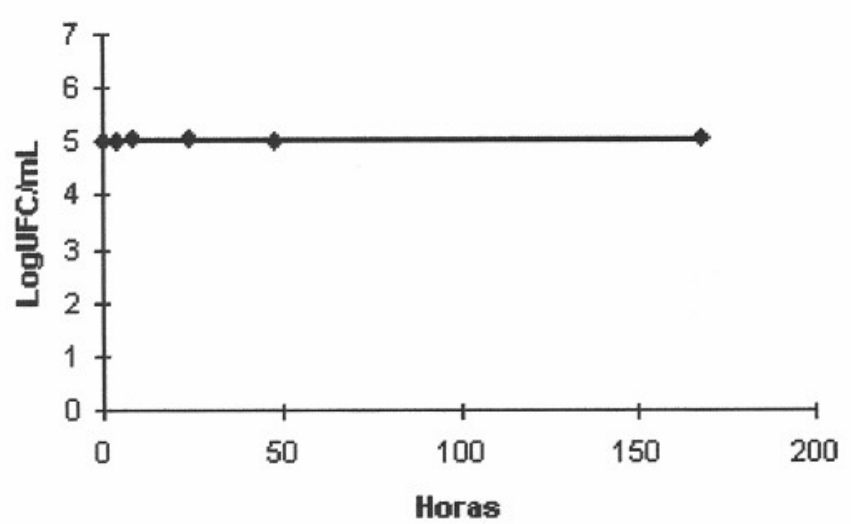

Fórmula 14

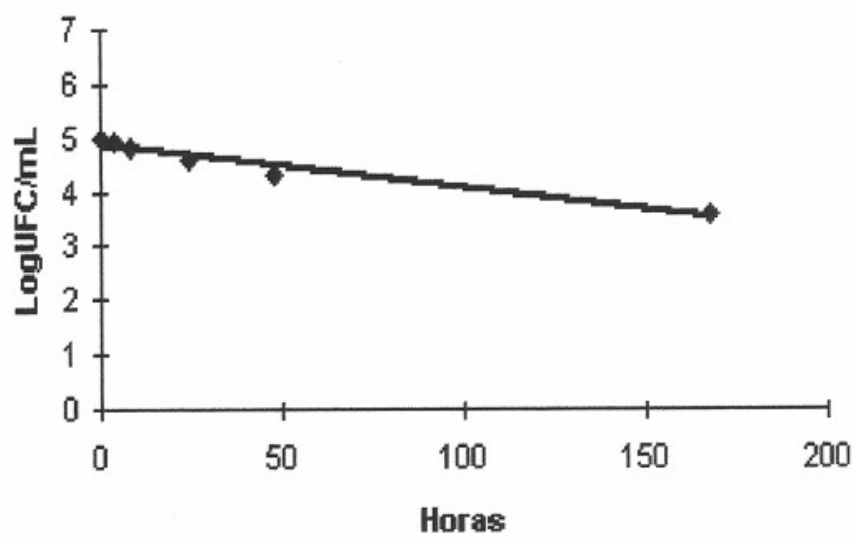

Fórmula 16

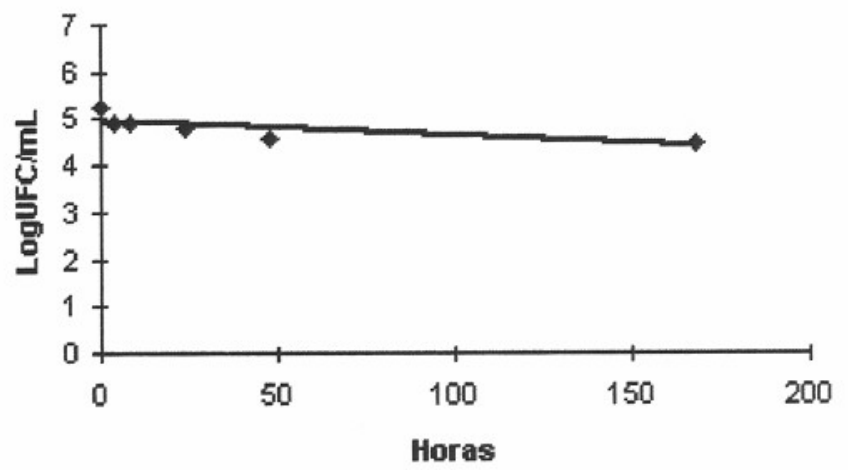

Fórmula 18

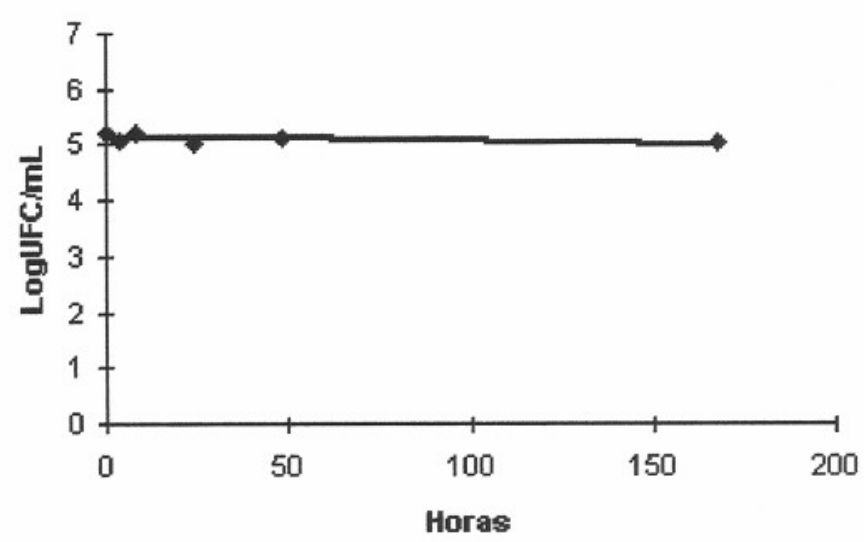

FIGURA 16 Comparativo do Perfil das Curvas de Letalidade (Log UFC/mL $\times$ Hora) de Aspergillus niger para Fórmulas de 13 a 18. 
TABELA 38 Resultados dos Testes Realizados para Avaliar a Significância dos Termos da Equação Cúbica para Pseudomonas cepacia.

\begin{tabular}{|c|c|c|c|c|c|c|}
\hline Exteito & Goeficiente & G) & Erro & ti & $P$ & Concusaio \\
\hline $\mathrm{X}_{1}$-Clorhexidina & 26,77 & 1 & 6,89 & 3,89 & 0,0037 & *夫 \\
\hline $\mathrm{X}_{2}$-Álcool Feniletílico & 5,37 & 1 & 6,89 & 0,78 & 0,4554 & NS \\
\hline$X_{3}-$ EDTA & 88,64 & 1 & 6,89 & 12,87 & $<0,0001$ & $\star \star *$ \\
\hline$X_{1} X_{2}$ & $-61,24$ & 1 & 39,24 & $-1,56$ & 0,1530 & NS \\
\hline$X_{1} X_{3}$ & 180,01 & 1 & 39,24 & 4,59 & 0,0013 & $\star \star *$ \\
\hline$x_{2} X_{3}$ & $-199,14$ & 1 & 39,24 & $-5,07$ & 0,0007 & ** \\
\hline$X_{1} X_{2} X_{3}$ & $-790,23$ & 1 & 290,08 & $-2,72$ & 0,0234 & * \\
\hline
\end{tabular}

Desvio Padrão do $\quad 10,14$

erro

$r^{2}$ ajustado $\quad 0,938$

$r^{2}$ : coeficiente de determinação

GL: grau de liberdade

$t$ : estatística $t$

$P$.: nível de significância

**: significante se $\mathrm{P}<0,01(\alpha 1 \%)$

* significante se $\mathrm{P}<0,05$ ( $\alpha 5 \%)$

NS.: não significante

Valor $\mathrm{D}_{\text {teórico }}=+26,77 \mathrm{X}_{1}+5,37 \mathrm{X}_{2}+88,64 \mathrm{X}_{3}-61,24 \mathrm{X}_{1} \mathrm{X}_{2}+180,01 \mathrm{X}_{1} \mathrm{X}_{3}-$ $-199,14 X_{2} X_{3}-790,23 X_{1} X_{2} X_{3}$

TABELA 39 Resultados dos Testes Realizados para Avaliar a Significância dosTermos da Equação Cúbica para Staphylococcus aureus.

\begin{tabular}{|c|c|c|c|c|c|c|}
\hline Eferto & Coeficiente & GL. & oadra & i. & P & Conclusa \\
\hline $\begin{array}{l}X_{1} \text { - Clorhexidina } \\
X_{2} \text { Álcool Feniletílico } \\
X_{3} \text {-EDTA } \\
X_{1} X_{3} \\
X_{2} X_{3}\end{array}$ & $\begin{array}{c}0,82 \\
1,66 \\
10,68 \\
-18,36 \\
-25,52 \\
\end{array}$ & $\begin{array}{l}1 \\
1 \\
1 \\
1 \\
1 \\
\end{array}$ & $\begin{array}{l}0,936 \\
0,921 \\
1,032 \\
6,361 \\
5,469 \\
\end{array}$ & $\begin{array}{c}0,87 \\
1,80 \\
10,35 \\
-2,89 \\
-4,67 \\
\end{array}$ & $\begin{array}{c}0,4023 \\
0,1016 \\
<0,0001 \\
0,0162 \\
0,0009 \\
\end{array}$ & $\begin{array}{l}\text { NS } \\
\text { NS } \\
\star \star \\
\star \\
\star \star \\
\end{array}$ \\
\hline $\begin{array}{l}\text { Desvio Padrão do } \\
\text { erro } \\
r^{2} \text { ajustado }\end{array}$ & 1,51 & & & & & \\
\hline
\end{tabular}

$r^{2}$ : coeficiente de determinação

GL: grau de liberdade

t: estatística t

$P$.: nível de significância

**: significante se $\mathrm{P}<0,01(\alpha 1 \%)$

* significante se $P<0,05(\alpha 5 \%)$

NS.: não significante

Valor $\mathrm{D}_{\text {teórico }}=+0,82 \mathrm{X}_{1}+1,66 \mathrm{X}_{2}+10,68 \mathrm{X}_{3}-18,36 \mathrm{X}_{1} \mathrm{X}_{3}-25,52 \mathrm{X}_{2} \mathrm{X}_{3}$ 
TABELA 40 Resultados dos Testes Realizados para Avaliar a Significância dos Termos da Equação Cúbica para Candida albicans.

\begin{tabular}{|c|c|c|c|c|c|c|}
\hline weito. & Coeficiente & Gi. & pariaro & t & P & Conglusaio \\
\hline $\begin{array}{l}X_{1}-\text { Clorhexidina } \\
X_{2} \text {-Álcool Feniletílico } \\
X_{3} \text {-EDTA } \\
X_{1} X_{2} \\
X_{1} X_{3} \\
X_{2} X_{3} \\
X_{1} X_{2} X_{3}\end{array}$ & $\begin{array}{c}8,50 \\
30,11 \\
31,98 \\
-43,30 \\
-42,43 \\
-93,38 \\
241,75\end{array}$ & $\begin{array}{l}1 \\
1 \\
1 \\
1 \\
1 \\
1 \\
1 \\
1\end{array}$ & $\begin{array}{c}1,392 \\
1,392 \\
1,392 \\
7,934 \\
7,934 \\
7,934 \\
58,646\end{array}$ & $\begin{array}{c}6,11 \\
21,62 \\
22,97 \\
-5,46 \\
-5,35 \\
-11,77 \\
4,12\end{array}$ & $\begin{array}{c}0,0002 \\
<0,0001 \\
<0,0001 \\
0,0004 \\
0,0005 \\
<0,0001 \\
0,0026\end{array}$ & $\begin{array}{l}* * \\
\star * \\
* * \\
* * \\
* * \\
* * \\
\text { ** }\end{array}$ \\
\hline
\end{tabular}

Desvio Padrão do $\quad 2,05$

erro

$r^{2}$ ajustado $\quad 0.954$

$r^{2}$ : coeficiente de determinação

GL: grau de liberdade

t: estatística t

$P$.: nível de significância

** significante se $\mathrm{P}<0,01$ ( $\alpha 1 \%)$

Valor $\mathrm{D}_{\text {teórico }}=+8,50 \mathrm{X}_{1}+30,11 \mathrm{X}_{2}+31,98 \mathrm{X}_{3}-43,30 \mathrm{X}_{1} \mathrm{X}_{2}-42,43 \mathrm{X}_{1} \mathrm{X}_{3}-$ - $93,38 X_{2} X_{3}+241,75 X_{1} X_{2} X_{3}$

TABELA 41 Resultados dos Testes Realizados para Avaliar a Significância dos Termos da Equação Cúbica para Aspergillus niger.

\begin{tabular}{|c|c|c|c|c|c|c|}
\hline Efferto & Coeficientel: & G.: & Padrao & ti & p & Conclusaro \\
\hline $\begin{array}{l}X_{1}-\text { Clorhexidina } \\
X_{2} \text {-Álcool Feniletílico } \\
X_{3} \text {-EDTA } \\
X_{1} X_{2} \\
\end{array}$ & $\begin{array}{c}346,92 \\
39,53 \\
311,82 \\
-203,92 \\
\end{array}$ & $\begin{array}{l}1 \\
1 \\
1 \\
1 \\
\end{array}$ & $\begin{array}{l}16,80 \\
16,81 \\
74,61 \\
91,37 \\
\end{array}$ & $\begin{array}{c}20,65 \\
2,35 \\
4,18 \\
-2,23 \\
\end{array}$ & $\begin{array}{c}<0,0001 \\
0,0783 \\
0,0139 \\
0,0894 \\
\end{array}$ & $\begin{array}{c}* \star \\
N S \\
* \\
N S \\
\end{array}$ \\
\hline $\begin{array}{l}\text { Desvio Padrão do } \\
\text { erro } \\
r^{2} \text { ajustado } \\
\end{array}$ & $\begin{array}{l}24,11 \\
0,963 \\
\end{array}$ & & & & & \\
\hline \multicolumn{7}{|c|}{$\begin{array}{l}r^{2} \text { : coeficiente de determinação } \\
\text { GL: grau de liberdade } \\
\text { t: estatística t } \\
P .: \text { nível de significância } \\
\text { **: significante se } P<0,01(\alpha 1 \%) \\
\text { * significante se } P<0,05(\alpha 5 \%) \\
\text { NS.: não significante }\end{array}$} \\
\hline
\end{tabular}

Valor $\mathrm{D}_{\text {teórico }}=+346,92 \mathrm{X}_{1}+39,53 \mathrm{X}_{2}+311,82 \mathrm{X}_{3}-203,92 \mathrm{X}_{1} \mathrm{X}_{2}$ 

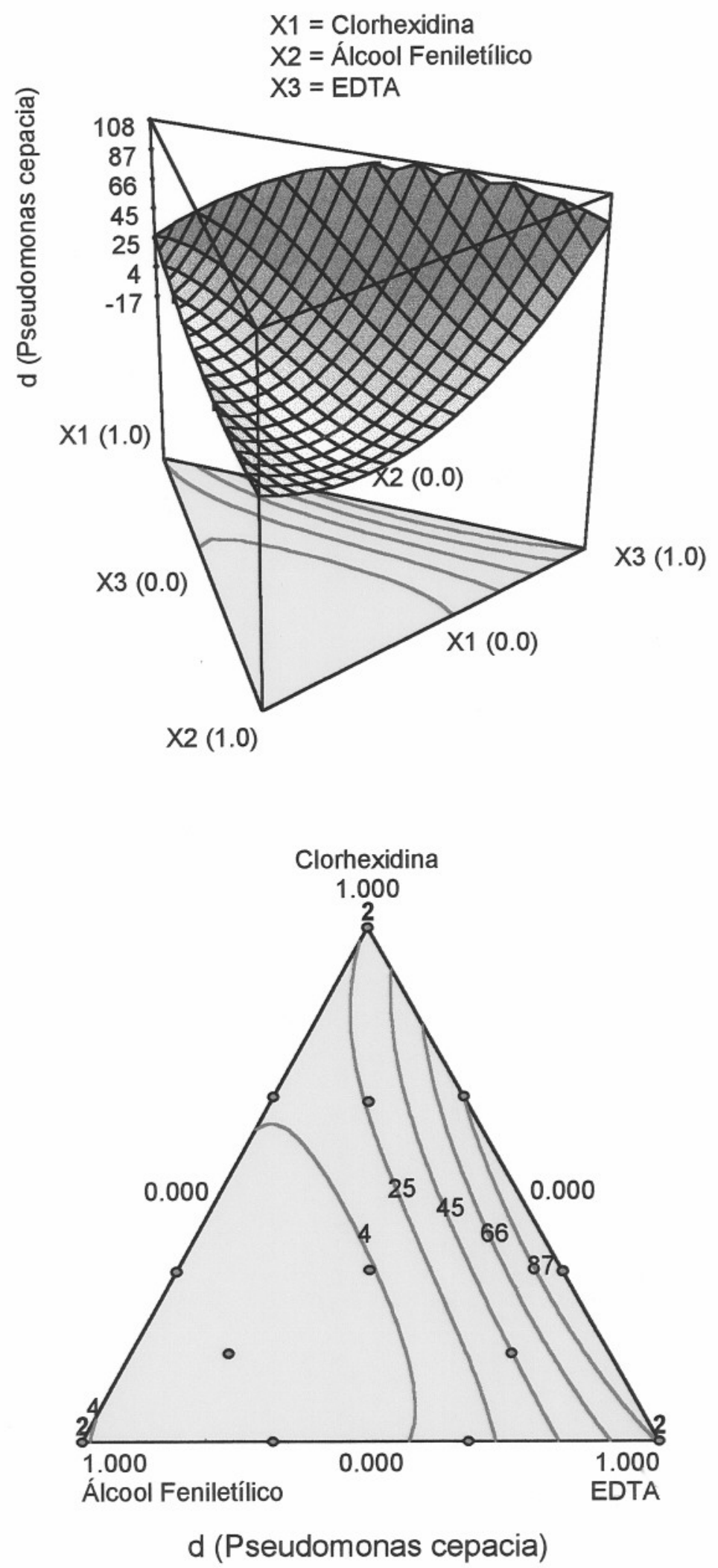

FIGURA 17 Superfície de Resposta e Gráfico de Contorno Correspondente para Pseudomonas cepacia. 

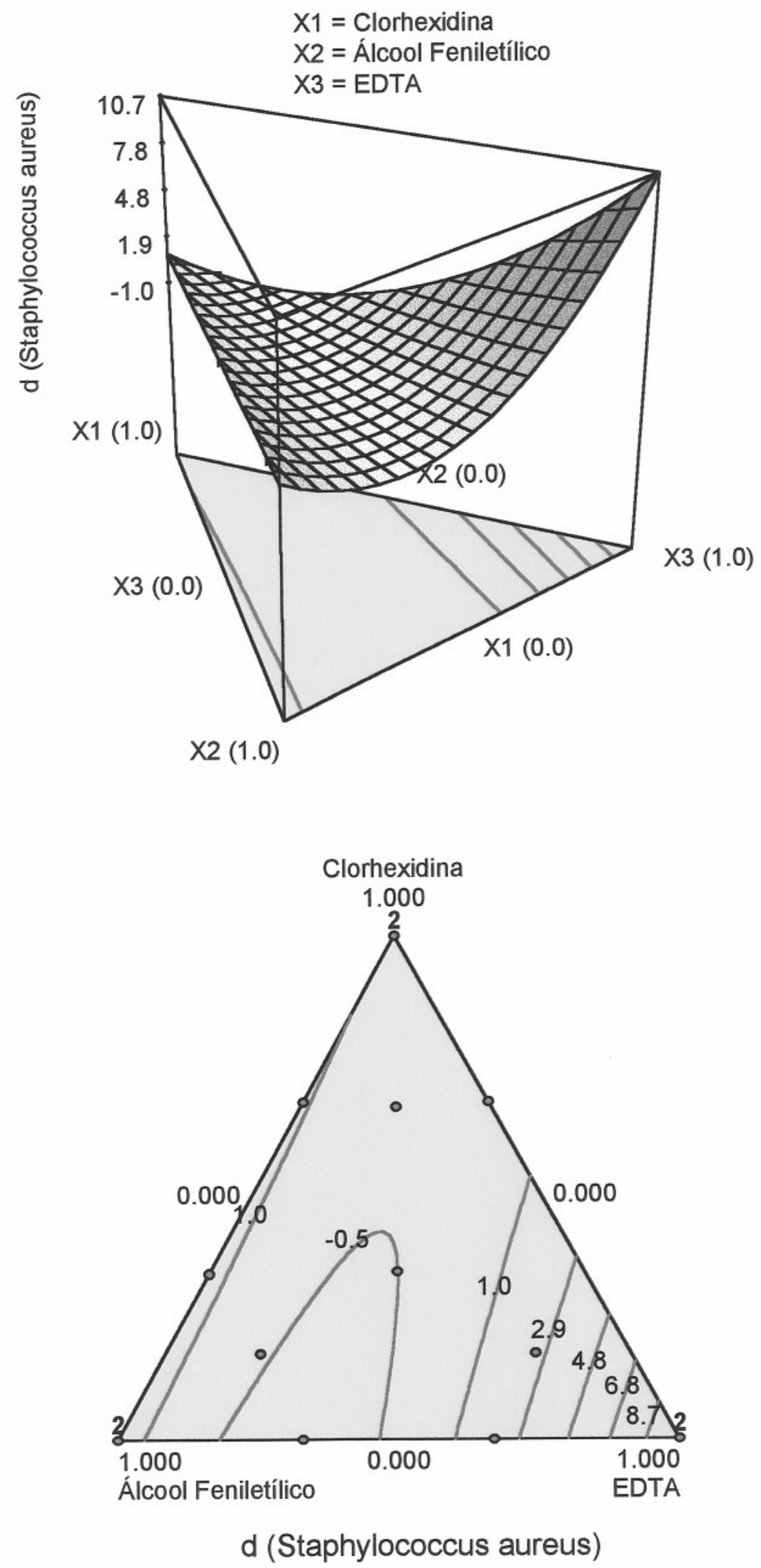

FIGURA 18 Superfície de Resposta e Gráfico de Contorno Correspondente para Staphylococcus aureus. 

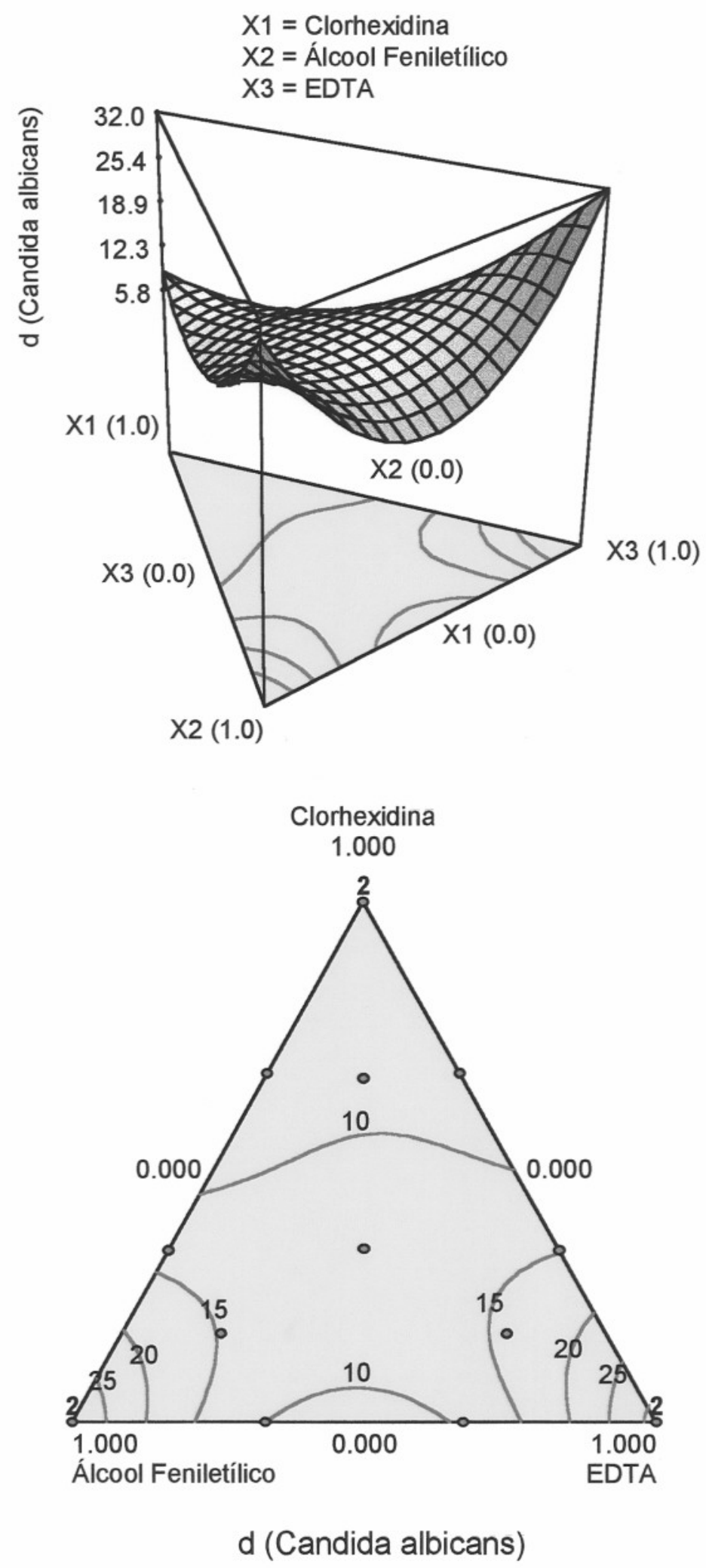

FIGURA 19 Superfície de Resposta e Gráfico de Contorno Correspondente para Candida albicans. 


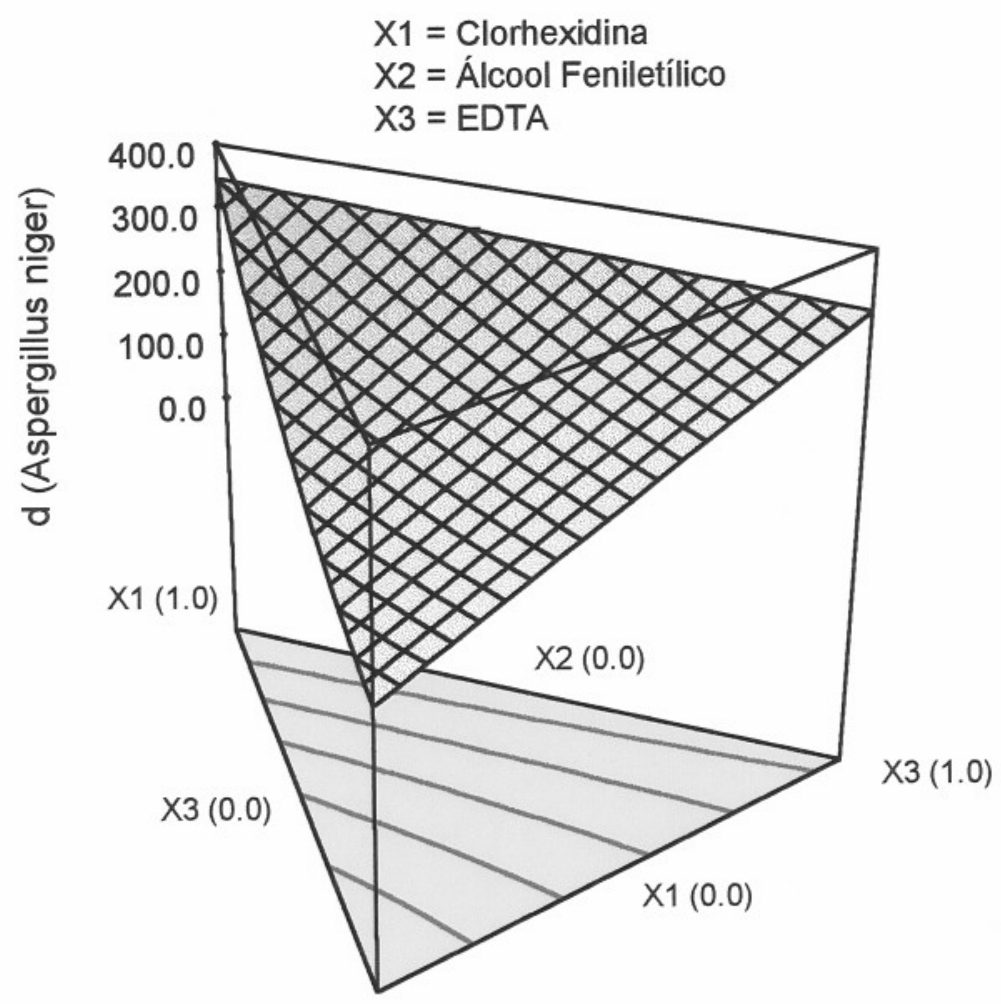

X2 (1.0)

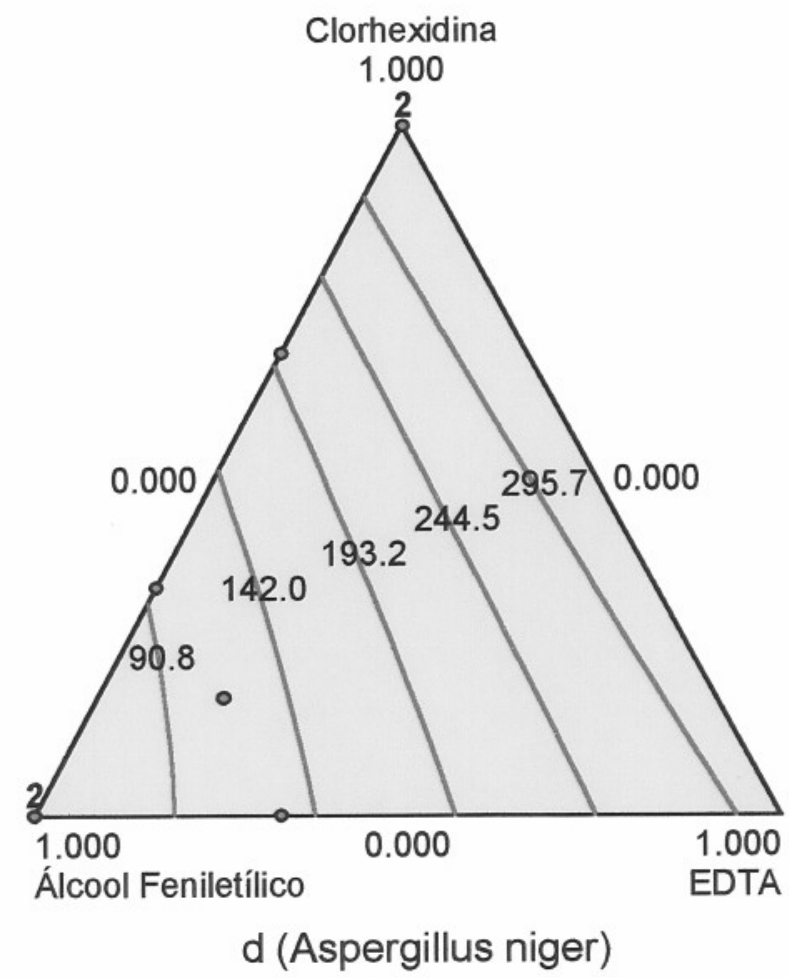

FIGURA 20 Superfície de Resposta e Gráfico de Contorno Correspondente para Aspergillus niger. 


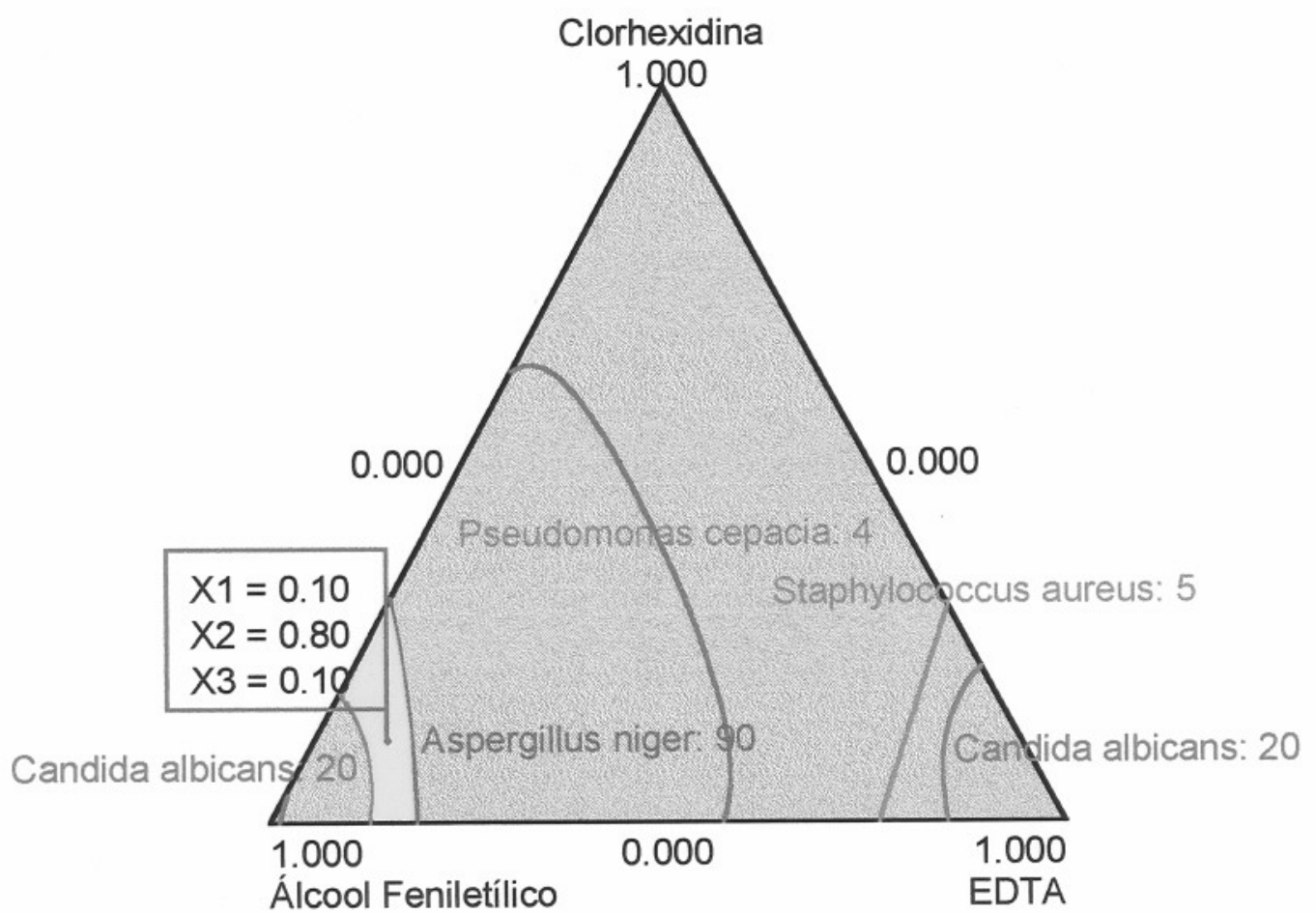

FIGURA 21 Otimização Gráfica Conjunta das Respostas para Pseudomonas cepacia, Staphylococcus aureus, Candida albicans e Aspergillus niger. 

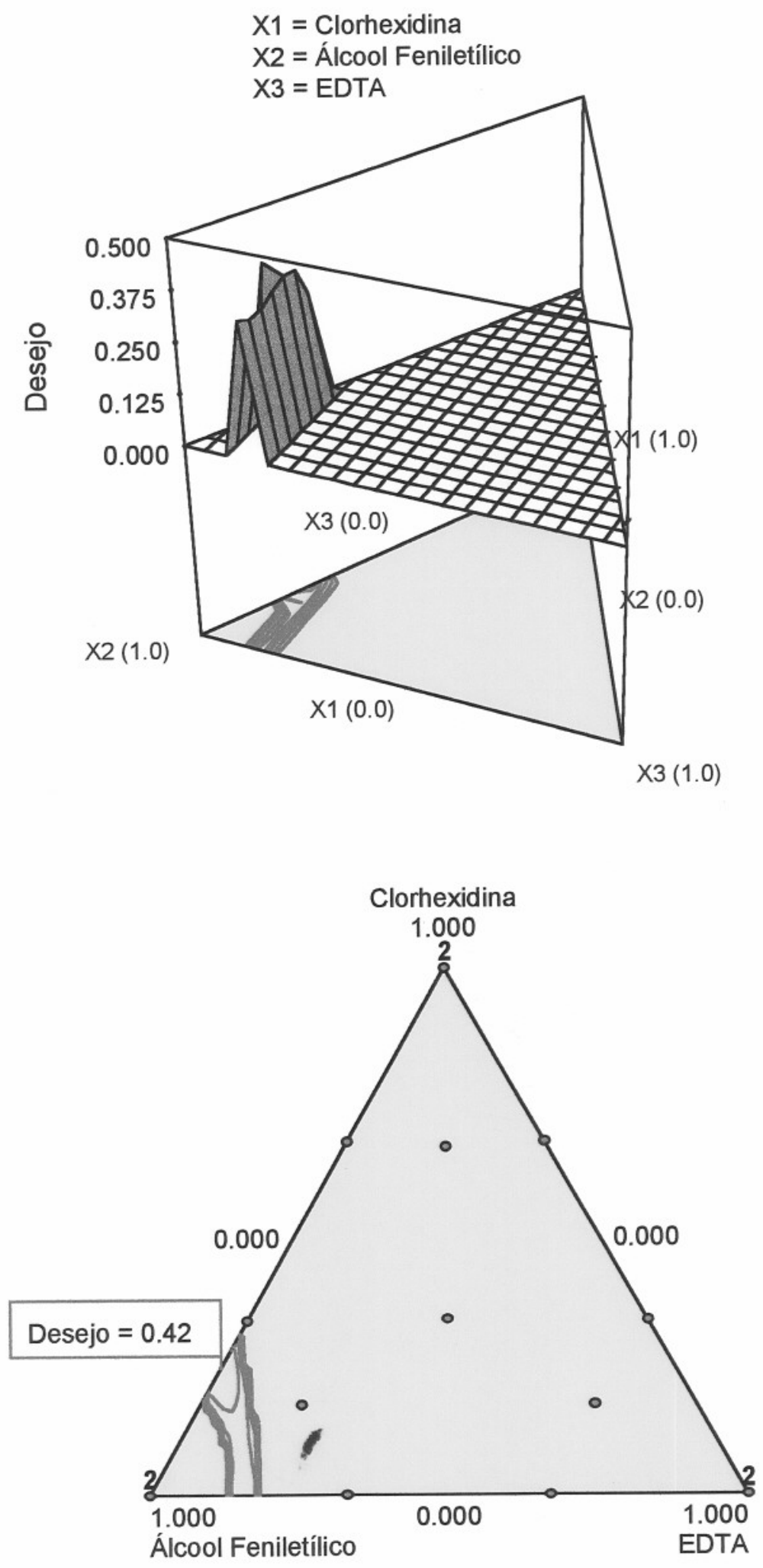

FIGURA 22 Superfície de Resposta e Curvas de Contorno da Estratégia Numérica Empregando a Função "Desejo" (expectativa do pesquisador). 
TABELA 42 Valores de pH e Viscosidade das Suspensões Oftálmicas de Dexametasona e Polimixina B Determinados Imediatamete $\left(T_{0}\right)$ e Decorridos 7 dias da Preparação $\left(T_{7}\right)$

\begin{tabular}{|c|c|c|c|c|}
\hline \multirow[t]{2}{*}{ Formulas } & \multicolumn{2}{|c|}{ PH } & \multicolumn{2}{|c|}{ Viscosidiade (ces) } \\
\hline & $\mathrm{T}_{6}$ & T. T. & $T_{0}$ & T. \\
\hline 19 & 5,69 & 5,73 & 18,43 & 18,45 \\
\hline 20 & 5,70 & 5,70 & 18,55 & 18,50 \\
\hline
\end{tabular}

Tabela 43 Valores de Volume do Fármaco Disperso e Classificação das Suspensões Oftálmicas de Dexametasona e Polimixina B, quanto ao Tipo de Sedimento e Características de Ressuspensão, Determinados Logo Após a Preparação $\left(T_{0}\right)$ e Decorridos 7 dias $\left(T_{7}\right)$

\begin{tabular}{|c|c|c|c|c|}
\hline \multirow{2}{*}{ formmias } & \multicolumn{2}{|c|}{ Volume do fámaco disperso $\%$} & \multirow{2}{*}{$\frac{\text { Ressuspensáo }}{T}$} & \multirow{2}{*}{ Sedimento } \\
\hline & $919.1 \%$ & (1. T. & & \\
\hline 19 & 100,0 & 95,0 & $\mathrm{Fa}$ & $\mathrm{F}$ \\
\hline 20 & 100,0 & 95,0 & $\mathrm{Fa}$ & $\mathrm{F}$ \\
\hline
\end{tabular}

TABELA 44 Número de Sobreviventes de Pseudomonas cepacia e Staphylococcus aureus (UFC/mL) no Teste de Eficácia de Conservantes, para as Fórmulas 19 e 20.

\begin{tabular}{c|c|c|c|c|c|c}
\hline Microrganismos & Formula & $T_{0}$ & $T_{0.2}$ & $T_{0.5}$ & $T_{0.8}$ & I. \\
\hline Pseudomonas & 19 & $2,2 \times 10^{7}$ & zero & zero & zero & zero \\
cepacia & 20 & $2,1 \times 10^{7}$ & zero & zero & zero & zero \\
Staphylococcus & 19 & $1,6 \times 10^{6}$ & zero & zero & zero & zero \\
aureus & 20 & $1,6 \times 10^{6}$ & zero & zero & zero & zero \\
\hline
\end{tabular}

$T_{0}=$ contagem imediatamente após a inoculação da amostra

$T_{0,2}, T_{0,5}, T_{0,8}$ e $T_{1}=$ contagem $0,2,0,5,0,8$ e 1 hora após a inoculação 
TABELA 45 Logarítmo (base 10) do Número de Sobreviventes de Pseudomonas cepacia e Staphylococcus aureus (LogUFC/mL) no Teste de Eficácia de Conservantes para as Fórmulas 19 e 20.

\begin{tabular}{|c|c|c|c|c|c|c|}
\hline Microrganismos & Iormula & 1. & T. & To.: & T: $:$ & $T_{1}$ \\
\hline Pseudomonas & 19 & 7,34 & - & - & - & - \\
\hline cepacia & 20 & 7,32 & - & - & - & - \\
\hline Staphylococcus & 19 & 6,21 & - & - & - & - \\
\hline aureus & 20 & 6,20 & 1,30 & - & - & - \\
\hline
\end{tabular}

( - ) não calculado

TABELA 46 Valores D, Equação da Reta e Coeficiente de Correlação Referentes a Pseudomonas cepacia e Staphylococcus aureus para as Fórmulas 19 e 20.

\begin{tabular}{|c|c|c|c|c|c|}
\hline Microrganismos & Formula & $\begin{array}{l}\text { Valor D } \\
\text { Teorico } \\
\text { (noras) } \\
\end{array}$ & $\begin{array}{l}\text { Valor } 8 \\
\text { Pratico } \\
\text { (horas) }\end{array}$ & Equaçáo & $\begin{array}{l}\text { Coeticiente } \\
\text { correlaca }\end{array}$ \\
\hline \multirow{2}{*}{$\begin{array}{c}\text { Pseudomonas } \\
\text { cepacia }\end{array}$} & 19 & zero & 0,03 & $Y=-36,7 X+7,34$ & $-1,00$ \\
\hline & 20 & zero & 0,03 & $Y=-36,6 X+7,32$ & $-1,00$ \\
\hline \multirow{2}{*}{$\begin{array}{c}\text { Staphylococcus } \\
\text { aureus }\end{array}$} & 19 & 0,25 & 0,03 & $Y=-31,05 X+6,21$ & $-1,00$ \\
\hline & 20 & 1,45 & 0,03 & $Y=-31,0 X+6,20$ & $-1,00$ \\
\hline
\end{tabular}

TABELA 47 Número de Sobreviventes de Candida albicans e Aspergillus niger (UFC/mL) no Teste de Eficácia de Conservantes, para as Fórmulas 19 e 20.

\begin{tabular}{|c|c|c|c|c|c|c|}
\hline Microrganismos & Fórmula & To horas & T.2 noras & $T_{48}$ horas & Trentras & T. da dias \\
\hline Candida & 19 & $6,5 \times 10^{6}$ & $3,0 \times 10^{5}$ & $1,3 \times 10^{4}$ & $6,5 \times 10^{2}$ & zero \\
\hline albicans & 20 & $7,2 \times 10^{6}$ & $2,5 \times 10^{5}$ & $9,1 \times 10^{3}$ & $3,2 \times 10^{2}$ & zero \\
\hline Aspergillus & 19 & $3,8 \times 10^{5}$ & $1,0 \times 10^{5}$ & $9,5 \times 10^{4}$ & $5,0 \times 10^{4}$ & $3,5 \times 10^{2}$ \\
\hline niger & 20 & $3,6 \times 10^{5}$ & $1,8 \times 10^{5}$ & $9,1 \times 10^{4}$ & $4,2 \times 10^{4}$ & $3,3 \times 10^{2}$ \\
\hline
\end{tabular}

$\mathrm{T}_{0}=$ contagem imediatamente após a inoculação da amostra

$T_{24}, T_{48}$ e $T_{72}=$ contagem 24, 48 e 72 horas após a inoculação

$\mathrm{T}_{10}=$ contagem 10 dias após a inoculação 
TABELA 48 Logarítmo (base 10) do Número de Sobreviventes de Candida albicans e Aspergillus niger (LogUFC/mL) no Teste de Eficácia de Conservantes para as Fórmulas 19 e 20.

\begin{tabular}{|c|c|c|c|c|c|c|}
\hline Microrganismos & Irormula & T. & $T_{24}$ trotis & T.t. noris: & TY, horrs & $T_{10} \mathrm{dins}$ \\
\hline Candida & 19 & 6,81 & 5,48 & 4,11 & 2,81 & - \\
\hline albicans & 20 & 6,86 & 5,41 & 3,96 & 2,50 & - \\
\hline Aspergillus & 19 & 5,58 & 5,28 & 4,98 & 4,70 & 2,55 \\
\hline niger & 20 & 5,56 & 5,26 & 4,96 & 4,62 & 2,52 \\
\hline
\end{tabular}

$\mathrm{T}_{0}=$ contagem imediatamente após a inoculação da amostra

$\mathrm{T}_{24}, \mathrm{~T}_{48}$ e $\mathrm{T}_{72}=$ contagem 24,48 e 72 horas após a inoculação

$\mathrm{T}_{10}=$ contagem 10 dias após a inoculação

( - ) não calculado

TABELA 49 Valores D, Equação da Reta e Coeficiente de Correlação Referentes a Candida albicans e Aspergillus niger para as Fórmulas 19 e 20.

\begin{tabular}{|c|c|c|c|c|c|}
\hline Microrganismins & Iformoula & 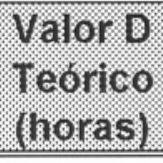 & 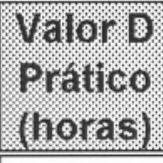 & Equaçáo & a veriglente \\
\hline \multirow{2}{*}{$\begin{array}{l}\text { Candida } \\
\text { albicans }\end{array}$} & 19 & 18,71 & 17,95 & $Y=-0,0557 X+6,81$ & $-1,00$ \\
\hline & 20 & 16,59 & 16,53 & $Y=-0,0605 X+6,86$ & $-1,00$ \\
\hline \multirow{2}{*}{$\begin{array}{c}\text { Aspergillus } \\
\text { niger }\end{array}$} & 19 & 81,18 & 79,37 & $Y=-0,0126 X+5,59$ & $-1,00$ \\
\hline & 20 & 78,14 & 78,74 & $Y=-0,0127 X+5,56$ & $-1,00$ \\
\hline
\end{tabular}


TABELA 50 Número de Sobreviventes (UFC/mL) de Pseudomonas cepacia, Staphylococcus aureus, Candida albicans e Aspergillus niger na Fórmula 19.

\begin{tabular}{|c|c|c|c|c|c|c|c|c|}
\hline Microrganismo & T. & $T_{0}$ & 724 & T.18. & T: & I: 1. & 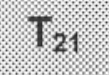 & T: 28 \\
\hline $\begin{array}{c}\text { Pseudomonas } \\
\text { cepacia }\end{array}$ & $8,7 \times 10^{6}$ & zero & zero & zero & zero & zero & zero & zero \\
\hline $\begin{array}{c}\text { Staphylococcus } \\
\text { aureus }\end{array}$ & $7,8 \times 10^{6}$ & zero & zero & zero & zero & zero & zero & zero \\
\hline $\begin{array}{l}\text { Candida } \\
\text { albicans }\end{array}$ & $7,0 \times 10^{6}$ & $3,1 \times 10^{6}$ & $3,8 \times 10^{5}$ & $1,5 \times 10^{4}$ & zero & zero & zero & zero \\
\hline $\begin{array}{c}\text { Aspergillus } \\
\text { niger }\end{array}$ & $4,0 \times 10^{5}$ & $3,4 \times 10^{5}$ & $2,1 \times 10^{5}$ & $9,8 \times 10^{4}$ & $3,2 \times 10^{3}$ & $2,2 \times 10^{1}$ & zero & zero \\
\hline
\end{tabular}

$T_{0}=$ contagem imediatamente após a inoculação da amostra

$T_{6}, T_{24}, T_{48}=$ contagem 6,24 e 48 após a inoculação

$T_{7}, T_{14}, T_{21}, T_{28}=$ contagem $7,14,21$ e 28 dias após a inoculação 
TABELA 51 Número de Sobreviventes (UFC/mL) de Pseudomonas cepacia, Staphylococcus aureus, Candida albicans e Aspergillus niger na Fórmula 20.

\begin{tabular}{|c|c|c|c|c|c|c|c|c|}
\hline Microrganisino & $T_{0}$ & $T_{6}$ & 124 & (2: 48 & ?: & 1.1. & $T_{21}$ & T. \\
\hline $\begin{array}{c}\text { Pseudomonas } \\
\text { cepacia }\end{array}$ & $8,3 \times 10^{6}$ & zero & zero & zero & zero & zero & zero & zero \\
\hline $\begin{array}{c}\text { Staphylococcus } \\
\text { aureus }\end{array}$ & $7,3 \times 10^{6}$ & zero & zero & zero & zero & zero & zero & zero \\
\hline $\begin{array}{l}\text { Candida } \\
\text { albicans }\end{array}$ & $7,5 \times 10^{6}$ & $3,2 \times 10^{6}$ & $2,6 \times 10^{5}$ & $9,5 \times 10^{3}$ & zero & zero & zero & zero \\
\hline $\begin{array}{c}\text { Aspergillus } \\
\text { niger }\end{array}$ & $4,3 \times 10^{5}$ & $3,2 \times 10^{5}$ & $2,0 \times 10^{5}$ & $9,4 \times 10^{4}$ & $3,0 \times 10^{3}$ & $2,5 \times 10^{1}$ & zero & zero \\
\hline
\end{tabular}

$T_{0}=$ contagem imediatamente após a inoculação da amostra

$T_{6}, T_{24}, T_{48}=$ contagem 6,24 e 48 após a inoculação

$T_{7}, T_{14}, T_{21}, T_{28}=$ contagem $7,14,21$ e 28 dias após a inoculação 
6 Discussão 


\title{
6 DISCUSSÃO
}

\begin{abstract}
As suspensões oftálmicas se constituem em preparações estéreis contendo partículas sólidas micronizadas dispersas em veículo apropriado. A função da micronização do material sólido é de evitar ou prevenir que estas partículas causem irritação da córnea. Além deste aspecto, as suspensões oftálmicas não devem apresentar evidências de formação de caking ou de agregação das partículas. Assim, após a ressuspensão das mesmas, mediante agitação manual e imediata administração, a fórmula desenvolvida deve garantir sua eficácia terapêutica.
\end{abstract}

Os principais constituintes da fórmula são, além dos princípios ativos, o agente suspensor e molhante que, em concentrações adequadas, conferem característica de estabilidade físico-química ao sistema bifásico e os agentes antimicrobianos responsáveis pela estabilidade biológica, uma vez que o produto é de múltipla dose. Esta especialidade está descrita na Farmacopéia Americana desde sua 21a. edição ${ }^{297}$ e consiste na associação de dexametasona, de sulfato de polimixina $B$ e de sulfato de neomicina. No presente estudo, assim como no estudo preliminar ${ }^{29}$ foram mantidos a dexametasona e o sulfato de polimixina B.

As concentrações oficialmente ${ }^{299}$ recomendadas para o corticosteróide é da ordem de 0,05 a 0,1\% (p/v). Quanto ao antibiótico, visando atividade contra bactérias gram negativas, a concentração compreende a faixa entre 6.000 a $16.250 \mathrm{UI} / \mathrm{mL}$. Normalmente, a escolha do agente molhante recai sobre os polissorbatos, empregando-se concentração de 0,05\% (p/v), por apresentarem baixa toxicidade para o tecido ocular ${ }^{120}$. Esta substância 
também pode ser utilizada em produtos oftálmicos para conferir limpidez à solução e mais raramente pode ser utilizada como co-solvente, com a finalidade de aumentar a solubilidade dos constituintes da fórmula ${ }^{120}$. Como característica indesejável, estas substâncias podem se ligar ao sistema conservante inativando-os parcial ou totalmente ${ }^{155,158,164,173,180}$ $182,217,224,225,235,249$

O agente suspensor, além de conferir estabilidade físico-química permite maior tempo de contato da substância ativa com o tecido ocular e conseqüente aumento de sua absorção e atividade. As substâncias recomendadas são, de forma geral, metilcelulose, álcool polivinílico e hidroxipropilmetilcelulose ${ }^{120,299}$. Este último apresenta como vantagem melhor dispersão, resultando em dispersões límpidas ${ }^{288}$ Variações nas concentrações de sais não alteram sua viscosidade ${ }^{176,288}$ e ainda, por ser do tipo não iônico, apresentam pouca mobilidade eletroforética negativa ${ }^{145}$ e desta forma não interferem de maneira acentuada nos fenômenos de sedimentação de dexametasona dispersa em seu interior. O gel também apresenta termoestabilidade podendo ser esterilizado por via úmida. A concentração oficialmente ${ }^{299}$ recomendada é de 0,5 a 2,0\% (p/v) e viscosidade da suspensão oftálmica de 15 a 25 cps.

As 16 fórmulas estudadas anteriormente ${ }^{29}$ foram desenvolvidas empregando-se polissorbato 20 nas concentrações de $0,025 \%$ (p/v) ou de 0,075\% (p/v) e hidroxipropilmetilcelulose nas concentrações de $0,25 \%(p / v)$ ou de $0,75 \%(p / v)$. Além da variação das concentrações do agente suspensor e molhante foram incorporados às fórmulas diferentes sistemas conservantes: clorobutanol a 0,5\% (p/v) e álcool feniletílico a 0,5\% (p/v); cloreto de benzalcônio a 0,001\% (p/v) e EDTA a $0,1 \%(p / v)$; digluconato de clorhexidina a 0,01\% (p/v) e álcool feniletílico a $0,5 \%(p / v)$ e digluconato de clorhexidina a 0,01\% (p/v) e 
EDTA a $0,1 \%(\mathrm{p} / \mathrm{v})$. Embora a natureza dos conservantes tenha interferido na estabilidade das suspensões, as fórmulas contendo polissorbato 20 a $0,025 \%$ (p/v) e hidroxipropilmetilcelulose a 0,75\% (p/v) foram aquelas que demonstraram adequada característica físicoquímica. Desta forma, no presente trabalho, as 17 fórmulas testadas mantiveram estas concentrações, variando somente o tipo e a concentração dos conservantes e EDTA, visando alcançar a estabilidade biológica por meio da otimização dos conservantes empregados, conforme o objetivo do trabalho.

No mercado, o conservante eleito para as soluções e suspensões oftálmicas é o cloreto de benzalcônio, na concentração entre 0,001 a $0,01 \%(p / v)^{55,63,83,295,296}$, mesmo sendo conhecida sua característica de ser facilmente inativado por macromoléculas de carga oposta ou por adsorção, como no caso clássico de sua interação com os polissorbatos. Este representante da classe dos amônios quaternários apresenta como vantagem, nesta faixa de concentração, baixa toxicidade e estabilidade física em ampla faixa de $\mathrm{pH}(4-10)^{86}$.

No trabalho preliminar ${ }^{29}$, as fórmulas conservadas com cloreto de benzalcônio associado ao EDTA, agente potencializador da atividade antimicrobiana desta substância, foram avaliadas quanto a sua eficácia. Esta associação, bem como as outras 2 associações estudadas (clorobutanol e álcool feniletílico; digluconato de clorhexidina e EDTA), apresentaram eficácia antimicrobina bastante inferior quando comparada a associação de digluconato de clorhexidina e álcool feniletílico.

Das duas fórmulas avaliadas quanto a sua eficácia antimicrobiana naquele estudo, contendo o cloreto de benzalcônio e o EDTA, observou-se redução de apenas 3 ciclos logarítmicos no 
intervalo de tempo igual a 48 horas para uma das fórmulas e nenhuma redução durante todo o intervalo de tempo monitorizado, ou seja, 28 dias, para a outra fórmula desafiada frente a Pseudomonas cepacia. Todas as fórmulas avaliadas anteriormente contendo a associação de digluconato de clorhexidina a $0,01 \%(\mathrm{p} / \mathrm{v})$ e álcool feniltetílico a $0,5 \%(\mathrm{p} / \mathrm{v})$ obtiveram redução de 6 ciclos logarítmicos no intervalo de tempo igual a 6 horas, frente ao mesmo microrganismo.

Em função do local de administração, a maior preocupação dos formuladores com relação aos conservantes é a de reações de sensibilização provocada por estas substâncias. Tal preocupação pode ser visualizada na análise das alterações do critério de aceitação do Teste de Eficácia de Conservantes da Farmacopéia Britânica $^{41}$ de 1988 , quando comparada com a edição posterior ${ }^{42}$, de 1993, para os produtos oftálmicos. A edição de 1988 recomendava redução de 3 ciclos logarítmicos no intervalo de tempo igual a 6 horas e nenhum microrganismo recuperado em 24 horas do teste, para as bactérias. Já a edição de 1993 assume critério menos exigente: redução de 2 ciclos logarítmicos no intervalo de tempo igual a 6 horas, redução de 3 ciclos em 24 horas e nenhum microrganismo recuperado em 28 dias do teste, para bactérias. Este compêndio ${ }^{42}$ também descreve outro critério, ainda menos exigente, para casos justificados, nos quais o primeiro critério não possa ser atendido em função de aumento de risco de efeitos adversos: redução de 1 ciclo logarítmico em 24 horas do teste e redução de 3 ciclos no intervalo de tempo igual a 7 dias e nenhum aumento da população bacteriana após este período. Para os fungos, o critério anterior assim como o de 1993 recomenda redução de 2 ciclos logarítmicos no intervalo de tempo igual a 7 dias e nenhum aumento da população no intervalo de tempo igual a 28 dias. Porém, nesta última edição, de 1993, este compêndio descreve um outro critério, menos exigente, em função da mesma observação relatada anteriormente: 
redução de 1 ciclo logarítmico no intervalo de tempo igual a 14 dias e nenhum aumento da população fúngica no intervalo de tempo igual a 28 dias.

Como já mencionado, no estudo anterior ${ }^{29}$, observou-se acentuada redução da população microbiana no Teste de Eficácia de Conservantes das fórmulas contendo associação de digluconato de clorhexidina a 0,01\% (p/v) e álcool feniletílico a 0,500\% (p/v). Este resultado indicou que estes agentes antimicrobianos poderiam ou deveriam ser otimizados, visando a redução de suas concentrações, de forma a minimizar o risco de efeitos adversos decorrentes da utilização da suspensão oftálmica, sem, no entanto, comprometer sua estabilidade físico-química e biológica.

As suspensões estudadas, tendo por meta a otimização do sistema conservante acima apresentado, foram formuladas recorrendo a planejamento estatístico. Assim, as 17 fórmulas estudadas foram decorrentes do planejamento tipo Simplex-Lattice ${ }^{64}$. Estas suspensões apresentaram como variáveis as concentrações de digluconato de clorhexidina, de álcool feniltetílico assim como de EDTA. As concentrações do agente suspensor e molhante foram mantidas constantes em função da avaliação anterior ${ }^{29}$ que revelou as melhores fórmulas quanto às características físico-químicas.

Assim como no trabalho anterior ${ }^{29}$, no atual, determinaram-se os valores de viscosidade (Tabela 14). Tais valores estiveram entre 18,34 a $18,78 \mathrm{cps}$ e, portanto, de acordo com o compêndio oficial ${ }^{299}$ que recomenda faixa entre 15 a $25 \mathrm{cps}$. Assim, o parâmetro viscosidade não irá prejudicar a eficácia terapêutica da fórmula. Em função dos dados permanecerem constantes, não se justificou a análise de variância para o fenômeno. 
Outro parâmetro avaliado foi $0 \mathrm{pH}$, que deve ser ajustado em algum momento durante a etapa da formulação em função da estabilidade físico-química dos componentes da fórmula, especialmente os princípios ativos e da via de administração. Neste particular, faixas ácidas seriam de menor preocupação em decorrência do efeito tamponante da lágrima, entretanto faixas alcalinas poderiam, promover reações extremamente agressivas. De forma ideal, as preparações oftálmicas deveriam ser formuladas com $\mathrm{pH}$ equivalente ao fluido lacrimal, ou seja, 7,4 , o que é por vezes não aplicável pois a maioria dos ingredientes ativos utilizados na oftalmologia são sais de bases fracas e estáveis em $\mathrm{pH}$ ácido ${ }^{120}$. No caso da dexametasona, valores de $\mathrm{pH}$ acima de 7,0 não são adequados pois pode ocorrer oxidação da cadeia lateral cetônica ${ }^{171}$. Para a polimixina B o valor recomendado encontra-se no intervalo de 5,0 a 7,0 ${ }^{296}$. Entretanto, as suspensões oftálmicas de dexametasona em associação com polimixina B e neomicina, descritas pela USP XXIII ${ }^{299}$ apresentam especificação de $\mathrm{pH}$ entre 3,5 e $6,0^{299}$.

Deve-se considerar que a melhor atividade do conservante pode ser dependente do valor de $\mathrm{pH}$. No caso do digluconato de clorhexidina, o pH ótimo situa-se em faixa entre 5,0 e 8,0 porém a atividade do álcool feniletílico praticamente não varia em função do $\mathrm{pH}^{93}$. Desta forma, os valores obtidos de $\mathrm{pH}$, conforme Tabela 14 variando de 5,65 a 5,84, foram considerados adequados. A diferença entre os valores de $\mathrm{pH}$ das 17 preparações não foi considerada significativa, não tendo sido portanto selecionado como variável de interesse na comparação entre as suspensões estudadas.

Determinaram-se ainda para todas as fórmulas propostas as características de ressuspensão e sedimento, após 7 dias, 
e o volume do fármaco disperso (relação volumétrica percentual) ${ }^{260}$. Este último parâmetro foi substituído pelo volume ocupado pelo sedimento decantado em decorrência da gravidade em relação ao volume total da suspensão devido a baixa concentração da substância dispersa, a dexametasona a $0,1 \%(\mathrm{p} / \mathrm{v})$.

Analisando os dados da Tabela 15 observou-se que não houve variação na porcentagem do volume do fármaco disperso. Este resultado corroborou com o estudo preliminar confirmando que as concentrações do agente molhante e do agente suspensor foram adequadas e, portanto, não se justificou a análise de variância para este parâmetro.

Com relação a característica de ressuspensão e tipo de sedimento, também indicados na Tabela 15, observou-se a influência dos conservantes nestes parâmetros. Este comportamento, também observado no estudo anterior ${ }^{29}$ era portanto, esperado. Assim, as fórmulas 2=8, contendo EDTA a $0,1 \%(p / v)$ e as fórmulas $7=15$, contendo $0,003 \%(\mathrm{p} / \mathrm{v})$ de digluconato de clorhexidina a 0,067\% (p/v) de EDTA, apresentaram sedimento compactado (C) e característica de rehomogeneização difícil (Di). Todas as fórmulas contendo concentração de álcool feniletílico acima de 0,167\% (p/v), ou seja, as fórmulas $6,9=10,11,12,13,14$ e 17 apresentaram além de característica de rehomogeneização fácil (Fa), sedimento tipo floculado (F) assim como a fórmula controle (18). A atividade floculante do álcool feniletílico foi também relatada por PORTNOFF e colaboradores ${ }^{226}$. As fórmulas $1=5, \quad 3,4$ e 16 apresentaram característica de rehomogeneização regular $(\mathrm{Re})$ e sedimento do tipo floculado $(F)$. 
No sentido de assegurar a adequacidade das fórmulas também no seu uso clínico, de forma adicional comprovou-se, tendo sido satisfatórios os resultados quanto a isotonicidade, esterilidade e irritabilidade ocular. Esta última conformidade era de se esperar, tendo em vista a faixa de $\mathrm{pH}$ entre outros fatores, superior a 5,6.

As fórmulas, após o estudo de suas características físico-químicas, foram avaliadas quanto a eficácia de seu sistema conservador, mesmo aquelas que apresentaram rehomogeneização difícil e sedimento do tipo compactado (2=8 e 7=15). Esta decisão foi tomada em função do desejo de se obter informações sobre os possiveis efeitos decorrentes da interação entre o EDTA e a polimixina $B$ e do digluconato de clorhexidina e EDTA. Neste sentido, RICHARDS ${ }^{234}$ descreveu que as concentrações testadas de EDTA entre 0,05 - 0,1\% (p/v) não apresentaram ação esterilizante sobre Pseudomonas aeruginosa, embora o autor observasse que por vezes o crescimento deste microrganismo não era evidente na presença do agente em pauta, indicando alguma atividade inibitória do EDTA a Pseudomonas aeruginosa. Em outro trabalho, RICHARDS e RICHARDS ${ }^{247}$ relataram que na presença de EDTA, o digluconato de clorhexidina apresentava efeito menor contra Pseudomonas cepacia e Staphylococcus aureus. Assim, optou-se por não desprezar qualquer das fórmulas, objetivando com isto melhor observação dos efeitos antimicrobianos derivados dos sistemas propostos.

O Teste de Eficácia de conservantes quer seja pelo método oficial quer seja pelo método de Regressão Linear, proposto por $\mathrm{ORTH}^{198}$, consiste na determinação da carga microbiana sobrevivente em intervalos de tempo definidos. Embora tecnicamente semelhantes, este último método emprega como critério de interpretação da eficácia antimicrobiana do sistema conservante o valor $D$, ou seja, o tempo de 
redução decimal, obtido da função entre o logarítmo do número de sobreviventes e o tempo de inoculação. Os critérios adotados pelo autor, para bactérias patogênicas, corresponde ao valor D igual ou menor a 4 horas e, para bactérias não patogênicas e fungos, $D$ igual ou menor a 28 horas. A avaliação por esse método permite obtenção de resultados em 48 horas, para bactérias e em 7 dias, para fungos, contrastando com os 28 dias requeridos pelo método oficial. Além de rápido, as fórmulas podem ser comparadas empregando-se parâmetro quantitativo (valor D) sendo também possível observar os efeitos de adição, sinergismo ou antagonismo nas combinações de antimicrobianos.

Quanto aos microrganismos desafiantes, no presente trabalho, além dos oficialmente recomendados, empregou-se também cepa de Pseudomonas cepacia. Este microrganismo, em estudo anterior ${ }^{29}$, foi de fundamental importância para a escolha do sistema conservante. Os outros 2 microrganismos testados anteriormente foram Staphylococcus aureus e Pseudomonas aeruginosa. O representante gram-positivo, freqüentemente presente na pele humana, revelou, no trabalho preliminar ${ }^{29}$, elevada susceptibilidade frente as fórmulas testadas. As fórmulas tiveram capacidade autoesterilizante frente a este microrganismo no intervalo de tempo igual a 24 horas, excetuando-se apenas uma fórmula que apresentou este mesmo comportamento no intervalo de tempo igual a 48 horas. Susceptilidade ainda maior foi observada no desafio ao se empregar Pseudomonas aeruginosa. Este microrganismo é altamente recomendado para o desafio de produtos oftálmicos por apresentar habilidade na produção enzima que destrói o colágeno da córnea 102, 111, podendo causar sua ulceração, com conseqüente perda total ou parcial da visão ${ }^{295,296,297}$. Ainda por ser de ocorrência comum, de difícil eliminação e por apresentar tendência para o desenvolvimento de cepas resistentes ${ }^{56}$. Porém, este germe gram- 
negativo foi inibido drasticamente, de maneira semelhante àquela observada em estudo anterior, não tendo sido possível sua recuperação mesmo imediatamente após ser inoculado. Tal comportamento foi idêntico nas diferentes fórmulas, induzindo à conclusão de que o agente inibidor tenha sido a polimixina B, já que também na formulação sem sistema conservante houve comportamento coincidente, com a ausência total do crescimento microbiano. Ainda assim, este microrganismo foi mantido no estudo das fórmulas, na expectativa de eventual interação antagônica entre o antibiótico e os conservantes estudados. O desafio das fórmulas com fungos, inlusive oficialmente recomendados, também é revelante em função de apresentarem característica de resistência própria e terem sido relatados como contaminantes em produtos oftálmicos 32, 46, 119, 120, 254.

Ainda com relação a Pseudomonas cepacia, diversos autores, a partir da década de 70, relataram a ocorrência deste germe, como contaminante em produtos farmacêuticos ${ }^{78,151}$, cosméticos ${ }^{30,56,275} \mathrm{e}$ desinfetantes de uso hospitalar ${ }^{8,270}$. Em produtos farmacêuticos o isolamento de Pseudomonas cepacia, com determinação de contagens da ordem de $3 \times 10^{3}$ UFC/mL foi relatado por KHOTARI e colaboradores ${ }^{151}$ durante o uso de suspensão parenteral de metilprednisolona de dose múltipla. Após aplicação intra-articular do produto em paciente, iniciouse processo infeccioso cujo tratamento exigiu altas doses de gentamicina. Também DECICCO e colaboradores ${ }^{78}$ detectaram a presença de Pseudomonas cepacia, em descongestionante nasal conservado com tiomersal, inclusive constatando a degradação de compostos organomercuriais.

Diversos outros relatos apontam, dentre contaminantes de produtos cosméticos ${ }^{30,56,275}$, em desinfetantes ${ }^{8,270}$ a presença de Pseudomonas cepacia, induzindo a crer na sua universalidade como 
constituinte de biocargas de formulações de natureza distinta. Este fato, por si justificaria a inclusão da cepa dentre os microrganismos desafiantes. Acresce ainda conhecimento quanto a sua patogenicidade, constatada por LEYDEN e STEWART ${ }^{161}$ quando da inoculação em tecido cutâneo escarificado, assim como virulência refratária a tratamento com antibióticos usuais ${ }^{153,186}$, particularmente em pacientes imunodeprimidos ou portadores de fibrose cística ${ }^{187,256,258,268,282}$.

O Teste de Eficácia de Conservantes consiste na quantificação da carga desafiante em intervalos de tempo especificados. Estas determinações induzem ao emprego de técnicas de contagem microbiana, sejam aquelas mais rotineiramente empregadas ou convencionais, sejam as emergentes adotando sistemas rápidos. A confiabilidade que se possa conferir aos resultados obtidos está sempre na dependência de validações que sejam efetuadas. Esta recomendação consta nos compêndios oficiais ${ }^{42,96,131,299}$ ainda que de forma genérica, pois o desenvolvimento da metodologia analítica cabe exclusivamente ao fabricante, que detém todo o conhecimento sobre sua fórmula. A neutralização química dos agentes antimicrobianos foi utilizada como recurso por diversos autores 4, 91, 122, 148, 156, 198, 204, 205, 206, 234 , 250, 266 . Outro cuidado inerente à escolha do agente inativante consiste em que a sua ação seja rápida e isenta de ação sobre o crescimento microbiano, diretamente ou em decorrência de interações ${ }^{266}$.

Respeitando as considerações acima, empregou-se, para a técnica de semeadura em profundidade meio de cultura acrescido de $0,7 \%(\mathrm{p} / \mathrm{v})$ de polissorbato 20 e 0,1\% (p/v) de lecitina de soja e solução salina a $0,9 \%(p / v)$ como diluente contendo $0,2 \%(p / v)$ de polissorbato 20 e 0,2\% (p/v) de lecitina de soja. Este sistema neutralizante demonstrou ser eficaz em trabalho preliminar ${ }^{29}$. Ainda assim, a validação não foi excluída em função das diferentes 
concentrações dos conservantes utilizados neste trabalho.

Para comprovar a inativação do sistema conservante, embora seja permissível o emprego de carga microbiana na faixa de 10 a 100 células optou-se pelo valor superior por questões de reprodutibilidade e, por induzir a resultados mais precisos. Efetivamente, os valores observados na Tabela 16, após determinação das médias e desvios padrões (Tabela 17) foram submetidos a análise de variância (Tabela 18), não indicando diferenças estatisticamente significantes entre as fórmulas e o controle para Pseudomonas cepacia e Staphylococcus aureus. No caso dos fungos, merece especial cautela a interpretação que se deva dar à conclusão quanto a significância das fontes de variação (Tabela 18). Haja visto a rigidez do modelo empregado, o valor absoluto das diferenças entre as médias, para Candida albicans entre -3,8 e -4,8 e para o Aspergillus niger, entre -5,2 e 4,0 (Tabela 19) devem ser consideradas tendo em mente os valores obtidos na contagem dos mesmos microrganismos em solução fisiológica, empregada como controle, sendo de 96 UFC/placa e 105 UFC/placa, respectivamente para o bolor e a levedura. A Figura 2 evidencia, para os dois fungos, maior dispersão das médias dos valores de UFC/placa, comparativamente às bactérias. Sabe-se entretanto que contagens com desvios de $5 \%$ são ainda aceitáveis, e atribuíveis a erros de diluições, dificuldades em homogeneização e não condenáveis dentro da prática microbiológica.

\footnotetext{
Etapa subseqüente deve considerar quanto a interferência dos agentes neutralizantes empregados sobre o crescimento do microrganismo. O ensaio, cujos resultados obtidos estão expressos na Tabela 20, foi conduzido também com carga aproximada de 100 células, e complementa o estudo anterior para a validação da metodologia analítica. Não foi encontrada significância para os efeitos
} 
estudados, conforme observado nas Tabelas 21 e 22 e Figura 3, indicando portanto, não interferência dos agentes neutralizantes sobre o crescimento microbiano.

Os resultados indicaram a adequacidade dos agentes neutralizantes empregados na técnica de semeadura em profundidade a partir da diluição 1:10, permitindo sua aplicabilidade na técnica de avaliação quanto a eficácia de conservantes.

Além da técnica de semeadura em profundidade utilizou-se técnica de contagem por membrana filtrante que também foi objeto de validação. Esta técnica teve por meta efetuar contagem microbiana diretamente no produto, em maior volume, garantindo maior precisão dos resultados. A técnica de filtração mostrou-se especialmente útil quando da presença de baixas cargas microbianas nas suspensões oftálmicas, não detectáveis pela técnica de semeadura em profundidade. Normalmente, após a filtração do produto, efetua-se sucessivas lavagens da membrana filtrante, com porções de fluido apropriado. Este procedimento tem como finalidade a eliminação dos possíveis efeitos inibitórios decorrentes da impregnação da membrana por substâncias antimicrobianas. A possivel interferência da ação residual dos agentes antimicrobianos no crescimento dos microrganismos foi estudada e, os resultados obtidos constam na Tabela 29. O tratamento dos valores obtidos de UFC/placa, após cálculo de médias e desvios padrões (Tabela 24), foram submetidos a análise de variância (Tabela 25). As conclusões quanto a não significância das interferência do tratamento e este associado aos microrganismos como fontes de variações são apresentados na Tabela 25. Tais resultados, assim como a visualização comparativa entre o teste e o controle (Figura 4) conferem a confiabilidade ao sistema de avaliação empregado, podendo-se assim inferir quanto a ausência de 
efeito inibitório.

À semelhança do estudo anterior ${ }^{29}$ dificuldades técnicas induziram a que não se buscasse a inativação de polimixina $\mathrm{B}$, o que, entretanto, encontra respaldo na literatura. Segundo $\mathrm{KOHN} e$ colaboradores $^{149}$, a inativação de até $2.000 \mathrm{UI} / \mathrm{mL}$ de sulfato de polimixina só foi possível empregando-se lecitina de soja $(0,5 \%)$ e glicerina (4\%) e, mesmo assim, quando o ensaio foi realizado com cepa resistente de Pseudomonas aeruginosa. A polimixina $B$, segundo RICHARDS e MCBRIDE ${ }^{246}$ reduziu a razão de crescimento de Pseudomonas aeruginosa até mesmo em concentrações da ordem de $1 \mathrm{Ul} / \mathrm{mL}$, enquanto que Pseudomonas cepacia demonstrava baixa sensibilidade a esta substância.

Quanto ao EDTA, embora classificado como agente quelante, SINGER ${ }^{266}$ recomendou sua inativação com cloreto de cálcio, classificando-o como conservante. Também RICHARDS ${ }^{234}$ atribuíu alguma atividade inibitória a esta substância, como já mencionado. Porém, mais comumente, é atribuída a esta substância efeito potencializador da atividade de alguns conservantes ${ }^{186,237,247}$. No presente estudo, assim como no anterior foi possível a neutralização dos conservantes sem o emprego de cloreto de cálcio.

Tendo em vista a validação metodológica referente a determinação de contagens microbianas, por sua vez vinculadas a inativação de agentes antimicrobianos, ou mesmo as justificativas para sua não inativação, pondere-se os aspectos inerentes intrinsecamente ao estudo da eficácia de conservantes.

Todas as suspensões oftálmicas, inclusive a fórmula utilizada como controle, sem conservantes, desafiadas com 
Pseudomonas aeruginosa apresentaram efeito esterilizante imediatamente após a inoculação, indicando rápida atividade biocida. Este resultado corroborou com o estudo anterior ${ }^{29}$ demonstrando a intensa susceptibilidade deste microrganismo ao sulfato de polimixina $B$. Assim sendo, a presença de sulfato de polimixina B não permitiu a observação do efeito dos sistemas conservantes testados frente a Pseudomonas aeruginosa.

Diferentemente da Pseudomonas aeruginosa, sensível até mesmo em concentrações da ordem de $1 \mathrm{UI} / \mathrm{mL}^{246}$ a $2,25 \mathrm{UI} / \mathrm{mL}^{236}$ de polimixina $B$, sendo que concentrações da ordem de $6 \mathrm{UI} / \mathrm{mL}$ deste antibiótico causaram destruição das células, concentrações de $25 \mathrm{UI} / \mathrm{mL}$ de polimixina B não teve nenhum efeito nas células de Pseudomonas cepacia. Segundo o autor ${ }^{236}$, o comportamento constrastante destes 2 microrganismos em relação a polimixina B pode ser devido a diferença qualitativa ou quantitativa nos lipopolissacárides existentes nos dois tipos de células. Este resultado corroborou com o presente trabalho uma vez que não foi observada redução da carga de Pseudomonas cepacia na fórmula 18 , sem sistema conservante, durante o período do teste, ou seja 48 horas, conforme ilustrado na Figura 7.

Neste âmbito, no início da década de $60, \mathrm{KOHN}$ e colaboradores ${ }^{149}$ consideraram, arbitrariamente, que a esterilização de carga de $10^{6} \mathrm{UFC} / \mathrm{mL}$ de Pseudomonas aeruginosa, em preparações oftálmicas, deveria ser inferior a 1 hora. Em 1973, RICHARDS e McBRIDE ${ }^{245}$ determinaram que a solução oftálmica de sulfacetamida descrita pelo British Pharmaceutical Codex ${ }^{37}$ requeria 5 horas para esterilizar aproximadamente $4 \times 10^{8}$ células $/ \mathrm{mL}$ de Pseudomonas aeruginosa e sugeriram a alteração do sistema presente por outro com tempo de esterilização inferior a 1 hora. Estes autores, em outro trabalho ${ }^{241}$, também consideraram que tempo de esterilização superior 
a 1 hora poderia ser considerado muito vagaroso para o conservante em preparações oftálmicas de dose múltipla, desafiadas com Pseudomonas aeruginosa.

Embora não houvesse, no presente trabalho, a mesma preocupação dos autores acima citados, nesse trabalho, no sentido de estabelecer meta de redução de carga de $10^{6}$ a $10^{8} \mathrm{UFC} / \mathrm{mL}$ de Pseudomonas aeruginosa em intervalo de tempo inferior a 1 hora, esta condição foi obtida, porém em função do antibiótico.

Ainda analisando o desafio com Pseudomonas cepacia, as suspensões $6,9=10,11,12,13$ e 14 apresentaram comportamento similar, como mostram as Tabelas 26 e 27 , tendo havido letalidade total do desafiante no intervalo de tempo igual a 2 horas. Os perfis apresentados nas figuras 5, 6 e 7 permitem visualizar tal fenômeno. 0 valor D obtido para as fórmulas mencionadas, expresso na Tabela 28 , foi coincidente e igual a 0,29 horas. A fórmula 17, com menor velocidade da razão de morte, quando comparada a essas últimas suspensões, apresentou valor D significativamente maior, de 3,63 horas. A Figura 7 evidencia este comportamento, indicando a menor atividade antimicrobiana da fórmula. Já quando comparada as outras suspensões $(1=5,2=8,3,4,7=15$ e 16), a fórmula 17 apresentou-se vantajosa frente as demais. Os valores $D$ observados para estas fórmulas também constam na Tabela 28 e mantiveram-se na faixa de 29,03 a 119,82 horas. Os comportamentos distintos para este desafio indicaram claramente os sistemas mais vantajosos assim como aqueles menos adequados. De acordo com a superfície de resposta e gráfico de contorno, ilustrados na Figura 17, a região com os menores valores D (<4horas) e, portanto, a que atendeu ao critério adotado abrange associações binárias de álcool feniletílico e EDTA, digluconato de clorhexidina e álcool feniletílico e asssociação ternária de digluconato 
de clorhexidina, álcool feniletílico e EDTA. Como fator comum, as fórmulas que apresentaram os menores valores $D(0,29$ e 3,63 horas) foram aquelas contendo álcool feniletílico em sua composição em concentração igual ou superior a 0,167\% (p/v).

A atividade inibitória do álcool feniletílico em bactéria gram-negativa, inclusive contra cepa de Pseudomonas aeruginosa, foi anteriormente relatada por LILLEY e BREWER ${ }^{162}$ e MACKIE e colaboradores ${ }^{166}$. Entre os álcoois aromáticos testados por estes últimos autores (álcool benzílico, álcool feniletílico, 3-fenilpropanol, 4fenilbutanol e 5-fenilpentanol) cepa de Pseudomonas aeruginosa foi a mais resistente a estas substâncias, exceto para o álcool feniletílico.

A associação de conservantes ao álcool feniletílico e/ou ao EDTA foi principalmente estudada por RICHARDS e seus colaboradores em diversos trabalhos publicados $234,238,239,241,243,244,245$, $246,247,248$

A substituição do nitrato de fenilmercúrio ou do tiomersal, em solução oftálmica de sulfacetamida, por acetato de clorhexidina a $0,01 \%$ ou clorocresol a 0,05\% associado a 0,4\% (p/v) de álcool feniletílico e 0,05\% (p/v) de EDTA foi necessária para se obter redução da população de aproximadamente $10^{8}$ de Pseudomonas aeruginosa por periodo de tempo inferior a 1 hora ${ }^{245}$. RICHARDS ${ }^{234}$, em 1971, já havia proposto esta mesma associação ternária, ou seja, a combinação destes 2 compontes (álcool feniletílico e EDTA), e nestas mesmas concentrações, com outro agente antimicrobiano (principal), quando não houvessse argumento contrário, principalmente relativo a cepa resistente de Pseudomonas aeruginosa. As propriedades inibitórias da associação ternária proposta por RICHARDS e colaboradores 234,245 foram confirmadas neste trabalho para a 
Pseudomonas cepacia nas suspensões 11 e 13.

Assim, o álcool feniletílico pode ser utilizado com vantagens em combinação com outros agentes antibacterianos na conservação de produtos farmacêuticos, tais como o cloreto de benzalcônio, o clorobutanol, o diacetato de clorhexidina entre outros ${ }^{239}$. A utilização de álcool feniletílico em combinação com outro conservante é mais efetiva na inativação de contaminantes resistentes ${ }^{246}$ e também permite o emprego de concentrações individuais menores do conservante principal, sugerindo efeito sinérgico entre estes antimicrobianos.

Além de intensificar a ação de vários agentes antimicrobianos, o álcool feniletílico é relativamente compatível quimicamente com vários princípios ativos utilizados em preparações oftálmicas ${ }^{36}$, tem propriedade levemente anestésica ${ }^{36}$ e possui agradável odor de rosas ${ }^{166}$, nas concentrações normalmente utilizadas. Porém BOER ${ }^{24}$ relatou que concentrações acima de $0,6 \%(p / v)$ em colírios provocou irritação ocular em pacientes.

O sucesso das associações contendo álcool feniletílico pode ser explicado pela alteração promovida por este composto na permeabilidade da membrana celular, permitindo ao outro conservante atingir maior concentração dentro da célula ${ }^{248,265}$. Este fenômeno pode justificar o efeito potencializado da atividade antimicrobiana do digluconato de clorhexidina na presença do álcool ${ }^{244}$, também observado nas fórmulas pertencentes a região da Figura 17 apresentando valor $\mathrm{D}$ menor ou igual a 4 horas.

Neste sentido, RICHARDS e HARDIE ${ }^{238}$ relataram que concentração de $0,0003 \%$ de fentichlor $($ di(2-hidroxi-5clorofenil) sulfito 
teve efeito potencializado na presença de $0,2 \%$ de álcool feniletílico. A combinação destes foi mais efetiva contra cepas de Staphylococcus aureus, Escherichia coli, Proteus vulgaris e Pseudomonas aeruginosa quando comparado ao efeito destes conservantes utilizados em separado, nas mesmas concentrações.

Outros álcoois aromáticos, além do feniletílico foram estudados por RICHARDS e McBRIDE ${ }^{243,244}$. Os autores relataram que o 3-fenilpropanol, o álcool feniletílico e o álcool benzílico intensificaram a ação do cloreto de benzalcônio com intensidade decrescente e sugeriram que o 3-fenilpropanol pode ser utilizado com vantagem em preparações orais em função de seu agradável odor de canela na concentração de $0,4 \%(p / v)$, em água ${ }^{243}$. Também quando testados em combinação com acetato de clorhexidina, o álcool benzílico, o álcool feniletílico e o 3-fenilpropanol apresentaram resultado superior a simples adição se comparado aos resultados destes, isoladamente.em separado $^{244}$.

O efeito do cloreto de benzalcônio $(0,003 \%)$, do acetato de clorhexidina $(0,002 \%)$ e do nitrato de fenilmercúrio $(0,004 \%)$ na razão de crescimento de Pseudomonas aeruginosa, resistente ao álcool feniletílico, em caldo nutriente acrescido de $0,2 \%(\mathrm{v} / \mathrm{v})$ de álcool feniletílico, foi muito maior que o efeito das mesmas concentrações de cada agente antimicrobiano, quando utilizados individualmente ${ }^{242}$.

Em outro trabalho, RICHARDS e colaboradores ${ }^{248}$ também verificaram a ação sinérgica entre $0,002 \%(p / v)$ de nitrato de fenilmercúrio e $0,4 \%(\mathrm{p} / \mathrm{v})$ de álcool feniletílico frente cepa de Pseudomonas aeruginosa. Da mesma forma, além do nitrato de fenilmercúrio, o cloreto de benzalcônio, o acetato de clorhexidina, o clorocresol e clorobutanol foram testados em combinação ao álcool 
feniletílico e ao EDTA empregando inóculo contendo $10^{6}$ a $10^{7} \mathrm{UFC} / \mathrm{mL}$ de Pseudomonas aeruginosa. As combinações destes conservantes com o álcool feniletílico foram consistentemente mais efetivas, alcançando-se esterilização em até 15 minutos, de soluções oftálmicas contendo alcalóides (atropina, fisostigmina e pilocarpina) ${ }^{241}$.

No presente estudo, observou-se que as suspensões oftálmicas, contendo associação binária de digluconato de clorhexidina e EDTA (fórmulas 3 e $7=15$ ) apresentaram elevado valor $D$, respectivamente de 81,05 horas e de 118,76 horas (valor médio), (Tabela 28). Estes resultados podem ser justificados em função de efeito antagônico ocorrido entre o digluconato de clorhexidina e EDTA Este fenômeno foi relatado anteriormente no estudo de RICHARDS e RICHARDS ${ }^{247}$. Esses autores concluiram que a associação do cloreto de benzalcônio ou do gluconato de clorhexidina com o EDTA apresenta atividade menor contra Pseudomonas cepacia quando comparado ao seus efeitos individuais. Tal fato não ocorreu com a Pseudomonas aeruginosa, onde a atividade destes conservantes era incrementada na presença de EDTA. Os autores concluiram que o EDTA antagonizou o efeito do gluconato de clorhexidina e do cloreto de benzalcônio frente a Pseudomonas cepacia e ao Staphylococcus aureus ${ }^{247}$. As suspensões 2=8, formuladas apenas com o EDTA na concentração de 0,1\% (p/v) apresentaram valor $D$ superior ás fórmulas $7=15(0,03 \%(p / v)$ de digluconato de clorhexidina e 0,067\% (p/v) de EDTA e atividade superior à fórmula 18, sem sistema conservante. $A$ atividade antimicrobiana da fórmula 2=8 (valor D médio igual 90,71 horas) contra a Pseudomonas cepacia pode ser explicada em função da associação entre a polimixina $B$ e o EDTA.

Ainda observando a Tabela 28, as fórmulas $1=5$ contendo apenas digluconato de clorhexidina apresentaram valor D 
médio igual a 29,28 horas, 10 vezes superior ao valor $D$ observado para as fórmulas $6,9=10,11,12,13,14$, as quais tem em comum a característica da presença de álcool feniletílico a $0,0167 \%$ (p/v) ou acima. Também RICHARDS e RICHARDS ${ }^{247}$ haviam observado menor efeito do digluconato de clorhexidina em comparação com este agente em associação com o álcool feniletílico.

A fórmula 4 , contendo $0,002 \%(p / v)$ de digluconato de clorhexidina , 0,083\% (p/v) de álcool feniletílico e 0,067\% (p/v) de EDTA e a fórmula 16 , contendo $0,007 \%(\mathrm{p} / \mathrm{v})$ de digluconato de clorhexidina, 0,083\% (p/v) de álcool feniletílico e 0,017\% (p/v) de EDTA, diferentes quanto a concentração de digluconato de clorhexidina e do EDTA, apresentaram valores D iguais a 35,18 e 23,03 horas, respectivamente. A diferença entre estes valores (aproximadamente 12 horas) foi bastante inferior quando comparada com a situação das fórmulas 6 e 11 (valor D coincidente e igual a 0,28 horas) contendo concentrações de digluconato de clorhexidina de 0,07 e 0,002 \% (p/v), respectivamente, porém associadas ao álcool feniletílico a 0,167\% (p/v) e 0,333 \% (p/v). Comparando-se, por exemplo, as fórmulas 4 e 11 e 6 e 16, observa-se diferenças de valores D iguais a 41 e 29 horas respectivamente, indicando que o álcool feniletílico em concentração superior a 0,167\% (p/v) pode ser o responsável pelo rápido decaimento da Pseudomonas cepacia nas fórmulas 6 e 11 .

Além da ação potencializadora ou antagônica resultante da combinação de agentes antimicrobianos (digluconato de clorhexidina e álcool feniletílico) e EDTA, relatados anteriormente, pode eventualmente ocorrer ação apenas aditiva, resultante dos efeitos destas substâncias. Efeito semelhante pode eventualmente ter ocorrido em situações de valores D intermediários, ficando entretanto comprometedor assegurar sua ocorrência. Assim, RICHARDS e 
RICHARDS ${ }^{247}$ relataram em seus experimentos que o álcool feniletílico em associação ao cloreto de benzalcônio ou ao acetato de clorhexidina apresentou efeito apenas aditivo contra a fase logarítmica de culturas de Pseudomonas cepacia.

Quando as mesmas suspensões oftálmicas foram desafiadas com Staphylococcus aureus (Tabela 29) este demonstrou susceptibilidade ao sulfato de polimixina B, apresentando comportamento distinto quando comparado a Pseudomonas cepacia. Esta cepa, manteve-se com carga constante durante as 48 horas estudadas, na fórmula 18, sem conservantes. O Staphylococcus aureus apresentou para esta fórmula, redução de cerca de 2,5 ciclos logarítmicos (Tabela 30) e valor D igual a 22,94 horas, como consta na Tabela 31. Este comportamento também foi observado no trabalho anterior ${ }^{29}$ porém com maior intensidade, sendo que a redução total da carga microbiana presente foi observada no intervalo de tempo igual 24 horas. A diferença observada entre os resultados dos dois trabalhos pode estar relacionado com diferentes resistências das cepas empregadas. As sucessivas transferências do microrganismo para o meio de cultura visando sua manutenção pode ocasionar alterações no seu comportamento. Neste sentido, a Farmacopéia Americana em sua $23^{\circ}$ edição ${ }^{299}$ recomenda que o número de transferências do microrganismo (repiques) não seja superior a 5. A observância desta recomendação conduziu à utilização, neste trabalho, de cepas liofilizadas provenientes de fontes reconhecidamente confiáveis, tais como Instituto Adolfo Lutz e Instituto Nacional de Controle de Qualidade em Saúde (INCQS).

A fórmula $2=8$, contendo $0,1 \%(p / v)$ de EDTA apresentou valor D médio de 11,28 horas e, portanto, inferior ao obtido para a fórmula 18 , sem sistema conservante (valor D igual a 22,94 
horas). A atividade antimicrobiana desta suspensão, também observada para o microrganismo anteriormente discutido, porém com menor intensidade, pode ser atribuida ao EDTA ou a sua associação com a polimixina $B$. Para a fórmula $7=15$ não foi calculado o valor $D$ em função do coeficiente de correlação apresentar valor inferior a 0,80 (Tabela 31). Mesmo assim, o perfil da curva de decaimento da população do microrganismo pode ser observado nas Figuras 8 e 9 demonstrando atividade antimicrobiana da fórmula contra o Staphylococcus aureus. Porém, esta atividade antimicrobiana foi inferior as outras fórmulas estudadas, excetuando-se a $2=8$, comentada acima

Tomando em particular a adoção do limite de 0,80 para coeficiente de correlação aplicado no raciocínio acima assim como em outros momentos de decisão, justifica-se um detalhamento quanto a sua origem.

Neste sentido, TRAN e COLLIER ${ }^{289}$, trabalhando com desafio de maquiagem, relataram que valores entre $-1,00$ a - -0,84 poderiam indicar para o fenômeno comportamento de reação cinética de primeira ordem. Também ORTH e colaboradores ${ }^{204}$, concluiram que valores de coeficiente de correlação a partir de -0,75 indicavam, no caso de estudo de estabilidade de xampus, reações tipicamente de primeira ordem ou de pseudo-primeira ordem. SUTTON e colaboradores ${ }^{281}$, trabalhando com soluções desinfetantes para lentes de contato consideraram criticáveis quaisquer experimentos envolvendo coeficientes de correlação ao quadrado menores que 0,80 . Ainda mais rigidamente, $\mathrm{AKERS}^{4}$ posiciona, para trabalhos envolvendo soluções parenterais valores de coeficiente de correlação nos dados de eficácia de conservantes superiores a 0,90. De tal forma se considera justificável que apenas após constatado valor limite de 0,80 ter se efetuado o cálculo do valor $D$.

Observou-se, no presente estudo, que os valores de 
coeficiente de correlação obtidos para as equações referentes a Pseudomonas cepacia (Tabela 28) estiveram na faixa de $-1,00$ a 0,92, excetuando-se apenas a fórmula controle. Para esta fórmula foi observado coeficiente baixo, além de positivo, igual a +0,76. Este comportamento, para a fórmula sem conservantes, pode indicar aumento da população do microrganismo no decorrer do intervalo de tempo estudado. Para o Staphylococcus aureus, os valores de coeficiente de correlação apresentados na Tabela 31 estiveram entre $-1,00$ a - -0,84, para 16 das 18 fórmulas estudadas, sendo que a fórmula 7=15 apresentou coeficiente de correlação médio de -0,78. Ainda analisando os coeficientes de correlação obtidos, as equações referentes a Candida albicans apresentaram todos os valores entre 1,00 a - 0,80 (Tabela 33) e, excluindo-se a fórmula controle, a faixa compreendeu valores entre $-1,00$ a $-0,95$, indicando ótima correlação para este microrganismo, para todas as fórmulas. De forma contrária, os valores de coeficiente de correlação para o Aspergillus niger foram os mais baixos entre todos os obtidos (Tabela 37). A faixa para o bolor, quando negativa, esteve entre $-1,00$ a - 0,51 e, quando positiva, entre $+0,42$ a $+0,57$. Para este microrganismo foram observados 4 valores de coeficientes positivos inferindo evidências, assim como para o caso anterior, quanto ao crescimento ao invés de inativação microbiana, demonstrando a não adequacidade do sistema para este bolor.

Ainda com relação a análise dos resultados do teste de eficácia de conservantes empregando-se Staphylococcus aureus, as suspensões oftálmicas $1=5,3,9=10,13$ e 16 apresentaram valor D semelhantes (0,28 ou 0,29 horas), e as suspensões 4, 6, 11, 14 e 17 apresentaram também valor $D$ baixo: 0,56 ou 0,59 horas (Tabela 31). No primeiro conjunto de fórmulas, apresentando os menores valores D $(0,28$ e 0,29) foi observada alta sensibilidade do microrganismo desafiante nas fórmulas com as maiores concentrações estudadas de 
digluconato de clorhexidina $0,01 \%(p / v)(1=5)$ e de álcool feniletílico $0,5 \%(\mathrm{p} / \mathrm{v}), \quad(9=10)$. Os sistemas conservantes incorporados nas fórmulas 3 e 16 constituem-se de digluconato de clorhexidina a 0,007\% $(\mathrm{p} / \mathrm{v})$. Além deste conservante, a fórmula 3 possui EDTA a 0,033\% (p/v) e a fórmula 16 contém EDTA a $0,017 \%(\mathrm{p} / \mathrm{v})$ e álcool feniletílico a 0,083\% (p/v). Também a fórmula 13, contendo associação ternária, com sistema conservante a $0,003 \%(p / v)$ de digluconato de clorhexidina, $0,167 \%(\mathrm{p} / \mathrm{v})$ de álcool feniletílico e 0,033\% (p/v) de EDTA apresentou, assim como as fórmulas 3 e 16, acentuada redução da população de Staphylococcus aureus. Esta última associação apresenta somente 30\% da concentração de clorhexidina da fórmula 1=5 e 57\% da concentração deste agente nas suspensões 3 e 16. Com relação ao álcool feniletílico, na fórmula em questão foi incorporada apenas 33\% do álcool presente na fórmula $9=10$. Sendo assim, pode-se dizer que a associação ternária da fórmula 13 permitiu a redução das concentrações individuais dos antimicrobianos (clorhexidina e álcool feniletílico) sem que este fato representasse redução de sua atividade antimicrobiana sobre o Staphylococcus aureus quando comparada às fórmula 1=5, 3, 9=10 e 16.

O valor D observado para a fórmula 12 (3,99 horas) não era esperado uma vez que a fórmula 17 , contendo quantidades menores dos mesmos conservantes apresentou D igual a 0,59 horas. Este resultado pode ser em decorrência de interações antagônicas, como relatada para a fórmula $7=15$ entre os antimicrobianos.

Excluindo-se as fórmulas 2=8 e 7=15 todas as fórmulas conservadas apresentaram valores D inferiores a 4 horas (Tabela 31), demonstrando a alta sensibilidade do Staphylococcus aureus às fórmulas em questão, conforme ilustrado nos gráficos das Figuras 8, 9 e 10 e na superfície de resposta e gráficos de contorno da Figura 18. Tal 
comportamento de extrema susceptibilidade do Staphylococcus aureus, diferente particularmente das cepas gram-negativas, se de um lado confere tranquilidade e liberdade na otimização de fórmulas, de outro induz a obtenção de valores $\mathrm{D}$ baixos em termos absolutos. Portanto, quaiquer erros metodológicos estarão sempre representando frações relativas proporcionalmente elevadas.

O desafio das suspensões oftálmicas com Candida albicans cujos resultados estão expressos na Tabela 32 também revelou a sensibilidade deste microrganismo à fórmula 18 , sem sistema conservante, porém, menor que aquela observada para o Staphylococcus aureus. Para a levedura, a redução foi de cerca de 1,7 ciclos logarítmicos durante o período do teste, ou seja, em 48 horas (Tabela 33). À semelhança do caso anterior, para o gram positivo, podese atribuir a atividade inibitória da fórmula 18 ao antibiótico. O comportamento observado nas Figuras 11, 12 e 13 para a fórmula controle (18) e para as fórmulas 2=8 e 9=10 contendo EDTA a 0,1\% $(p / v)$ e álcool feniletílico a $0,5 \%(p / v)$, respectivamente apresentou-se semelhante. Tal fato constituiu-se em indício quanto a não contribuição do EDTA e do álcool feniletílico para a atividade antifúngica da fórmula. A Tabela 33 mostrou o comportamento semelhante das 3 fórmulas com redução da população de 1,7, 1,5 (valor médio), e 1,7 (valor médio) ciclos logarítmicos, respectivamente para as fórmulas $18,2=8$ e $9=10$. Da mesma forma, os valores $D$ médios calculados para as fórmulas $2=8$ e 9=10, expressos na Tabela 34, foram semelhantes, sendo iguais a 31,98 e 30,59 horas, respectivamente, e, portanto, superiores ao critério especificado pela metodologia adotada ( $\mathrm{D} \leq 28$ horas).

Todas as outras fórmulas conservadas $(1=5,3,4,6$, $7=15,16$ e 17) exceto as acima comentadas, apresentaram valor $D$, no mínimo, 2 vezes menor, entre 7,84 a 14,16. Observou-se também que 
as associações binárias ou ternárias contendo álcool feniletílico (4, 6, $11,12,13,14,16$ e 17) foram mais eficazes quando comparada a fórmula $9=10$, em que este conservante foi empregado isoladamente, na concentração mais elevada, ou seja, de 0,5\% (p/v).

As únicas fórmulas que apresentaram autoesterilização no intervalo de tempo monitorizado (48 horas) foram as fórmulas 1=5, 3, 6 e 16. Para estas fórmulas foram observados valores $D$ próximos, na faixa entre 7,84 a 8,57. Excetuando-se a fórmula $1=5$ que contém concentração de digluconato de clorhexidina a $0,01 \%(\mathrm{p} / \mathrm{v})$ as outras citadas apresentaram combinações de conservantes contendo digluconato de clorhexidina a 0,007\% (p/v). Assim, a Candida albicans parece ser mais sensivel a este antimicrobiano que ao álcool feniletílico ou ao EDTA, como observado na superfície de resposta e gráfico de contorno correspondente (Figura 19). Outras associações, inclusive não contendo o digluconato de clorhexidina também foram eficazes embora apresentando valores $\mathrm{D}$ maiores que os mencionados e, portanto, não alcançando a redução total da carga microbiana no intervalo de tempo igual a 48 horas. Este é o caso da fórmula 14 e 17, com valores D próximos, e iguais a 9,84 e 10,72 horas, contendo respectivamente associação de álcool feniletílico e EDTA. As fórmulas 4, 7, 11, 12, 13 e 15 apresentaram valores $D$ entre 11,96 a 17,45 horas e também abaixo do especificado pelo método por regressão linear ( $D \leq 28$ horas).

Embora todas as fórmulas estejam atendendo ao critério-limite, excetuando-se as fórmulas 2=8 e 7=15, ficam implícitos aspectos vantajosos da associação de álcool feniletílico e EDTA.

Quanto ao desafio empregando-se Aspergillus niger observou-se que não houve decaimento da população deste microrganismo na fórmula controle (18), no intervalo de tempo igual a 7 
dias, bem como para as fórmulas $2=8,7=15$ e 17, conforme Tabelas 41 e 42. Os comportamentos observados nas Figuras 14, 15 e 16 revelaram a elevada resistência do Aspergillus niger aos sistemas conservantes. A capacidade esporulante, a versatilidade das vias bioquímicas inerentes aos bolores podem se constituir em justificativas para tal comportamento, apenas não acompanhado pela fórmula $9=10$ (Figura 15). Esta fórmula é caracterizada pela presença de álcool feniletílico a $0,5 \%(\mathrm{p} / \mathrm{v})$ sendo que o respaldo do efeito antimicrobiano deste agente sobre o bolor não foi localizado na literatura.

Agrupando-se as fórmulas 6, 11, 12 e 14 em função da ordem de grandeza dos valores D (Tabela 37) excetuando-se a fórmula 6 , entre todas a menos similar, as outras combinações apresentam álcool feniletílico na concentração de 0,333\% (p/v). Tal fato reforça que o álcool feniletílico possa ter sido o fator de maior contribuição na atividade antifúngica, inclusive porque a fórmula 6 , apesar da adição de digluconato de clorhexidina a 0,007\% (p/v) apresenta, comparativamente, a menor concentração de álcool feniletílico $(0,167 \%$ $(p / v))$, demonstrando ser dentre as fórmulas em questão, a menos eficaz.

A superfície de resposta (Figura 19 superior) aproximase do vértice vinculado a variável $X_{2}$ (álcool feniletílico). Também o gráfico de contorno (Figura 19 inferior) evidencia destaque a este agente conservante, tornando-o centro de convergência para os valores $\mathrm{D}$ mais adequados.

O trabalho experimental permitiu já conhecer tendências, assim como resultados de regressão linear para distintas fórmulas, frente a desafios com os microrganismos propostos. Ainda, distintos gráficos de contorno definiram sistemas conservantes ideais 
para cada cepa.

Persistia, entretanto, o questionamento quanto a qual, dentre várias propostas já avaliadas, ou se uma distinta poderia surgir como ideal. Assim, os valores D (variável dependente) obtidos para os microrganismos desafiantes foram utilizados para o ajuste das funções das variáveis independentes $X_{1}$ (digluconato de clorhexidina), $X_{2}$ (álcool feniletílico) e $X_{3}$ (EDTA), empregando-se equações cúbicas cuja significância dos termos foi avaliada mediante análise estatística conforme Tabelas 38, 39, 40 e 41, respectivamente, para Pseudomonas cepacia, Staphylococcus aureus, Candida albicans e Aspergillus niger. A partir dos coeficientes obtidos para as variáveis independentes, viabilizou-se, para cada microrganismo, equação que conduziu a previsão dos valores $D$ (teóricos) em função das concentrações dos agentes conservantes e EDTA. Os coeficientes de determinação obtidos para cada uma das equações cúbicas foram, no geral, adequados $(0,954 ; 0,963 ; 0,938)$, apenas deixando a desejar aquele obtido para o Staphylococcus aureus $(0,846)$. Conforme anteriormente discutido, este microrganismo tendeu efetivamente a valores discrepantes. Preferiu-se assumir tal discrepância, pois transformações matemáticas aplicadas a resposta, com a finalidade de encontrar modelo de interpretação mais apropriado não foram consideradas melhores.

Adotando modelo estatístico gráfico (Software Design Expert/ W, Stepwise ) foi possível efetuar graficamente a sobreposição das superfícies de resposta assim como dos gráficos de contorno. Tal recurso constituiu-se em ferramenta útil para se atingir a meta fundamental do trabalho. Assim, ao se visualizar a Figura 21 ficam caracterizadas as regiões ótimas que, por sua vez, levam àquela de otimização conjunta. Esta região corresponde a misturas binárias e ternárias de conservantes e EDTA sempre caracterizadas pela 
predominância do álcool feniletílico. Dentre muitas fórmulas possíveis selecionou-se, aleatoriamente, a fórmula representada por: $X_{1}=0,10$; $X_{2}=0,80 ; X_{3}=0,10$.

Trabalhou-se, adicionalmente, em estratégia numérica em que a função designada "desejo" representou o anseio na obtenção dos menores valores $\mathrm{D}$, entretanto compatibilizando ainda na permanência de situação que tornasse factível a operacionalização do trabalho. De forma semelhante a metodologia anterior (gráfica) também buscou-se inicialmente caracterizar matematicamente os desejos inerentes a cada cepa em questão e a seguir compatibilizadas em situação de maior restrição abrangente a todas. Assim, chegou-se a situação ótima representada seja na superfície de resposta ou nas curvas de contorno apresentadas na Figura 22 (desejo=0,42).

Torna-se agora fácil o entendimento de que independentemente da metodologia adotada obteve-se respostas extremamente semelhantes privilegiando concentrações proporcionalmente elevadas do álcool feniletílico. Nesta situação, a fórmula ideal foi não mais aleatória, porém resultante dos próprios cálculos envolvidos como sendo: $X_{1}=0,25 ; X_{2}=0,75 ; X_{3}=0$.

A decisão tomada frente aos resultados coerentes a que se chegou empregando ambas as estratégias conduziu ao prosseguimento do trabalho experimental com segurança, e ao mesmo tempo com o desafio de validação da sistemática de trabalho adotada.

Assim, a fórmula 19, resultante da estratégia gráfica apresentou concentração de $0,001 \%$ (p/v) de digluconato de clorhexidina, 0,4\% (p/v) de álcool feniletílico e 0,01\% (p/v) de EDTA e a fórmula 20, resultante da estratégia numérica, concentração de 
0,0025\% (p/v) de digluconato de clorhexidina e 0,375\% (p/v) de álcool feniletílico. Os sistemas conservantes nelas adotados apresentara alguma semelhança com aquele proposto por RICHARDS ${ }^{234}$.Este autor recomendou a utilização da combinação de álcool feniletílico a 0,4\% (p/v) e EDTA a 0,05\% (p/v) associada a outro agente antimicrobiano quando não houvesse indicações contrárias. Da mesma forma, após 2 anos, em 1973, este mesmo autor e MCBRIDE ${ }^{245}$ reafirmaram os benefícios da associação de álcool feniletílico a 0,4\% (p/v) e EDTA a 0,05\% (p/v) com o digluconato de clorhexidina a 0,01\% (p/v) ou com o clorocresol a $0,05 \%$ (p/v) para a conservação de solução oftálmica de sulfacetamida.

Avaliações físico-químicas anteriormente efetuadas, embora em fórmulas semelhantes não foram consideradas como argumento suficiente para dispensar tal cuidado naquelas recémpreparadas. Esta preocupação decorreu, em parte, da observação quanto a influência exercida pelos conservantes sobre a estabilidade das suspensões ${ }^{29}$.

Como era previsto, as fórmulas apresentaram ressuspensão fácil e sedimento tipo floculado, (Tabela 43) provavelmente em função da alta concentração de álcool feniletílico $(0,375 \%(p / v)$ e $0,4 \%(p / v))$. As determinações anteriores revelaram que todas as fórmulas contendo pelo menos $0,167 \%(p / v)$ do álcool apresentaram o mesmo comportamento. Quanto aos valores de $\mathrm{pH} e$ viscosidade também não eram esperadas variações em função das novas propostas de misturas de conservantes e EDTA e a expectativa foi confirmada como consta na Tabela 42. Assim, as fórmulas otimizadas (19 e 20) quanto ao aspecto de conservação também apresentaram excelente estabilidade físico-química. Foram, ainda, satisfatórios os resultados pertinentes a isotonicidade, assim como 
confirmada a característica de esterilidade das suspensões.

Conforme antecipado, buscou-se para validação da metodologia empregar não apenas avaliação da eficácia de conservantes utilizando-se regressão linear, mas confirmá-la através de método descrito na Farmacopéia Britânica ${ }^{42}$. Selecionou-se este critério por apresentar exigências mais rígidas que o proposto na Farmacopéia Americana ${ }^{299}$.

Os resultados obtidos, conforme Tabela 44 e 45 evidenciaram excelente comportamento de ambas as fórmulas frente ao desafio com bactérias. Os dados para Pseudomonas cepacia foram próximos a zero (Tabela 46), conforme previsão matemática, mostrando indícios quanto a pertinência do modelo empregado. Em contraposição, os valores D previstos matematicamente para o gram-positivo não foram atingidos quando da execução experimental. Esse comportamento podia ser esperado pelas discrepâncias já relatadas para os valores D desta cepa microbiana. Ainda assim, permanece compatível com a eficácia do sistema conservante proposto.

Ainda com relação a aplicação metodológica, os valores de UFC/mL de sobreviventes foram avaliados em intervalos de tempo distintos dos recomendados tendo em vista o conhecimento prévio do comportamento da cepa frente a sistemas similares e também pela previsão teórica.

O comportamento obtido para os fungos (Tabelas 47, 48 e 49) enaltece a compatibilidade entre valores $D$ teóricos e práticos. Surpreende a extrema proximidade entre ambos, valorizando adicionalmente o modelo empregado. De forma semelhante àquela descrita para bactérias também se adotou intervalos de tempo distintos 
dos preconizados cabendo justificativas idênticas a aquelas mencionadas para bactérias.

As avaliações conforme metodologia farmacopéica foram efetuadas com o intuito de comprovação da eficácia do sistema conservante em condições que melhor representasse aquelas de uso rotineiro (tempo maior de contato).

A observação dos resultados das Tabelas 50 e 51 mostram atendimento às exigências oficiais, endossando, portanto, as primeiras conclusões obtidas via regressão linear.

Tendo em vista a susceptibilidade observada da Pseudomonas aeruginosa frente ao sulfato de polimixina, foi evidenciada a importância da inclusão, no teste de eficácia de sistemas conservantes, da Pseudomonas cepacia como representante do grupo de bacilos gram-negativos não fermentadores, principalmente em produtos oftálmicos que apresentem fármacos com atividade contra Pseudomonas aeruginosa.

Apesar de se ter procedido ampla revisão de literatura quanto a metodologia alternativa empregando-se parâmetros elétricos, com ênfase dado à técnica de impedância, optou-se por não adotá-la no desenvolvimento experimental do trabalho. Observa-se que, embora adotada sem restrições na área de alimentos, a sua aceitação na prática da indústria farmacêutica é ainda incipiente. Existem desafios de natureza técnico-científica, assim como a justificativa para o investimento de capital envolvido tendo em vista o retorno limitado. Tais aspectos retardam que, de forma definitiva, se possa definir claramente quanto à importância de sua adoção irrestrita. 
Assim, considerou-se válido manter parte das informações obtidas, inclusive porque evidenciam aspectos polêmicos existentes. E, na dependência da evolução que ocorra nesta área, eventualmente passe a aplicação desta metodologia a se constituir em próximo desafio, como continuidade do trabalho ora desenvolvido.

Depreende-se portanto, não apenas informações que permitem valorizar os sistemas conservantes empregados e avaliados como ideais, envolvendo o digluconato de clorhexidina, o álcool feniletílico e o EDTA, mas também a importância fundamental no emprego de metodologia racional para caracterizá-lo e para comprovar sua eficácia. 
7 Conclusão 


\section{CONCLUSÃO}

7.1 Todas as fórmulas estudadas contendo álcool feniletílico em concentração igual ou superior a $0,167 \%(\mathrm{p} / \mathrm{v})$ apresentaram sistema floculado e maior eficácia antimicrobiana frente a Pseudomonas cepacia.

7.2 Todas as fórmulas avaliadas contendo álcool feniltetílico e ou digluconato de clorhexidina foram eficazes contra Staphylococcus aureus mas ineficazes contra o Aspergillus niger segundo critério adotado.

7.3 Todas as fórmulas estudadas, contendo conservantes, foram eficazes contra a Candida albicans, segundo critério adotado, exceto àquela contendo apenas álcool feniletílico.

7.4 Empregando-se os modelos ajustados, foi possível determinar uma região na qual as fórmulas apresentaram propriedades adequadas no que diz respeito ao aspecto de conservação. A região selecionada privilegiou concentrações proporcionalmente elevadas de álcool feniletílico.

7.5 Na região considerada ótima, de acordo com o estudo estatístico aplicado, foram obtidas duas fórmulas expressas como: $X_{1}=0,10 ; X_{2}=0,80 ; X_{3}=$ 0,10 e $X_{1}=0,25 ; X_{2}=0,75 ; X_{3}=0$, sendo $X_{1}$ a concentração de digluconato de clorhexidina, $X_{2}$ de álcool feniletílico e $X_{3}$ de EDTA. Da mesma maneira poderia se obter outras semelhantes fórmulas que melhor se adequassem às necessidades específicas de cada formulador. 


\section{REFERÊNCIAS BIBLIOGRÁFICAS}




\section{REFERÊNCIAS BIBLIOGRÁFICAS}

1 ABSHIRE, R. L., CASH, P. Sterile ophthalmic ointment and suspension manufacturing. J. Parenter. Sci. Tecnol., Philadelphia, v.40, n.3, p. 9799, 1986.

2 ABSHIRE, R. L., SCHLECH, B. A. A method for evaluating the effectiveness of preservative systems in water-immiscible ointments. $J$. Parenter. Sci. Tecnol., Philadelphia, v.36, n.5, p. 216-221, 1982.

3 AKERS, M. J., ATTIA, I., A., AVIS, K. E. The Effect of liquid viscosity, fill volume, and load configuration on $\mathrm{F}_{0}$ values. J. Parenter. Drug. Assoc., Philadelphia, v. 33, n. 4., p. 195-202, 1979.

4 AKERS, M. J., BOAND, A. V., BINKLEY, D. A. Preformulation method for parenteral preservative efficacy evaluation. J. Pharm. Sci., Washington, v. 73, n. 7, p. 903-905, 1984.

5 ALLWOOD, M. C. Preservative efficacy testing of pharmaceuticals. Pharm. Int., Cambridge, v. 7, p. 172-175, 1986.

6 ALLISON, J. B., ANDERSON, J. A., COLE, W. H. The method of electrical condutivity in studies on bacterial metabolism. J. Bacteriol., Baltimore, v. 36, p. $571-586,1938$.

\footnotetext{
* De acordo com a norma NBR 6023/89 preconizada pela ASSOCIAÇÃO BRASILEIRA DE NORMAS TÉCNICAS (ABNT). As abreviaturas dos títulos dos periódicos seguem o CHEMICAL ABSTRACTS SERVICE SOURCE INDEX (CASSI) 1994.
} 
7 ANDERS, B., WIEDEMANN B. Mikrobiologische kontamination gebrauchter augentropfen. Pharm. Ztg., Frankfurt, v. 130, n. 26, p. 1648-1655, 1985.

8 ANDERSON, R. L., VeSS, W., PANLILIO, A. L., FAVERO, M. S. Prolonged survival of Pseudomonas cepacia in commercially manufactured povidone-iodine. Appl. Environ. Microbiol., Washington, v. 56, n. 11, p.3598-3600, 1990.

9 AMERICAN PUBLIC HEALTH ASSOCIATION. Standard methods for the examination of water and wastewater. 10.ed. Washington: American Water Work Asssociation and Water Pollution Control Federation, 1955.

10 AMERICAN PUBLIC HEALTH ASSOCIATION. Standard methods for the examination of water and wastewater. 11.ed. Washington: American Water Work Asssociation and Water Pollution Control Federation, 1960.

11 ASSOCIAÇÃO BRASILEIRA DE NORMAS TÉCNICAS. Áreas limpas: classificacão e controle de contaminação. Rio de Janeiro, 1996. 29 p. [ABNT 13.700].

12 ATTWOOD, D., COLLETT, J. H., O'CONNOR, C. A. Influence of gamma irradiation on the rheological properties of gels of the poloxamine, Synperonic T908. Int. J. Pharm., Amsterdam, v.70, n.1-2, p. 147-152, 1991.

13 AVIS, K. E. Parenteral preparations In: OSOL, A., ed. Remington's pharmaceutical sciences. 15.ed. Easton: Mack 1975. p.1461-1487. 
14 BAIRD, R. M. Microbiological contamination of manufactured products: official and unofficial limits. In: BAIRD, R. M., BLOOMFIELD, S. F., eds. Microbial quality assurance in pharmaceuticals, cosmetic and toiletries. London: Francis \& Taylor, 1996. p. 235-251.

15 BAYNES, N. C., COMRIE, J., PRAIN, J.H. Detection of bacterial growth by the malthus conductance meter. Med. Lab. Sci., London, v. 40, p. 149-158, 1983

16 BARNES, A. R., NASH, S. Preservative eficcacy in cefuroxime and ceftazidime eye drop formulations. J. Clin. Pharm. Ther., London, v. 19, p. 327-332, 1994.

17 BASEM, A., GARDINI, F., PAPARELLA, A., GUERZONI, M.E. Suitability of a rapid gas chromatographic method for total mesophilic bacteria and coliform enumeration in hamburgers. Lett. Appl. Microbiol., Glasgow, v. 14, p. 255-259, 1992.

18 BEAN, H.S. Preservatives for pharmaceuticals. J. Soc. Cosmet. Chem., New York, v. 23, p. 703-720, 1972.

19 BEAN, H.S., DEMPSEY, G. The effect of suspensions on the bactericidal activity of $\mathrm{m}$-cresol and benzalkonium chloride. J. Pharm. Pharmacol., London, v. 23, p. 669-704, 1971.

20 BISHOP, J. R., WHITE, C. H. Estimation of potential shelf-life of pasteurized fluid milk utilizing bacterial numbers and metabolites. J. Food Prot., Ames, v. 48, n. 8, p. 663-667, 1985. 
21 BISHOP, J. R., WHITE, C. H., FIRSTENBERG-EDEN, R. Rapid impedimetric method for determining the potential shelf-life of pasteurized whole milk. J. Food Prot., Ames, v. 47, n. 6, p. 471-475, 1984.

22 BLACKBURN, H. D., POLACK, A. E. ROBERTS, M. S. Preservation of ophthalmic solutions: some observations on the use of chlorbutanol in plastic containers. J. Pharm. Pharmacol., London, v. 30, p. 666-667, 1978.

23 BOAS práticas de fabricação de produtos farmacêuticos. Brasilia: Ministério da Saúde/Secretaria de Vigilância Sanitária 1994. 146 p. [trigésimo segundo relatório].

24 BOER, Y. Irritation by eyedrops containing 2-phenylethanol. Pharm. Weekbl. Sci., Amsterdam, v.3, p.122-123, 1981.

25 BOLLE, A., MIRIMANOFF, A. Antagonism between non-ionic detergents and antiseptics. J. Pharm. Pharmacol., London, v. 2, n. 7, p. 685-692, 1950.

26 BOLTON, F.J. An investigation of indirect conductimetry for detection of some food-borne bacteria. J. Appl. Bacteriol., Oxford, v. 69, n. 5, p. 655-661, 1990.

27 BOPP, C. A., WACHSMUTH, I. K. Luciferase assay to detect bacterial contamination of intravenous fluids. Am. J. Hosp. Pharm., Washington, v. 38, p. 1747-1750, 1981. 
28 BOSSUYT, R. G., WAES, G. M. Impedance measurements to detect post-pasteurization contamination of pasteurized milk. J. Food Prot., Ames, v. 46, n. 7, p. 622-624, 1983.

29 BOU-CHACRA, N. A. Suspensão oftálmica de dexametasona e polimixina $B$ formulação e avaliação da eficácia antimicrobiana de conservantes. São Paulo. 1993, 149 p. [ Dissertação - Mestrado, Faculdade de Ciências Farmacêuticas - USP].

30 BOVORIAN, G. E. Pseudomonas cepacia: growth in and adaptability to increased preservative concentration. J. Soc. Cosmet. Chem., New York, v. 34, p. 197-203, 1983.

31 BOWMAN, F.W. Microbial contamination of antibiotic ophthalmic ointments. J. Pharm. Sci., Washington, v. 58, n. 2, p. 277-278, 1969.

32 BOWMAN, F. W., KNOLL, E. W., WHITE, M., MISLEVIC, P. Survey of microbial contamination of antibiotic ophthalmic ointments. J. Pharm. Sci., Washington, v. 61, n. 4, p. 532-535, 1972.

33 BOWMAN, F. W., HOLDOWSKY, S. Sterility of antibiotic ophthalmic ointment. J. Am. Pharm. Assoc. Sci. Ed., Washington, v. 48, p. 95$96,1959$.

34 BRANNAN, D. Cosmetic preservation. J. Soc. Cosmet. Chem., New York, v. 46, p. 199-220, 1995.

35 BRASIL. Leis, Decretos etc. - Portaria nํ 71 de 29 de maio de 1996, Secretaria de Vigilância Sanitátria. Diário Oficial da União, Brasilia, n. 104, 30 maio1996, seção I, p.9391-9404. 
36 BREWER, J. H., GOldStein, S. W., McLAUGHLIN, C. B. Phenylethyl alcohol as a bacteriostatic agent in ophthalmic solutions. J. Am. Pharm. Assoc. Sci. Ed., Washington, v. 42, p. 584-585, 1953.

37 BRITISH pharmaceutical codex. London: Pharmaceutical Press, 1968.

38 BRITISH pharmacopoeia. London: Her Majesty's Stationery Office, 1932.

39 BRITISH pharmacopoeia. London: Her Majesty's Stationery Office, 1968.

40 BRITISH pharmacopoeia. London: Her Majesty's Stationery Office, 1980.

41 BRITISH pharmacopoeia. London: Her Majesty's Stationery Office, 1988.

42 BRITISH pharmacopoeia. London: Her Majesty's Stationery Office, 1993.

43 BRITISH Standard 5295 Environmental cleanliness in enclosed spaces. British Standards Institution, London, 1989. Apud: WHITE, P. J. P The design of controlled environments. In: DENYER, S., BAIRD, R. M., eds. Guide to microbiological control in pharmaceuticals. Chichester: Ellis Horwood, 1990. p. 87-124.

44 BROWN, M. R. W. Survival of Pseudomonas aeruginosa in fluorescein solution - preservative action of PMN and EDTA. J. Pharm. Sci., Washington, v. 57, n. 3, p. 389-392, 1968.

45 BROWN, M. R. W., RICHARDS, R. M. E. Effect of polysorbate (tween) 80 on the resistance of Pseudomonas aeruginosa to chemical inactivation. J. Pharm. Pharmacol., London, v.16, n. supl., p. 51T-55T, 1964. 
46 BRUCH, C.W. Microbial quality assurance of eye products. Drug Cosmet. Ind., New York, v. 118, n. 6, p. 49-53, 161-162, 1976.

47 BULLOCK, K., KEEPE, W. G. Bacterial survival in systems of low moisture content. J. Pharm. Pharmacol., London, v. 3, n. 11, p. 717$733,1951$.

48 BUSSEY, D. M., TSUJI, K. Bioluminescence for USP sterility testing of pharmaceutical suspension products. Appl. Environ. Microbiol., Washington, v. 51, n. 2, p. 349-355, 1986.

49 BUSSEY, D. M., KANE, M. P., TSUJI, K. Sterilization of corticosteroids by ${ }^{60}$ Co irradiation. J. Parenter. Sci. Technol., Philadelphia, v. 37, n. 2, p. $51-54,1983$.

50 CADY, P. Rapid automated bacterial identification by impedance measurement. In: HEDEN E., ILLENIT, C.G., eds. New approaches to the identification of microrganisms. New York: Wiley, 1975. p. 7399.

51 CADY, P., DUFOUR, S. W., SHAW, J., KRAEGER, S. J. Electrical impedance measurements: rapid method for detecting and monitoring microorganisms. J. Clin. Microbiol., Washington, v. 7, n. 3, p. 265-272, 1978.

52 CADY, P., HARDY, D., MARTINS, S., DUFOUR, S. W., KRAEGER, S. J. Automated impedance measurements for rapid screening of milk microbial content. J. Food Prot., Ames, v. 41, n. 4, p. 277-283, 1978.

53 CHAIN, V. S., FUNG, Y. C. Comparison of redigel, petrifilm, spiral plate system, isogrid, and aerobic plate count for determining the numbers of aerobic bacteria in selected foods. J. Food Prot., Ames, v. 54, n. 3, p. 208-211, 1991. 
54 CHANDLER, S. W., TRISSEL, L. A., WAMSLEY, L. M., LAJEUNESSE, J. D., ANDERSON, R. W. Evaluation of air quality in a sterile-drug preparation area with an electronic particle counter. Am. J. Hosp. Pharm., Washington, v. 50, n. 11, p. 2330-2334, 1993.

55 CHAPMAN, D. G. Preservatives available for use. In: BOARD, R. G., ALLWOOD, M. C., BANKS, J. G., eds. Preservatives in food, pharmaceutical and environmental industries. Oxford: Blackwell, 1987. p. $177-195$.

56 ClOSE, J., NIELSEN, P. A. Resistance of a strain of Pseudomonas cepacia to esters of p-hydroxybenzoic acid. Appl. Environ. Microbiol., Washington, v. 31, p. 718-722, 1976.

57 COATES, D. Preservative/ colloid interaction. Manuf. Chem. Aerosol News, London, v. 44, p. 34-37, 1973.

58 COLQUHOUN, K. O., TIMMS, S., FRICKER, C. R. Detection of Escherichia coli in potable water using direct impedance technology. J.Appl. Bacteriol., Oxford, v. 79, n. 6, p. 635-639, 1995.

59 COMPOUNDS that contribute to preservative activity. Cosmet. Toiletries, Oak Park, v. 105, n. 3, p. 61-63, 1990.

60 CONNOLLY, P., BLOOMFIELD, S. F., DENYER, S. P. A study of the use of rapid methods for preservative efficacy testing of pharmaceuticals and cosmetics. J. Appl. Bacteriol., Oxford, v. 75, p. 456-462, 1993. 
61 CONNOlLy, P., BloOMFiELD, S. F., DENYER, S. P. The use of impedance for preservative efficacy testing of pharmaceuticals and cosmetics. J. Appl. Bacteriol., Oxford, v. 76, p. 68-74, 1994.

62 CONNOlLY, P., LEWIS, S. J., CORRY, J. E. L. A medium for the detection of yeasts using a condutimetric method. Int. J. Food Microbiol., Amsterdam, v. 7, n. 1, p. 31-40, 1988.

63 COOPER, M. S. Preservative efficacy: compendial and regulatory issues. J. Parenter. Sci. Technol., Philadelphia, v. 43, n. 4, p. $187-$ $190,1989$.

64 CORNELL, J. A. Experiments with mixtures: designs, models and the analysis of mixture date. 2. ed. New York: Wiley, 1990, p. 21- 98.

65 COUSINS, D. L., MARLATT, F. An evaluation of a conductance method for the enumeration of Enterobacteriaceae in milk. J.Food Prot., Ames, v. 53, n. 7, p. 568-570, 625, 1990.

66 COWEN, R. A., STEIGER, B. Antimicrobial activity: a critical review of test methods of preservative efficiency. J. Soc. Cosmet. Chem., New York, v. 27, p. 467-481, 1976.

67 COWEN, R. A., STEIGER, B. Why a preservative system must be tailored to a specific product. Cosmet. Toiletries, Oak Park, v. 92, n. 3, p. 15-16, 18-20, 1977.

68 CROSHAW, B. Preservatives for cosmetics and toiletries. J. Soc. Cosmet. Chem., New York, v. 28, n. 1, p. 3-16, 1977. 
69 CTFA. Cosmetic preservative encyclopedia antimicrobials. Cosmet. Toiletries, Oak Park, v. 105, n. 3, p. 49-60, 1990.

70 CTFA. Interaction between cosmetic ingredients and preservatives. Cosmet. Toiletries, Oak Park, v. 110, n. 11, p. 81-86, 1995.

71 CTFA. Survey: test methods companies use. Cosmet. Toiletries, Oak Park, v. 105, n. 3, p. 79-82, 1990.

72 CURRY, A. S., GRAF J. G., McEWEN G. N. eds. CTFA. Microbiology Guidelines. Washington: CTFA, 1993.

73 CURRY, J. Water activity and preservation. Cosmet. Toliletries, Oak Park, v. 100, n. 2 , p. 53-55, 1985.

74 DALE, J. K., NOOK, M. A., BARBIERS, A. R. Effectiveness of preservatives. J. Am. Pharm. Assoc., Washington, v. 20, n. 1, p. 3235, 1959.

75 D'ARCY, P. F. Contamination of multiple application eye drops bottles. Int. J. Pharm., Amsterdam, v. 2, n. 2, p. 43, 1988.

76 DAVISON, A. L., HOOPER, W. L., SPOONER, D. F., FARWELL, J. A., BAIRD, R. The validity of the criteria of pharmacopoeial preservative efficacy tests: a pilot study. Pharm. J., London, v. 246, n. 6634, p. 555-557, 1991.

77 DAVISON, A. L. Preservative efficacy testing of pharmaceuticals, cosmetics and toiletries and its limitations. In: BAIRD, R. M. BLOOMFIELD, S. F., eds. Microbial quality assurance in pharmaceuticals, cosmetic and toiletries. London: Francis \& Taylor, 1996. p. 187-197. 
78 DECICCO, B. T., LEE, E. C., SORRENTINO, J. V. Factors affecting survival of Pseudomonas cepacia in decongestant nasal sprays containing thimerosal as preservative. J. Pharm. Sci., Washington, v. 71 , n. 11, p. 1231-1234, 1982.

79 DEAK, T., BEUCHAT, L. R. Comparison of conductimetric and traditional plating techniques for detecting yeasts in fruit juices. J. Appl. Bacteriol., Oxford, v. 75, p. 546-550, 1993.

80 DEAK, T., BEUCHAT, L.R. Evaluation of the indirect conductance method for the detection of yeasts in laboratory media and apple juice. Food Microbiol., London, v. 10, n. 3, p. 255-262, 1993.

81 DELUCA, P. P., KOSTENBAUDER, H. B. Interaction of preservatives with macromolecules IV. Binding of quaternary ammonium compounds by nonionic agents. J. Am. Pharm. Assoc., v. 49, n. 7, p. 430-437, 1960.

82 DEMPSEY, G. The effects of container materials and multiple-phase formulation components on the activity of antimicrobial agents. In: BAIRD, R., BLOOMFIELD, S.F., eds. Microbial quality assurance in cosmetics, toiletries and non-sterile pharmaceuticals. 2. ed. London: Taylor \& Francis, 1996. p. 87-98.

83 DENYER, S.P. Development of preservative system. In: BAIRD, R., BLOOMFIELD, S.F., eds. Microbial quality assurance in cosmetics, toiletries and non-sterile pharmaceuticals. 2. ed. London: Taylor \& Francis, 1996. p.133-148.

84 DENYER, S. P. Monitoring microbiological quality: aplication of rapid microbiological methods to pharmaceuticals. In: DENYER, S. P., BAIRD, R.M., eds. Guide to microbiological control in pharmaceuticals. New York: Ellis Horwood, 1990. p. 146-155. 
85 DENYER, S. P., HUGO, W. B., HARDING, V. D. Synergy in preservative combinations. Int J. Pharm., Amsterdam , v. 25, p. 245-253, 1985.

86 DENYER, S. P., WALLHAEUSSER, R. H. Antimicrobial preservatives and their properties. In: DENYER, S. P., BAIRD, R. M. eds. Guide to microbiological control in pharmaceuticals. New York: Ellis Horwood, 1990. p. $251-273$.

87 DENYER, S. P., WARD, K. H. A rapid method for the detection of bacterial contaminants in intravenous fluids using membrane filtration and epifluorescence microscopy. J. Parenter. Sci. Technol. , Philadelphia, v. 37, n. 5, p. 156-158, 1983.

88 DENYER, S. P., LYNN, R. A sensitive method for the rapid detection of bacterial contaminants in intravenous fluids. J. Parenter. Sci. Technol. , Philadelphia, v. 41, n. 2, p. 60-66, 1987.

89 DONNELLY, C. B., GLICHRIST, J. E., PEELER, J. T., CAMPBELL, J. E. Spiral plate count method for the examination of raw and pasteurized milk. Appl. Environ. Microbiol., Washington, v. 32, n. 1, p. 21-27, 1976.

90 DUPONT, J., MENARD, D., HERVE, C., MINIER, B. Analytical procedure for use of conductance measurement to estimate Escherichia coli in shellfish. J. Appl. Bacteriol., Oxford, v. 77, n. 3 p. 296-302, 1994.

91 ELKHOULY, A. E., YOUSEF, R. T. Antibacterial efficiency of mercurials. J. Pharm. Sci., Washington, v. 63, n. 5, p. 681-685, 1974. 
92 ENGLE, G. R. Sterile oinments: contamination and preservation. Pharm. Int., Amsterdam, v. 2, p. 141-144, 1981.

93 ERIKSEN, S.P. Preservation of ophthalmic, nasal \& otic products. Drug Cosmet. Ind., New York, v.107, p. 36-40, 147-148, 1970.

94 EUROPEAN pharmacopoeia 2. ed. Paris: Maisonneuve, 1980.

95 EUROPEAN pharmacopoeia. Paris: Maisonneuve, 1994. v.8, part. 17.

96 FARMACOPÉIA brasileira. 4. ed. São Paulo: Atheneu, 1988.

97 FAVET, J., FEHR, A., GRIFFITHS, W., AMACKER, P. A., SCHORER, E. Adaptation of Escherichia coli Pseudomonas aeruginosa and Staphylococcus aureus to Kathon CG and Germall II in an O/W cream. Cosmet. Toiletries, Oak Park, v. 102, n. 12, p. 75-85, 1987.

98 FAVET, J., HOLZNER, G., GRIFFITHS, W., AMACKER, P. A., SCHORER, E. Efficacité antimicrobienne de quelques agents conservateurs, seuls ou en association, dans des crèmes et gels hydrophiles. Pharm. Acta Helv., Zurich, v. 61, n. 1, p. 15-21, 1986.

99 FEDERATION INTERNATIONALE PHARMACEUTIQUE Validation and environmental monitoring of aseptic processing. J. Parenter. Sci. Technol., Philadelphia, v. 44, n. 5, p. 272-277, 1990.

100 FELS, P., GAY, M., KABAY, A., URBAN, S. Antimicrobial preservation. Manufactures'experience with pharmaceuticals in the efficacy test and in practice. Pharm. Ind., Aulendorf, v. 49, n. 6, p. 631-636, 1987. 
101 FERREIRA, M. R. S., OHARA, M. T., SAITO, T. Avaliação da eficácia antimicrobiana em condicionadores de cabelos. Rev. Farm. Bioquim. Univ. São Paulo, São Paulo, v. 28, n. 2, p. 132-144, 1992.

102 FISCHER, K., ALLEN, H. F. Corneal ulcers produced by cell-free extracts of Pseudomonas. Am. J. Ophthalmol., Chicago, v.46, p. 21-27, 1958.

103 FIRSTENBERG-EDEN, R. Rapid estimation of the number of microorganisms in raw meat by impedance measurement. Food Technol., Chicago, v. 37, n. 1, p. 64-70, 1983.

104 FIRSTENBERG-EDEN, R., KLEIN, C. S. Evaluation of a rapid impedimetric procedure for the quantitative estimation of coliforms. J. Food Sci., Chicago, v. 48, n. 3, p. 1307-1311, 1983.

105 FIRSTENBERG-EDEN, R., TRICARICO, M. K. Impedimetric determination of total mesophilic and psychrotrophic counts in raw milk. J. Food Sci., Chicago, v. 48, p. 1750-1754, 1983.

106 FOOD and DRUG ADMINISTRATION. Guidelines on sterile drug products produced by asseptic processing. Center for Drugs and Biologics Food and Drug Administration, Rockville, MD, 1987. Apud: HABERER, K., WALLHAEUSSER, K. H. Assurance of sterility by validation of the sterilization process. In: DENYER, S., BAIRD, R. M., eds. Guide to microbiological control in pharmaceuticals. Chichester: Ellis Horwood, 1990. p. 219-240.

107 FRYER, S. M., FORDE K. Electrical screening of powdered dairy products, In: STANNARD, C. J., PETITT, S. B., SKINNER, F. A, eds. Rapid microbiological methods for foods, beverages and pharmaceuticals. Oxford: Blackwell, 1989. p. 143-153. 
108 FUNG, D. Y. C., COX, N. A., GOLDSCHMIDT, M. C., BAILEY, J. S. Rapid methods and automation: a survey of professional microbiologists. J.Food Prot., Ames, v. 52, n. 1, p. 65-68, 1989.

109 FUNG, D.Y.C., MILLER, R. D. Rapid procedure for the detection of acid and gas production by bacterial cultures. Appl. Microbiol., Washington, v. 20, n. 3, p. 527-528, 1970.

110 GARRET, E. R. A basic model for the evaluation and prediction of preservative action. J. Pharm. Pharmacol., London, v. 18, p. 589$601,1966$.

111 GARRETSON, W. T., COSGROVE, K. W. Ulceration of the cornea due to Bacillus pyocyaneus. JAMA J. Am. Med. Assoc., Chicago, v. 88, n. 1, p. 700-703, 1927.

112 GIBSON, D. M. Predicting the shelf life of packaged fish from conductance measurements. J. Appl. Bacteriol., Oxford, v. 58, n. 5, p. $465-470,1985$.

113 GILChRist, J. E., DONNELly, C. B., PEELER, J. T., CAMPBELL, J. E. Collaborative study comparing the spiral plate and aerobic plate count methods. J. Assoc. Off. Anal. Chem., Washington, v. 60, n. 4, p. 807-811, 1977.

114 GILChRIST, J. E., CAMPBELL, J. E., DONNELly, C. B., PEELER, J. T., DELANEY, J. M. Spiral plate method for bacterial determination. Appl. Microbiol., Washington, v. 25, n. 2, p. 244-252, 1973. 
115 GNAN, S., LUEDECKE, L. O. Impedance measurements in raw milk as an alternative to the standard plate count. J. Food Prot., Ames, v.47 n. 1, p. 4-7, 1984

116 HANCOCK, I., BOINTON, B. M., MCATHEY, P. Rapid detection of Listeria species by selective impedimetric assay. Lett. Appl Microbiol., Glasgow, v. 16, p. 311-314, 1993.

117 HARDY, D., KRAEGER, S. J., DUFOUR, S. W., CADY, P. Rapid detection of microbial contamination in frozen vegetables by automated impedance measurements. Appl. Environ. Microbiol., Washingon, v. 34, n. 1, p. 14-17, 1977.

118 HATCHER, W. S., DIBENEDETTO, S., TAYLOR, L. E., MURDOCK, D I. Radiometric analysis of frozen concentrated orange juice for total viable microorganisms. J. Food Sci., Chicago, v. 42, n. 3, p. 636639, 1977.

119 HARTE, V. J., O'HANRAHAN, M. T., TIMONEY, R. F. Microbial contamination in residues of ophthalmic preparations. Int. J. Pharm., Amsterdam, v. 1, n. 3, p. 165-171, 1978.

120 HECHT, G. Ophthalmic preparations In: OSOL, A., ed. Remington's pharmaceutical sciences. 19. ed. Easton: Mack, 1995. p. 15631576.

121 HENSCHKE, P. A., THOMAS, D. S. Detection of wine-spoiling yeasts by eletronic methods. J. Appl. Bacteriol., Oxford, v. 64, n. 2, p. 123133,1988 
122 HELOU, J. H. Soluções: isotonia. In: HELOU, J. H., CIMINO, J. S., DAFRE, C. Farmacotécnica. São Paulo: Artpress, 1975. p. 169201.

123 HIND, H. W., SZEKELY, I. J. Self-sterilizing ophthalmic solutions. J. Am. Pharm. Assoc. Pract. Ed., Washington, v. 14, n. 10, p. 644-645, 1953.

124 HORRY, J. M., CROSS, J. R. Purifying water for ophthalmic and injectable preparations. Pharm. J., London, v. 242, p. 169-171, 1989.

125 HOULSBY, R. D. An alternate approach for preservative testing of ophthalmic multiple-dose products. J. Parenter. Drug Assoc., Philadelphia, v. 34, p. 272-276, 1980.

126 HUGO, P. G. Additive and synergism in vitro as displayed by mixtures of some commoly employed antibacterial preservatives. Cosmet. Toiletries, Oak Park, v. 92, n. 3, p. 52, 55-56, 1977.

127 HUGO, P. G. Additive and synergistic actions of equipotent admixtures of some antimicrobial agents. Pharm. Acta Helv., Zurich, v. 51, n 10 , p. 284-289, 1976.

128 HUGO, P. G., FOSTER, J. H. S. Bactericidal effect upon Pseudomonas aeruginosa of chemical agents for use in ophthalmic solutions. J. Pharm. Pharmacol., London, v. 16, suppl., p. 124T-126T, 1964.

129 HUTCHESON, T. C., McKAY, T., FARR, L., SEDDON, B. Evaluation of the stain viable for the rapid estimation of viable yeast cells. Lett. Appl. Microbiol., Glasgow, v. 6, p. 85-88, 1988. 
130 IRVING, T. E., STANFIELD, G., HEPBURN, B. W. T. Eletrical methods for water quality testing. In: STANNARD, C. J., PETITT, S. B., SKINNER, F. A, eds. Rapid microbiological methods for foods, beverages and pharmaceuticals. Oxford: Blackwell, 1989. p. 119130.

131 JAPANESE pharmacopeia. 13. ed. Tokyo: Society of Japanese Pharmacopoeia, 1996.

132 JARVIS, B., LACH, V. H., WOOD, J. M. Evaluation of the spiral plate maker for the enumeration of micro-organisms in foods. J. Appl. Bacteriol., Oxford, v. 43, n. 1, p. 149-157, 1977.

133 JACOBS, G.P. The radiation sterilization of cefoxitin sodium. Int. J. Pharm., Amsterdam, v.7, n. 4, p. 279-283, 1981.

134 JURGENS, R. W. Preservatives for ophthalmic products. Drug Cosmet. Ind., New York, v. 118, n. 2, p. 56-60, 1976.

135 KABARA, J. J., WERNETTE, C.M. Cosmetic formulas preserved with food-grade chemicals. Part II. Cosmet. Toiletries, Oak Park, v. 97, n. 11 p. $77-84,1982$.

136 KAHN, P., FIRSTENBERG-EDEN, R. Prediction of shelf-life of pasteurized milk and other fluid dairy products in 48 hours. J. Dairy Sci., Champaing, v. 70, n. 8, p. 1544-1550, 1987.

137 KAISERMAN, J. M., MORAL, J., WOLF, B. A. A rapid impedimetric procedure to determine bacterial content in cosmetic formulations. J. Soc. Cosmet. Chem., New York, v. 40, p. 21-31, 1989. 
138 KAKEMI, K., SEZAKI, H., ARAKAWA, E., KIMURA, K., IKEDA, K. Interaction of parabens and other pharmaceutical adjuvants with plastic containers. Chem. Pharm. Bull., Tokyo, v. 19, p. 2523-2529, 1971.

139 KALLINGS, L. O., RINGERTZ, O., SILVERSTOLPE, L. Microbiological contamination of medical preparations. Acta Pharm. Suec., Stockholm, v. 3, p. 219-228, 1966.

140 KARABIT, M. S. Studies on the evaluation of preservative efficacy. I. The determination of antimicrobial characteristic of phenol. Acta Pharm. Suec., Stockholm, v. 22, p. 281-290, 1985.

141 KARABIT, M. S. Studies on the evaluation of preservative efficacy. V .Effect of concentration of microorganisms on the antimicrobial activity of phenol. Int. J. Pharm., Amsterdam, v. 60, n. 2, p. 147-150, 1990.

142 KARABIT, M. S., JUNESKANS, O. T., LUNDGREN, P. Studies on the evaluation of preservative efficacy III. The determination of antimicrobial characteristics of benzalkonium chloride. Int. J. Pharm., Amsterdam, v.46, p.141-147, 1988.

143 KAREL, M., FENNENA, E. R., LUND, D. B. Principles of food sciences. New York: Marcel Dekker, 1975. pt. 2, p.38-52.

144 KAZMI, S. J. A., MITCHELL, A. G. Interaction of preservatives with cetomacrogol, J. Pharm. Pharmacol., London, v. 23, p. 482-489, 1971. 
145 KELLAWAY, I. W., NAJIB, N. M. The effect of hydrophilic polymers on the electrophoretic mobility of suspended particles. Int. J. Pharm., Amsterdam, v. 7, n. 4, p. 285-292, 1981.

146 KENNEY, D. S., GRUNDY, W. E., OTTO, R. H. Spoilage and preservative tests as applied to pharmaceuticals. Bull. Parenter Drug Assoc., Philadelphia, v. 18, p. 10, 1964.

147 KENNEY, D. Cosmetic formulas preserved with food-grade chemicals. Part I. Cosmet. Toiletries, Oak Park, v. 97, n. 11, p. 71-76, 1982.

148 KOHN, S. R., GERSHENFELD, L., BARR, M. Antibacterial agents not presently employed as preservatives in ophthalmic preparations found effective against Pseudomonas aeruginosa. J. Pharm. Sci., Washington, v. 52, n. 12, p. 1126-1129, 1963.

$149 \mathrm{KOHN}$, S. R., GERSHENFELD, L., BARR, M. Effectiveness of antibacterial agents presently employed in ophthalmic preparations as preservatives against Pseudomonas aeruginosa. J.Pharm.Sci., Washington, v. 52, n. 10, p. 967-974, 1963.

150 KOMATSU, H., HIGAKI, K., OKAMOTO, H., MIYAGAWA, K., HASHIDA, M., SEZAKI, H. Preservative activity and in vivo percutaneos penetration of butylparaben entrapped in liposomes. Chem. Pharm. Bull., Tokyo, v. 34, n. 8, p. 3415-3430, 1986.

151 KOTHARI, T., REYES, M. P., BROOKS, N., BROWN, W. J., LERNER, A. M. Pseudomonas cepacia septic arthritis due to intra-articular injections of methylprednisolone. Can. Med. Assoc. J., Ottawa, v. 116, p.1230-1232, 1977. 
152 KOVARY, S. J., AGALlOCO, J. P., GORDON, B. M. Validation of the steam-in-place steriliation of disc filter housings and membranes. J. Parenter. Sci. Technol., Philadelphia, v. 37, n. 2, p. 55-64, 1983.

153 KUMAR, A., WOFFORD-MACQUEEN, R., GORDON, R. C. Ciprofloxacin, imipenem and rifampicin: in-vitro synergy of two and three drug combinations against Pseudomonas cepacia. Antimicrob. Agents Chemother., Washington, v. 23, p. 831-835, 1989.

154 KURUP, T. R. R., WAN, L. S. C., CHAN, L. W. Availability and activity of preservatives in emulsifield systems. Pharm. Acta Helv., Zurich, v. 66, n. 3, p. 76-82, 1991.

155 KURUP, T. R. R., WAN, L. S .C., CHAN, L. W. Effects of surfactants on the antibacterial activity of preservatives. Pharm. Acta Helv., Zurich, v.66, n.9-10, p. 274-280, 1991.

156 LAWRENCE, C. A. An evaluation of chemical preservatives for ophthalmic solutions. J. Am. Pharm. Assoc. Sci. Ed., Washington, v. 44, n. 8, p. $457-464,1955$.

157 LEECH, R. New methodology for microbiological quality assurance. In: BLOOMFIELD, S. F., BAIRD, R., LEAK, R. E., LEECH, R., eds. Microbial quality assurance in pharmaceuticals, cosmetic and toiletries. Chichester: Ellis Horwood, 1988. p. 195-215.

158 LEHNNER, S. J., MüLLER, B. W., SEYDEL, J. K. Interactions between p-hydroxybenzoic acid esters and hydroxypropil- $\beta$-ciclodextrin and their antimicrobial affect against Candida albicans. Int. J. Pharm., Amsterdam, v. 93, n. 1-3, p. 201-208, 1993. 
159 LEITZ, M. Critique of USP microbiological test. Bull. Parenter Drug Assoc., Philadelphia, v. 26, p. 212, 1972.

160 LEY, F.J. The effect of irrradiation on packaging materials. J. Soc. Cosmet. Chem., New York, v.27, n.10, 1976.

161 LEYDEN, J. J., STEWART, R. Experimental inoculation of Pseudomonas aeruginosa and Pseudomonas cepacia on human skin. J. Soc. Cosmet. Chem., New York, v. 31, p. 19-28, 1980.

162 LILLEY, B. D., BREWER, J. H. The selective antibacterial action of phenylethyl alcohol. J. Am. Pharm. Assoc. Sci. Ed., Washington, v. 42, n. 1, p. 6-8, 1953.

163 LITTEL, K. J., PIKELIS, S., SPURGASH, A. Bioluminescent ATP assay for rapid estimation of microbial numbers in fresh meat. J. Food Prot., Ames, v. 49, n. 1, p. 18-22, 1986.

164 LOFTSSON, T., STEFANSDOTTIR, O., FRIORIKSDOTTIR, H., GUOMUNDSSON, O. Interactions between preservatives and 2-

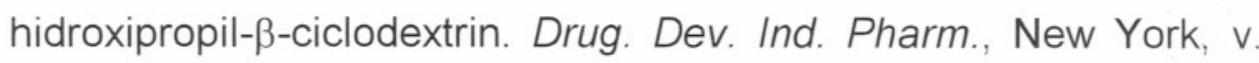
18, n. 13, p. 1477-1484, 1992.

165 LUCAS, J. E., McCARTHY, T. J. An evaluation of phenonip ${ }^{\oplus}$ as a preservative. Acta Pharm. Suec., Stockholm, v. 7, p. 149-155, 1970.

166 MACKIE, M. A. L., LYALL, J., McBRIDE, R. J., MURRAY, J. B., SMITH, G. Antimicrobial properties of some aromatic alcohols. Pharm. Acta Helv., Zurich, v. 61, n. 12, p. 333-336, 1986. 
167 MADDEN, R. H., GILMOUR, A. Impedance as an alternative to MPN enumeration of coliforms in pasteurized milks. Lett. Appl. Microbiol., Glasgow, v. 21, p. 387-388, 1995.

168 MAIGNAN, N. Méthode de comptage microbiologique á réponse rapide par épi-fluorescence appliquée aux produits de contraste. S.T.P. Pharma, v.1, n. 10, p. 993-996, 1985.

169 MARQUES, M. R. C., RODRIGUES, M. T. A., TAKENAKA, I. M., HIRAI, C. K., GREMIÃO, M. P. D., OHARA, M. T., SAITO, T. Características de biocompatibilidade de colírios. Rev. Bras. Farm., Rio de Janeiro, v. 64, n. 3, p. 84-92, 1983.

170 MARTINDALE, W. H. The extra pharmacopeia. 28. ed. London: Pharmaceutical Press, 1982. p. 547-578.

171 MARTINDALE, W. H. The extra pharmacopeia. 28. ed. London: Pharmaceutical Press, 1982. p. 1204-1205.

172 MARTINS, S. B., HODAPP, S., DUFOUR, S. W., KRAEGER, S. J. Evaluation of a rapid impedimetric method for determining the keeping quality of milk, J. Food Prot., Ames, v. 45, n. 13, p. 12211226, 1982.

173 McCARTHY, T. L., MYBURGH, J. A., BUTLER, N. Further studies on the influence of formulation on preservative activity. Cosmet. Toiletries, Oak Park, v. 92, n.3, 33-36, 1977.

174 McCARTHY, T. J. Ophthalmic preparations. S. Afr. Pharm. J., Johannesburg, v. 38, p. 4-6, 1971. 
175 McCULLOUGH J. C. Origin and pathogenicity of Pseudomonas pyocyanea in conjunctival sac. Arch. Ophthalmol., v. 29, p. 924934, 1943. Apud: THEODORE, F. H., FEINSTEIN, R. R. Practical suggestion for the preparation and maintenance of sterile ophthalmic solutions. Am. J. Ophthalmol., Chicago, v.35, n. 5, p. 656-659,1952.

176 MERCK index 11. ed. Rahway, 1989.

177 MitTelman, M. W., GeESEY, G. G., HITE, R. R. Epifluorescence microscopy a rapid method for enumerating viable and nonviable bacteria in ultrapure - water systems. Microcontamination, v.1, p. 32-37, 52, 1983. [ fotocópia].

178 MITTELMAN, M. W., GEESEY, G. G., PLATT, R. M. Rapid enumeration of bacteria in purified water systems. Med. Device Diagn. Ind., Santa Monica, v.7, p. 144-149, 1985.

179 MIXTURE encyclopedia update. Cosmet. Toiletries, Oak Park, v. 108, v. 10, p. 89-91, 1993.

180 MIYAWAKI, G. M., PATEL, N. K., KOSTENBAUDER, H. B. Interaction of preservatives with macromolecules III. Parahydroxybenzoic acid esters in the presence of some hydrophilic polymers. J. Am. Pharm. Assoc. Sci. Ed., Washington, v. 48, n. 6, p. 315-318, 1959.

181 MOORE, K. E. Evaluating preservative efficacy by challenge testing during the development stage of pharmaceutical produtcts. J. Appl. Bacteriol., Oxford, v. 44, p. sxliii, 1978. 
182 MORRIS, C., LEECH, R. Natural and physical preservative systems. In: BAIRD, R. M., BLOOMFIELD, S.F., eds. Microbial quality assurance in cosmetics, toiletries and non-sterile pharmaceuticals. London: Taylor \& Francis, 1996. p. 69-86.

183 MULBERRY, K. G., ENTRUP, R. M., AGIN, R. J. Rapid screening methods for preservative efficacy evaluations. Cosmet. Toiletries, Oak Park, v. 102, n. 12, p. 47-50, 52-24, 1987.

184 MUSCATIELLO, M. J., PENICNAK, A. J. Evaluation of impedance microbiology. Cosmet. Toiletries, Oak Park, v. 102, v. 12, p. 41-44, 46, 1987.

185 NEAVES, P., WADDELL, M. J., PRENTICE, G. A. A medium for detection of lancefield group $D$ Cocci in skimmed milk powder by electrometric methods. In: STANNARD, C. J., PETITT, S. B., SKINNER, F. A, eds. Rapid microbiological methods for foods, beverages and pharmaceuticals, Oxford: Blackwell, 1989. p. 203211.

186 NIELSEN, P. A., CLOSE, J. Edetate disodium mediated chloramphenicol resistance in Pseudomonas cepacia. J. Pharm. Sci., Washington, v. 71, n. 7, p.833-834, 1982.

187 NELSON, J. W., DOHERTY, C. J., BROWN, P. H., GREENING, A. P., KAUFMANN, M. E., GOVAN, J. R. Pseudomonas cepacia in inpatients with cystic fibrosis. Lancet, London, v. 338, p. 1525, 1991.

188 NEWBY, P. J. Analysis of high-quality pharmaceutical grade water by a direct epifluorescent filter technique microcolony method. Lett. Appl. Microbiol., Glasgow, v. 13, nr. 6, p. 291-293, 1991. 
189 NIEUWENHOF, F. F. J., HOOLWERF, J. D. Impedance measurement as an alternative to the plate count method for estimating the total count of bacteria in raw milk. J. Food Prot., Ames, v. 50, n. 8, p. 665$668,1987$.

190 O'CONNOR, F. An impedance method for the determination of bacteriological quality of raw milk. Ir .J. Food Sci. Technol., Dublin, v. 3 , p. 93-100, 1979.

191 OBLINGER, J. L., KRAFT, A. A. Oxidation-reduction potential and growth of Salmonella and Pseudomonas fluorescens. J. Food Sci., Chicago, v. 38, p. 1108-1112, 1973.

192 OGDEN, I. D. Use of conductance methods to predict bacterial counts in fish. J. Appl. Bacteriol., Oxford, v. 61, p. 263-268, 1986.

193 OHMAN, D. E., GOLDBERG, J. B. Genetics of alginate biosynthesis in Pseudomonas infections and alginates, biochemistry, genetics and pathology. ASM News, Ann Arbor, v. 55, p. 206-220, 1989.

194 OKIGBO, O. N., RICHARDSON, G. H. Detection of penicillin and streptomycin in milk by impedance microbiology. J. Food Prot., Ames, v. 48, n. 11, p. 979-981, 1985.

195 OLSON, O. T., ASLUND, B., SANDELL E. Studies on in-use microbial contamination of multiple-dose vials. Acta Pharm. Suec., Stockholm, v. 15, n. 6, p. $401-405,1978$.

196 ORTH, D.S. Establishing cosmetic preservative efficacy by use of Dvalues. J. Soc. Cosmet. Chem., New York, v. 31, p. 165-172, 1980. 
197 ORTH, D. S. Principles of preservative efficacy testing. Cosmet. Toiletries, Oak Park, v. 96, n. 3, p. 43-52, 1981.

198 ORTH, D. S. Linear regression method for rapid determination of cosmetic preservative efficacy. J. Soc. Cosmet. Chem., New York, v. 30, n. 11, p. $321-332,1979$.

199 ORTH, D. S. Standardizing preservative efficacy test data. Cosmet. Toiletries, Oak Park, v.106, n. 3, p. 45-51, 1991.

200 ORTH, D. S., BARLOW, R. F., GREGORY, L. A. The required D-value: evaluating product preservation in relation to packaging and consumer use/abuse. Cosmet. Toiletries, Oak Park, v.107, n. 12, p.39-43, 1992.

201 ORTH, D. S., BRUEGgen, L. R. Preservative efficacy testing of cosmetic products. Rechallenge testing and reliability of the linear regression method. Cosmetic. Toiletries, Oak Park, v. 97, n. 5, p. 61-65, 1982.

202 ORTH, D. S., LUTES, C. M. Adaptation of bacteria to cosmetic preservatives. Cosmet. Toiletries, Oak Park, v. 100, n. 2, p. 57-59, 63-64, 1985.

203 ORTH, D. S., LUTES, C. M., SMITH, D. K., MILSTEIN, S. R. Synergism of preservative system components: Use of the survival curve slope method to demonstrate anti-Pseudomonas synergy of methyl paraben and acrylic acid homopolymer / copolymers in vitro. J. Soc. Cosmet. Chem., New York, v. 40, p. 347-365, 1989. 
204 ORTH, D. S., LUTES, C. M., SMITH, D. K., MILSTEIN, S. R., ALLINGER, J. J. Determination of shampoo preservative stability and apparent activation energies by the linear regression method of preservative afficacy testing. J. Soc. Cosmet. Chem., New York, v. 38, p. 307-319, 1987.

205 ORTH, D. S., LUTES, C. M., SMITH, D. K. Effect of culture conditions and method of inoculum preparation on the kinetics of bacterial death during preservative efficacy testing. J. Soc. Cosmet. Chem., New York, v.40, p. 193-204, 1989.

206 ORTH, D. S., MILSTEIN, S. R. Rational development of preservative system for cosmetic product. Cosmet. Toiletries, Oak Park, v. 104, n. 10, p. 91-92, 94-100, 1989.

207 OWENS, J. D. Formulation of culture media for conductimetric assays: Theoretical considerations. J. Gen. Microbiol., Colchester, v.131, p. 3055-3076, 1985.

208 OWENS, J. D., KONIROVA, L., THOMAS, D. S. Causes of conductance change in yeast cultures. J.Appl. Bacteriol., Oxford, v. 72, p. $32-38,1992$.

209 OWENS, J. D., THOMAS, D. S., THOMPSON, P. S., TIMMERMAN, J. W. Indirect conductimetry: a novel approach to the conductimetric enumeration of microbial populations. Lett. Appl. Microbiol. Glasgow, v. 9, n. 6, p. 245-249, 1989.

210 PAREKH, A., GATTANI, O. R. Control of microbial contamination in pharmaceutical formulations. East. Pharm., New Delhi, v. 33, n. 390, p. 33-36, 1990. 
211 PARENTERAL drug association response to FDA proposal to prohibit the use of any antimicrobial preservative in single-dose parenteral drug products. J. Parenter Sci. Technol., Philadelphia, v. 39, n. 6, p. $231-232,1985$.

212 PARENTERAL DRUG ASSOCIATION. Validation of steam sterilization. Philadelphia: Cycles, 1978. 31 p. [Monografia Técnica n. 1].

213 PARMAR, N., EASTER, M. C., FORSYTHE, S. J. The detection of Salmonella enteritidis and $S$. typhimurium using immunomagnetic separation and conductance microbiology. Lett. Appl. Microbiol., Glasgow, v. 15, p. 175-178, 1992.

214 PARSONS, L. B., STURGES, W. S. Conductivity as applied to studies of bacterial metabolism. J. Bacteriol., Baltimore, v. 12, p. 267-272, 1926.

215 PARSONS, L. B., STURGES, W. S. The magnitude of the error due to ammonia and its salts in the van slyke amino nitrogen procedure as commonly applied in studies of bacterial metabolism. J.Bacteriol., Baltimore, v. 11, n. 2, p. 165-175, 1926.

216 PARSONS, L. B., STURGES, W. S. The possibilities of the conductivity method as applied to studies of bacterial metabolism. J. Bacteriol., Baltimore, v. 11, n 3, p. 177-188, 1926.

217 PATEL, N. K., KOSTENBAUDER, H. B. Interaction of preservatives with Macromolecules I. Binding of parahydroxybenzoic acid esters by polyoxyethylene 20 sorbitan monooleate (Tween 80). J. Am. Pharm. Assoc. Sci. Ed., Washington, v. 47, n. 4, p. 289-293, 1958. 
218 PAULSON, D. S. Calculating D-values for steam sterilization processes. Med. Device Diagn. Ind., Santa Monica, v. 17, n. 5, p. 198-204, 1995.

219 PETAT, E. A. Impedancemetrie: une mesure rapide de la contamination microbiologique. S. T. P. Pharma Prat., Paris, v. 4, n. 5, p. 379-382, 1994.

220 PETTIPHER, G. L., RODRIGUES, U. M. Rapid enumeration of microorganisms in foods by the direct epifluorescent filter technique. Appl. Environ. Microbiol., Washington, v. 44, n. 4, p. 809-813, 1982.

221 PETTIPHER, G. L., MANSELL, R. McKINNON, C. H.,COUSINS, C. M. Rapid membrane filtration-epifluorescent microscopy technique for direct enumeration of bacteria in raw milk. Appl. Environ. Microbiol., Washington, v. 39, n. 2, p. 423-429, 1980.

222 PETITT, S. B. A conductance screen for enterobacteriaceae in foods. In: STANNARD, C. J., PETITT, S. B., SKINNER, F. A, eds. Rapid microbiological methods for foods, beverages and pharmaceuticals, Oxford: Blackwell, 1989. p. 131-140.

223 PHARMACEUTICAL codex. 11. ed. London: Pharmaceutical Press, 1979. p. 346-349.

224 PISANO, F. D., KOSTENBAUDER, H. B. Interaction of preservatives With Macromolecules II. Correlation of binding data with requires preservative concentrations of $\mathrm{p}$-hydroxybenzoates in the presence of tween 80. J. Am. Pharm. Assoc. Sci. Ed., Washington, v. 48, n. 6 , p. 310-314, 1959. 
225 POELMAN, M. C., PUISIEUX, F., CHAUMEIL, J. C. Les interactions entre antiseptiques et surfactifs III, Étude de l'interaction parahydroxyéthylénés par une méthode de dialyse. Ann. Pharm. Fr., Paris, v. 33, n. 10, p. 693-699, 1975.

226 PORTNOFF, J. B., COHEN, E. M., HENLEY, M. W. Development of parenteral and sterile ophthalmic suspensions. The $R$ \& $D$ approach. Bull. Parenter. Drug Assoc., Philadelphia, v. 31, n. 3, p. 136-143, 1977.

227 PRESERVATIVE encyclopedia update. Cosmet. Toiletries, Oak Park, v. 108, p. 85-88, 1993.

228 PUENTEDURA, M. I. M., MONTEOLIVA-SANCHEZ, M., SANCHEZ, C. N., RODRIGUEZ, E. M., RAMOS-CORMENZANA, A. La contaminacion microbiana de colirios en condiciones semejantes a las de su empleo. Ars Pharm., Granada, v. 21, n. 4, p. 381-386, 1980.

229 RDZOK, E. J., GRUNDY, D. W. E., KIRCHMEYER, F. J., SYLVESTER, J. C. Determining the efficacy of preservatives in pharmaceutical products. J. Am. Pharm. Assoc. Sci. Ed., Washington, v. 44, p.613, 1955.

230 REYNOLDS, L. A. Guidelines for the preparation of sterile ophthalmic products. Am. J. Hosp. Pharm., Washington, v. 48, p. 2438-2439, 1991.

231 RICHARDS, J. C. S., JASON, A. C., HOBBS, G., GIBSON., D. M., CHRISTIE, R. H. Eletronic measurement of bacterial growth. J. Phys. E: Sci. Instrum., London, v. 11, p. 560-568, 1978. 
232 RICHARDS, R. M. E. An evaluation of the literature on the efectiveness of antibacterial agents used as preservative in ophthalmic solutions. Part I: 1949-1956. Aust. J. Pharm., Melborne, v. 48, n. 572, Sci. Suppl. 55, p. S86-S89, 1967.

233 RICHARDS, R. M. E. An evaluation of the literature on the effectiveness of antibacterial agents used as preservatives in ophthalmic solutions. Part II: 1957-1965. Aust. J. Pharm., Melborne, v. 48, n. 573, Sci. Suppl. 56, S96- S101, 1967.

234 RICHARDS, R. M. E. Inactivation of resistant Pseudomonas aeruginosa by antibacterial combinations. J. Pharm. Pharmacol., London, v. 23, suppl., p. 136s-140s, 1971.

235 RICHARDS, R. M. E. Effect of hypromellose on the antibacterial activity of benzalkonium chloride. J. Pharm. Pharmacol., London, v. 28, n 3 , p. $264,1975$.

236 RICHARDS, R. M. E. Differences in antibacterial resistance related to differences in cell envelope structure of Pseudomonas aeruginosa and Pseudomonas cepacia. J. Pharm. Pharmacol., London, v. 30, suppl., p. 14p, 1978.

237 RICHARDS, R. M. E., CAVILL, R. H. Electron microscope study of effect of benzalkonium chloride and edetate disodium on cell envelope of Pseudomonas aeruginosa. J. Pharm. Sci., Washington, v. 65, n. 1, p. 76-80, 1976. 
238 RICHARDS, R. M. E., HARDIE, M. P. Effect of polysorbate 80 and phenylethanol ont the antibacterial activity of fentichlor. J. Pharm. Pharmacol., London, v. 24, suppl., p. 90P-93P, 1972.

239 RICHARDS, R. M. E., McBRIDE, R. J. Phenylethanol enhancement of preservatives used in ophthalmic preparations. J. Pharm. Pharmacol., London, v. 23, suppl., p. 141s-146s, 1971.

240 RICHARDS, R. M. E., McBRIDE, R. J. Preservation of sodium bicarbonate eye lotion BPC against contamination with Pseudomonas aeruginosa. Br. J. Ophthalmol., London, v.55, p. 734, 1971.

241 RICHARDS, R. M. E., McBRIDE, R. J. The preservation of ophthalmic solutions with antibacterial combinations. J. Pharm. Pharmacol., London, v. 24, p. 145-148, 1972.

242 RICHARDS, R. M. E., McBRIDE, R. J. Cross-resistance in Pseudomonas aeruginosa resistant to phenylethanol. J. Pharm. Sci., Washington, v. 61, n. 7, p. 1075-1077, 1972.

243 RICHARDS, R. M. E., McBRIDE, R. J. Effect of 3- phenylpropan-1-ol, 2phenylethanol, and benzyl alcohol on Pseudomonas aeruginosa. J. Pharm. Sci., Washington, v. 62, n. 4, p. 585-587, 1973.

244 RICHARDS, R. M. E., McBRIDE, R. J. Enhancement of benzalkonium chloride and chlorhexidine acetate activity against Pseudomonas aeruginosa by aromatic alcohols. J. Pharm. Sci., Washington, v. 62, n. 12, p. $2035-2037,1973$. 
245 RICHARDS, R. M. E, McBRIDE, R. J. Preservation of sulphacetamide eye-drops BPC. Pharm. J., London, v. 210, p. 118-120, 1973.

246 RICHARDS, R. M. E., McBRIDE, R. J. Antipseudomonal effect of polymyxim and phenyletanol. J. Pharm. Sci., Washington, v. 63, n. 1, p. 54-56, 1974.

247 RICHARDS, R. M. E., RICHARDS, J. M. Pseudomonas cepacia resistance to antibacterials. J. Pharm. Sci., Washington, v. 68, n. 11, p. $1436-1438,1979$.

248 RICHARDS, R. M. E., SUWANPRAKORN, P., NEAWBANIJ, S., SURASDIKUL, N. Preservation of fluorescein solutions against contamination with Pseudomonas aeruginosa. J. Pharm. Pharmacol., London, v. 21, p. 681-686, 1969.

249 RICHARDSON, N. E., DAVIES, D. J. G., MEAKIN, B. J., NORTON, D. A. Loss of antibacterial preservatives from contact lens solutions during storage. J. Pharm.Pharmacol., London, v 29, n.12, p. 717 722, 1977.

250 RiEgElmAN, S., VAUGHAN, D. C., OKUMOTO, M. J. Antibacterial agents in Pseudomonas aeruginosa contaminated ophthalmic solutions. J. Am. Pharm. Assoc. Sci. Ed., Washington, v. 45, n. 2, p. 93-98, 1956.

251 ROBINSON, J. R. The need for new preservatives. J. Parenter. Sci. Technol., Philadelphia, v. 41, n. 5, p. 143, 1987. 
252 RODRIGUES, U. M., KROLL, R. G., The direct epifluorescent filter technique (DEFT): increased selectivity, sensitivity and rapidity. J. Appl. Bacteriol., Oxford, v. 59, p. 493-499, 1985.

253 RODRIGUES, U. M., KROLL, R. G., Use of the direct epifluorescent filter technique for the enumeration of yeasts. J. Appl. Bacteriol., Oxford, v. 61, p. 139-144, 1986.

254 RODRÍGUEZ, E. M., SÁNCHEZ C. N., MONTEOLIVA-SANCHEZ M., PUENTEDURA, M. I. M., RAMOS-CORMENZANA, A. Control de esterilidad en colirios: identificacion a nivel generico de las bacterias aisladas. Ars. Pharm., Granada, v. 22, n. 2, p. 207-210, 1981.

255 ROMANOWSKI, P., SCHUELLER, R. Microorganisms and personalcare products. Cosmet. Toiletries, Oak Park, v. 110, n. 11, p. 71-78, 1995.

256 ROSENSTEIN, B. J., HALL, D. E. Pneumonia and septicemia due to Pseudomonas cepacia in a patient with cystic fibrosis. Johns Hopkins Med. J., Baltimore, v. 147, n. 5, p. 188-189, 1980.

257 SAITO, T., MAUL, A. A., PIRES, J. B. Alguns aspectos de qualidade em colírios. Rev. Bras. Farm., Rio de Janeiro, v. 60, n.7-9, p. 77-84, 1979

258 SAJjAN, U. S., COREY, M., KARMALI, M. A., FORSTNER, J. F. Binding of Pseudomonas cepacia to normal human intestinal mucin and respiratory mucin from patients with cystic fibrosis. J. Clin. Invest., New York, v. 89, n. 2, p. 648-656, 1992. 
259 SAKUDA, T. M., OHARA, M. T., BERTUZZI, H. J., SAITO, T. Eficiência de conservantes em suspensão de caulim. II - Ácido benzóico, benzoato de sódio e nipaset®. Rev. Bras. Farm., Rio de Janeiro, n. 3, p. 63-67, 1983.

260 SAKUDA, T. M. Otimização de suspensões de benzoilmetronidazol. São Paulo. 1993. [Tese - Doutorado, Faculdade de Ciências Farmacêuticas - USP].

261 SEAL, D.V., CLARK, R.P. Eletronic particle counting for evaluating the quality of air in operating theatres: a potential basis for standards? J. Appl. Bacteriol., Oxford, v. 68, p. 225-230, 1990.

262 Sebert, P., ANDRIANOFF, N., ROLLet, M. Effect of gamma irradiation on hydroxypropylmethylcellulose powders: Consequences on physical, rheological and pharmacotechnical properties. Int. J. Pharm., Amsterdam, v.99, n.1, p. 37-42, 1993.

263 SERVIS, N. A., NICHOLS, S., ADAMS, J. C., Development of a direct viable count procedure for some gram-positive bacteria. Lett. Appl. Microbiol., Glasgow, v. 20, n. 4, p. 237-239, 1995.

264 SCHMOLKA, I. R. The synergistic effects of nonionic surfactants upon cationic germicidal agents. J. Soc.Cosmet. Chem., New York, v. 24, p. $577-592,1973$.

265 SILVER, S., WENDT, L. Mechanism of action of phenethyl alcohol: breakdown of the cellular permeability barrier. J. Bacteriol., Baltimore, v. 93, n. 2, p. 560-566, 1967. 
266 SINGER, S. The use of preservative neutralizers in diluents and plating media. Cosmet. Toiletries, Oak Park, v. 102, n. 12, p. 55-60, 1987.

267 SMART, R., SPOONER, D. F. Microbiological spoilage in pharmaceutical and cosmetic. J. Soc. Cosmet. Chem., New York, v. 23, p. 721-737, 1972.

268 SMITH, D. L., SMITH, E. G., GUMERY, L. B., STABLEFORTH, D. E. Pseudomonas cepacia infection in cystic fibrosis. Lancet, London, v. 339, p. $252,1992$.

269 SMITH, W. P. Cosmetic preservation: a survey. Cosmet. Toiletries, Oak Park, v. 108, v. 10, p. 67-75, 1993.

270 SOBEL, J. D., HASHMAN, N., REINHERZ, G., MERZBACH, D. Nosocomial Pseudomonas cepacia infection associated with chlorhexidine contamination. Am. J. Med., Washington, v. 73, p. 183-186, 1982.

271 SOPER, C. J., DAVIES, D. J. G. Principles of sterilization. In: DENYER, S.P., BAIRD, R.M., eds. Guide to microbiological control in pharmaceuticals. New York: Ellis Horwood, 1990. p. 158-180.

272 SORRELLS, K. M. Rapid detection of bacterial content in cereal grain products by automated impedance measurements. J.Food Prot., Ames, v. 44, n. 11, p. 832-834, 1981.

273 SOUTO, A. B., ALVARO, M. E., PENTEADO, N. Investigações sobre a esterilidade de preparações oftálmicas. Rev. Inst. Adolfo Lutz, São Paulo, v. 14, n. 1, p. 19-25, 1954. 
274 SOUZA, M. R. S. E. L., OHARA, M. T., SAITO, T. Avaliação da eficácia antimicrobiana em emulsões cosméticas para aplicação dérmica. Rev. Farm. Bioquim. Univ. São Paulo, São Paulo, v. 30, n. 2, p. 5561, 1994.

275 SOUZA, M. R. S. E. L. Qualidade microbiana em emulsões cosméticas para aplicação dérmica. São Paulo, 1993, 218 p. [Dissertação Mestrado, Faculdade de Ciências Farmacêuticas - USP].

276 SPOONER, D. F. Hazards associated with the microbiological contamination of cosmetics, toiletries and non-sterile pharmaceuticals. In: BAIRD, R., BLOOMFIELD, S. F., eds. Microbial quality assurance in cosmetic, toiletries and non-sterile pharmaceuticals. 2. ed. London: Taylor \& Francis, 1996. p.9-27.

277 STEINBERG, D.C. Preserving foundations. Cosmet. Toiletries, Oak Park, v. 110, n. 2, p. 71-73, 76, 1995.

278 STEWART, G. N. The changes produced by the growth of bacteria in the molecular concentration and eletrical conductivity of culture media. J. Exp. Med., New York, p. 235-243, 1899.

279 STORPIRTIS, S., BERTINI, E., CLOHS, L., VENTURA, N., BORGES, V. M., SAITO, T. Avaliação da eficácia antimicrobiana de soluções para lentes de contato. Rev. Farm. Bioquim. Univ. São Paulo, São Paulo, v. 22, n. 2, p. 87-96, 1986.

280 SYKES, G. The basis for "sufficient of a suitable bacteriostatic" in injections. J. Pharm. Pharmacol., London, v. 10, p. 40T, 1958. 
281 SUTTON, S. V. W., FRANCO, R. J., PORTER, D. A., MOWREYMcKeE, M. F., BuSSChAERT, S. C., HAMBERGER, J. F., PROUD, D. W. D-value determinations are an inappropriate measure of disinfecting activity of common contact lens disinfecting solutions. Appl. Environ. Microbiol., Washington, v. 57, n. 7, p. 2021-2026, 1991.

282 TABLAN, O. C., CHORBA, T. L., SCHIDLOW, D. V., WHITE, J. W., HARDY, K. A., GILLIGAN, P. H., MORGAN, W. M., CARSON, L.. A., MARTONE, W. J., JASON, J. M., JARVIS, W. R. Pseudomonas cepacia colonization in patients with cystic fibrosis: risks factors and clinical outcome. J. Pediatr., St. Louis, v. 107, n. 3, p. 382-387, 1985.

283 TEST for the effectiveness of antimicrobial preservation of pharmaceuticals. Pharm. Acta Helv., Zurich, v. 55, n. 2, p. 40-48, 1980.

284 THEODORE, F. H. Contamination of eye solutions. Am. J. Ophthalmol. Chicago, v. 34, n. 12, p. 1764, 1951.

285 THEODORE, F. H., FEINSTEIN, R. R. Practical suggestion for the preparation and maintenance of sterile ophthalmic solutions. Am. J. Ophthalmol., Chicago, v. 35, n. 5, p. 656-659,1952.

286 THERON, D. P., PRIOR, B. A., LATEGAN, P. M. Determination of bacterial ATP levels in raw milk: selectivity of non-bacterial ATP hydrolysis. J.Food Prot., Ames, v. 49, n. 1, p. 4-7, 1986. 
287 THERON, D. P., PRIOR, B. A., LATEGAN, P. M. Sensivity and precison of bioluminescent techniques for enumeration of bacteria in skim milk. J.Food Prot., Ames, v. 49, n. 1, p. 8-11, 1986.

288 TITCOMB, L. Ophthalmic products. In: COLLET, D. M., AULTON, M. E. Pharmaceutical practice. Edinburgh: Churchill Livingstone, 1990. p. 257-271.

289 TRAN T. T., COLLIER, S. W. Direct contact membrane inoculation of yeasts and moulds for evaluating preservative efficacy in solid cosmetics. Int. J. Cosmet. Sci., Washington, v. 14, p. 163-172, 1992.

290 UNITED States pharmacopeia. 11. ed. Easton: Mack, 1936.

291 UNITED States pharmacopeia. 12. ed. Easton: Mack, 1942.

292 UNITED States pharmacopeia. 14. ed. Easton: Mack, 1950.

293 UNITED States pharmacopeia. 15. ed. Easton: Mack, 1955.

294 UNITED States pharmacopeia. 18. ed. Easton: Mack, 1970.

295 UNITED States pharmacopeia. 19. ed. Rockville: United States Pharmacopoeial Convention : Mack, 1975.

296 UNITED States pharmacopeia. 20. ed. Rockville: United States Pharmacopoeial Convention : Mack, 1980.

297 UNITED States pharmacopeia. 21. ed. Rockville: United States Pharmacopoeial Convention : Mack, 1985. 
298 UNITED States pharmacopeia. 22. ed. Rockville: United States Pharmacopoeial Convention, 1990.

299 UNITED States pharmacopeia. 23. ed. Rockville: United States Pharmacopoeial Convention, 1995.

300 UNITED STATES FEDERAL STANDARD 209 E Airborne Particulate Cleanliness Classes in Cleanrooms and Clean Zones. Washington: FED-STD, 1992. 48 p.

301 UNITED STATES FEDERAL STANDARD 209 A, B, C and D (1962, 1976, 1987, 1988) Cleanroom and workstation requirements, controlled environment. Washington, DC. Apud: WHITE, P. J. P. The design of controlled environments. In: DENYER, S. P., BAIRD, R. M., eds. Guide to microbiological control in pharmaceuticals. Chichester: Ellis Horwood, 1990. p. 87-124.

302 VAN DOORNE, $\mathrm{H}$. Interactions between preservatives and pharmaceutical components. In: DENYER S. P., BAIRD, R. M., eds. Guide to microbiological control in pharmaceuticals. New York: Ellis Horwood, 1990. p.274-291.

303 VAUGHN, D. G. The contamination of fluorescein solutions with special reference to Pseudomonas aeruginosa (Bacillus pyocyaneus). Am. J. Ophthalmol., Chicago, v. 39, n. 1, p. 55-61, 1955.

304 VESSONI PENNA, T. C. Esterilização térmica. Conceitos básicos da cinética microbiana. Ver. Farm. Bioquím. Univ. S. Paulo., São Paulo, v. 33 (supl. 1), p. 1-5, 1997. [ Worshop CPCDM, 1. São Paulo, 1997.] 
305 VoORSPOELS, J., REMON, J. P., NELIS, H., VANDENBOSSCHE, G. Validation of filter sterilisation in autoclaves. Int. J. Pharm., Amsterdam, v. 133, p. 9-15, 1996.

306 WALLS, I., SHERIDAN, J. J., WELCH, R. W., McDOWELL, D. A. Separation of microorganisms from meat and their rapid enumeration using a membrane filtration-epifluorescent microscopy technique. Lett. Appl. Microbiol., Glasgow, v. 10, p. 23-26, 1990.

307 WATLING, E. M., LEECH, R. New Methodology for microbiological quality assurance. In: BAIRD, R. M., BLOOMFIELD, S.F.,eds. Microbial quality assurance in pharmaceuticals, cosmetic and toiletries. London: Taylor \& Francis, 1996 p. 217-234.

308 WATSON-CRAIK, I. A., AIDOO, K. E., ANDERSON, J. G. Development and evaluation of a medium for the monitoring of food-borne moulds by capacitance changes. Food Microbiol.,London, v. 7, n. 2, p. $129-145,1990$.

309 WATSON-CRAIK, I. A., AIDOO, K. E., ANDERSON, J. G. Induction of conductance and capacitance changes by food-borne fungi. Food Microbiol., London, v. 6, n. 4, p. 231-244, 1989.

310 WEDDERBURN, D. L. Interactions in cosmetic preservation. Am. Perfum. Cosmet., Oak Park, v. 85, n. 3, p.49-53, 1970.

311 WEIHE, J. L., SEIBT, S. L., HATCHER Jr., W. S. Estimation of microbial populations in frozen concentrated orange juice using automated impedance measurements. J.Food Sci., Chicago, v. 49, n. 1, p. 243-245, 1984. 
312 YABLONSKI, J. I. Fundimental concepts of preservation. Bull. Parenter. Drug Assoc., Philadelphia, v. 26, p. 220, 1972.

313 YABLONSKI, J. I. Strategies for cosmetic preservation. Cosmet. Toiletries, Oak Park, v.92, n.3, p. 22, 24, 26, 31, 1977.

314 YOUSEF, R. T., EL-NAKEEB, M. A., SALAMA, S. Effect of some Pharmaceutical Materials on the Bacteriostatic and Bactericidal Activity of Banzalkonium Chloride, Pharm. Ind., Aulendorf, v. 35, n. 3 p. $154-156,1973$.

315 ZINDULIS, J. A medium for the impedimetric detection of yeasts in foods. Food Microbiol.,London, p. 159-167, 1984. 
9 Resumo 


\section{RESUMO}

Um dos grandes desafios no desenvolvimento de fórmulas farmacêuticas e cosméticas é a adequação de seus sistemas conservantes. No presente trabalho, empregou-se método de otimização destes para suspensão oftálmica de dexametasona e sulfato de polimixina B. O experimento foi conduzido utilizando-se planejamento estatístico do tipo simplex-lattice. A matriz de ensaio contemplou 17 fórmulas sendo que as variáveis independentes foram as concentrações de conservantes álcool feniletílico $\left(X_{1}\right)$ e digluconato de clorhexidina $\left(\mathrm{X}_{2}\right)$ e EDTA $\left(\mathrm{X}_{3}\right)$. A variável dependente ou resposta foi o valor $\mathrm{D}$ obtido do desafio das fórmulas com Pseudomonas aeruginosa, Pseudomonas cepacia, Staphylococcus aureus, Candida albicans e Aspergillus niger, empregando-se nas determinações, o Método de Regressão Linear. A análise estatística dos resultados, para cada microrganismo desafiante, conduziu à equações que expressaram matematicamente o fenômeno observado. Como conseqüência, foi possível o cálculo teórico do valor $D$ em função das concentrações das variáveis independentes. Além das equações, obtiveram-se as superfícies de resposta e gráficos de contorno correspondentes aos ensaios, para cada germe. Para a seleção da fórmula ou região que atendesse o critério adotado e que conciliasse as condições ideais e factíveis ( $D \leq 4$ horas, para bactérias e D $\leq 28$ horas, para fungos) utilizaram-se duas estratégias: gráfica e numérica. A primeira consistiu na sobreposição dos gráficos de contorno resultando em região da qual selecionou-se, aleatoriamente, a fórmula empregando $X_{1}=0,10 ; X_{2}=0,80 ; X_{3}=0,10 . \quad A$ segunda, baseou-se na aplicação da função "desejo", tendo sido a fórmula ideal resultante de cálculos desenvolvidos, a partir de premissas, sendo: $X_{1}=0,25 ; X_{2}=0,75 ; X_{3}=0,0$. Ambas as fórmulas, derivadas das estratégias empregadas, foram submetidas à avaliação de seus sistemas conservantes 
pelo método de Regressão Linear. Os valores D obtidos foram semelhantes àqueles calculados por meio das equações anteriormente mencionadas, exceto para Staphylococcus aureus. A aplicação de métodos de otimização estatística permitiu, de forma racional, atingir o objetivo fixado. Através dessas técnicas, tornou-se possível a definição de regiões experimentais em melhores condições, demonstrando vantagens no uso do álcool feniletílico, bem como um melhor conhecimento dos mecanismos envolvidos. 
10 SUMmaRY 


\section{SUMMARY}

One of the greatest challenges in pharmaceutical and cosmetic formulations consist of the development of adequate preservative systems. Whose optimized development was proposed for ophthalmic suspension of dexametasone and polymyxin B. This was performed through simplex-lattice method. The matrix of essay completed 17 formulas, from which independent variables were the preservative concentrations: phenylethanol $\left(X_{1}\right)$, chlorhexidine digluconate $\left(X_{2}\right)$ and $\operatorname{EDTA}\left(X_{3}\right)$. The dependent variable was the D-value obtained from the challenge of those formulas with Pseudomonas aeruginosa, Pseudomonas cepacia, Staphhylococcus aureus, Candida albicans and Aspergillus niger, all result of the Linear Regression Method. The statistical analysis employment led to polynomial expressions which expressed mathematically the observed behavior in each organism. As a consequence the theoretical calculation of the D-value considering all the independent variables was possible. Besides these expressions, the response surfaces and the contour graphics corresponding to the essays, for each microorganism, were obtained. To the formula or region selection which better complied to the adopted criteria and conciliated ideal and realistic conditions ( $D \leq 4$ hours, for bacteria and $D \leq 28$ hours, for fungi) both graphic and numeric strategies were used. The former consisted of the superposition of contour graphics of each microorganism, what resulted in a region from which the formula was randomly selected using $X_{1}=0,10 ; X_{2}=0,80 ; X_{3}=0,10$. The latter was based on the application of "wish" function, and the ideal formula obtained from calculations developed from these premisses: $X_{1}=0,25, X_{2}=0,75 ; X_{3}=0,0$. Both formulas, derived from the employed strategies were submitted to evaluation of their preservative systems by Linear Regression Method. The D-values obtained were similar to those calculated through the previously mentioned expressions, except for Staphylococcus aureus. The application of optimized statistical methods enabled us, in a rational way, to achieve the fixed goal. Through these techniques, both experimental regions in better conditions, demonstrating advantages of using of the involved mechanisms were attained. 
11 Anexo 
ANEXO 1 Aplicação do Método Elétrico na Análise Microbiológica de Alimentos.

\begin{tabular}{|c|c|c|c|c|}
\hline Aplicacao & Detecrao diorast. & Parametro & correlactä & Reterercia \\
\hline $\begin{array}{l}\text { determinação da contaminação microbiana } \\
\text { em vegetais congelados }\end{array}$ & 5 & impedância & $92,6 \%$ & HARDY, KRAEGER, DUFOUR e CADY ${ }^{11 /}, 1977$ \\
\hline $\begin{array}{l}\text { avaliação da qualidade microbiana em leite } \\
\text { crú,em leite com baixo teor de gordura, } \\
\text { homogeneizado e skim }\end{array}$ & 13,7 & impedância & $91 \%$ & $\begin{array}{l}\text { CADY, HARDY, MARTINS, DUFOUR e KRAEGER } \\
52,1978\end{array}$ \\
\hline $\begin{array}{l}\text { determinação da qualidade bacteriológica } \\
\text { em leite crú }\end{array}$ & 8,5 & impedância & $-0,70$ & O'CONNOR ${ }^{190}, 1979$ \\
\hline $\begin{array}{l}\text { determinação da carga bacteriana em } \\
\text { cereais em grãos }\end{array}$ & 12 & impedância & - & SORRELLS $^{2 / 2}, 1981$ \\
\hline $\begin{array}{l}\text { determinação do tempo de prateleira de } \\
\text { leite pasteurizado }\end{array}$ & 14 & impedância & $80 \%$ & $\begin{array}{l}\text { MARTINS, HODAPP, DUFOUR e KRAEGER }{ }^{1 / 2} \text {, } \\
1982\end{array}$ \\
\hline $\begin{array}{l}\text { determinação de microrganismos em leite } \\
\text { crú }\end{array}$ & 7 & impedância & $97,2 \%$ & GNAN e LUEDECKE ${ }^{115}, 1982$ \\
\hline determinação de coliformes em carne & 7,6 & impedância & 0,90 & FIRSTENBERG-EDEN e KLEIN ${ }^{104}, 1983$ \\
\hline $\begin{array}{l}\text { estimativa do número de microrganismo } \\
\text { em carne crua }\end{array}$ & 2,6 a 4,2 & impedância & 0,97 & FIRSTENBERG-EDEN $^{103}, 1983$ \\
\hline $\begin{array}{l}\text { determinação de microrganismos em leite } \\
\text { pasteurizado }\end{array}$ & 24 & impedância & - & BOSSSUYT e WAES ${ }^{28}, 1983$ \\
\hline $\begin{array}{l}\text { estimativa da população microbiana em } \\
\text { suco de laranja concentrado e congel. }\end{array}$ & 10,2 e 15,8 & impedância & $96 \%$ & WEIHE, SEIBT e HATCHER ${ }^{311}, 1984$ \\
\hline determinação de antibiótico em leite & 5 a 10 & impedância & & OKIGBO e RICHARDSON ${ }^{194}, 1985$ \\
\hline $\begin{array}{l}\text { determinação do tempo de prateleira de } \\
\text { leite pasteurizado }\end{array}$ & 14 & impedância & 0,93 & BISHOP e WHITE ${ }^{20}, 1985$ \\
\hline $\begin{array}{l}\text { previsão do tempo de prateleira de leite } \\
\text { pasteurizado }\end{array}$ & 48 & impedância & 0,89 & KAHN e FIRSTENBERG-EDEN ${ }^{136}, 1987$ \\
\hline $\begin{array}{l}\text { determinação da contagem total de } \\
\text { bactérias em leite não processado }\end{array}$ & 15 & impedância & $\begin{array}{l}\text { usou desvio } \\
\text { padrão }\end{array}$ & NIEUWENHOF e HOOLWERF ${ }^{189}, 1987$ \\
\hline $\begin{array}{l}\text { detecção de leveduras deteriorantes de } \\
\text { vinho }\end{array}$ & 16 a 45 & impedância & - & HENSCHKE e THOMAS ${ }^{121}, 1988$ \\
\hline
\end{tabular}




\begin{tabular}{|c|c|c|c|c|}
\hline Aplicacaro: & 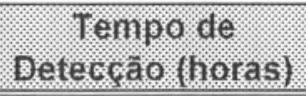 & Pardmetro & corretacia & Referenerat \\
\hline determinação de coliformes em água & 10 & impedância & $-0,95$ & IRVING, STANFIELD e HEPBURN $^{130}, 1989$ \\
\hline $\begin{array}{l}\text { determinação de Enterobacteriaceae em } \\
\text { carnes }\end{array}$ & - & condutância & 0,88 & PETTIT $^{222}, 1989$ \\
\hline $\begin{array}{l}\text { Contagem de viáveis totais em flocos de } \\
\text { milho }\end{array}$ & 6,0 & impedância & 0,89 & FRYER, FORDE ${ }^{10 /}, 1989$ \\
\hline $\begin{array}{l}\text { determinação do grupo coco D em leite em } \\
\text { pó }\end{array}$ & 24 & condutância & 0,93 & NEAVES, WADDELL e PRENTICE ${ }^{185}, 1989$ \\
\hline $\begin{array}{l}\text { determinação de Enterobacteriaceae em } \\
\text { leite }\end{array}$ & 6 a 12 & condutância & 0,92 & COUSINS e MARLATT ${ }^{65}, 1990$ \\
\hline $\begin{array}{l}\text { detecção de Salmonella enteritidis e S. } \\
\text { typhimurium em leite em pó }\end{array}$ & 7,5 & condutância & - & PARMAR, EASTER e FORSYTHE ${ }^{213}, 1992$ \\
\hline detecção de leveduras em suco de frutas & 14,1 & $\begin{array}{l}\text { condutância } \\
\text { indireta }\end{array}$ & 0,73 & DEAK e BEAUCHART $^{19}, 1993$ \\
\hline determinação de E. coli em ostras & 5,7 a 7,9 & condutância & $\begin{array}{c}\text { boa } \\
\text { reprodutibilidade }\end{array}$ & DUPONT, MÉNARD, HÉRVE e MINIER ${ }^{90}, 1994$ \\
\hline $\begin{array}{l}\text { determinação de coliformes em leite } \\
\text { pasteurizado }\end{array}$ & 20 & impedância & $\begin{array}{c}\text { significante } \\
\text { correlação com a } \\
\text { técnica NMP }\end{array}$ & MADDEN e GILMOUR ${ }^{161}, 1995$ \\
\hline detecção de $E$. coli em água potável & $11-14$ horas & $\begin{array}{l}\text { impedância } \\
\text { direta }\end{array}$ & $93 \%$ & COLQUHOUN, TIMMS e FRICKER ${ }^{58}, 1995$ \\
\hline
\end{tabular}

Continuação do Anexo 1 